Use of Triptorelin Acetate for Inducing Ovulation and Facilitating a Fixed Time Artificial Insemination of Sows Weaned on Small-Scale and Niche Market Pig Farms

\author{
Amanda Jean Fabi \\ Thesis submitted to the faculty of the \\ Virginia Polytechnic Institute and State University \\ in partial fulfillment of the requirements for the degree of \\ Master of Science \\ In \\ Animal and Poultry Sciences
}

Mark J. Estienne, Chair
Cynthia M. Wood
Sherrie G. Clark-Deener

January 9, 2017

Suffolk, VA

Key Words: OvuGel®, P.G. 600®, fixed-time artificial insemination, sow 


\title{
The Use of Triptorelin Acetate for Inducing Ovulation and Facilitating a Fixed-Time Artificial Insemination of Sows Weaned on Small-Scale and Niche Market Pig Farms
}

\author{
Amanda J. Fabi
}

\section{$\underline{\text { Academic Abstract }}$}

Developing a single fixed-time artificial insemination (FTAI) protocol would benefit small-scale and niche market pork producers by decreasing semen costs and labor associated with detection of estrus. The objective of this study was to test the efficacy of an artificial insemination (AI) breeding system using triptorelin acetate, a GnRH agonist (OvuGel@; JBS United Animal Health, LLC, Sheridan, IN) that induces ovulation. A total of 96 sows (parity, $3.5 \pm 0.2$; body condition score $(\mathbf{B C S}), 2.5 \pm 0.07$ ) were weaned (h 0) after a $24.8 \pm 0.6 \mathrm{~d}$ lactation on five participating small swine farms and allocated to one of four treatment groups: 1) TRT1: $(n=24)$ OvuGel applied intravaginally at h 96 and AI at h 120; 2) TRT2: (n = 24) P.G. 600® (400 IU eCG and 200 IU hCG, Merck Animal Health, Inc., De Sota, KS) injected intramuscularly at weaning, OvuGel at h 96 and AI at h 120; 3) TRT3: (n= 24) P.G. 600 at weaning, and AI at 0 and $24 \mathrm{~h}$ after first detection of estrus; and 4) TRT4: $(\mathrm{n}=24)$ AI at 0 and $24 \mathrm{~h}$ after first detection of estrus. Treatments 1 and 2 were FTAI protocols with sows being inseminated without regard to estrus onset. Treatments 3 and 4 were consistent with current industry AI practices. The proportion of females displaying estrus by d 7 post-weaning was greater $(P<0.05)$ for sows that received OvuGel $(94.5 \%)$ compared to sows that did not receive OvuGel $(82.2 \%)$. There were no effects $(P>0.05)$ of P.G. 600 or P.G. $600 \mathrm{x}$ OvuGel on females displaying estrus by $\mathrm{d} 7$ or d 10 post-weaning. Weaning to estrus interval was decreased $(P<0.05)$ for sows that received 
P.G. 600 (4.9 \pm 0.4 d) compared to sows that did not receive P.G. 600 (5.4 \pm 0.4 d). There were no effects $(P>0.05)$ of OvuGel or P.G. $600 \mathrm{x} \mathrm{OvuGel}$ on the weaning-to-estrus interval. There were no effects of P.G. 600, OvuGel or P.G. $600 \times$ OvuGel $(P>0.1)$ on pregnancy rate (total sows pregnant/inseminated) (61.2\%), total litter size (11.3), number born dead (1.0) or number of mummies $(0.2)$. There was an effect $(P<0.05)$ of P.G. $600 \times$ OvuGel on total born live (10.2). Sows treated with OvuGel had a greater number of live piglets born per semen dose (5.4) compared to sows that did not receive OvuGel $(3.2)(P<0.05)$. These results suggest that FTAI protocols may be employed on small-scale pig farms without compromising reproductive performance. 


\title{
The Use of Triptorelin Acetate for Inducing Ovulation and Facilitating a Fixed-Time Artificial Insemination of Sows Weaned on Small-Scale and Niche Market Pig Farms
}

\author{
Amanda J. Fabi
}

\section{General Abstract}

Reproductive tools such as the development of a single fixed-time artificial insemination (FTAI) protocol would benefit small scale and niche market swine producers by decreasing semen costs and labor associated with the detection of behavioral estrus or "standing heat". OvuGel® (JBS United Animal Health, LLC, Sheridan, IN) is a gonadotropin releasing hormone (GnRH) agonist in the form of triptorelin acetate that mimics endogenous secretion of $\mathrm{GnRH}$ from the hypothalamus. Because the drug stimulates pituitary luteinizing hormone (LH) secretion and ovulation in weaned sows it offers potential for use in FTAI. The objective of this study was to test the efficacy of a FTAI breeding system using OvuGel to induce ovulation on five participating small-scale and niche market swine farms. A total of 96 sows (parity, $3.5 \pm 0.2$; body condition score (BCS), $2.5 \pm 0.07$ ) were weaned (h 0) after a $24.8 \pm 0.6 \mathrm{~d}$ lactation and allocated to one of four treatment groups. In TRT1, OvuGel was administered $96 \mathrm{~h}$ after weaning with sows receiving a single insemination $22 \pm 2 \mathrm{~h}$ later. In TRT2, sows received an intramuscular injection of P.G. 600® (400 IU eCG and 200 IU hCG, Merck Animal Health, Inc., De Sota, KS) at weaning, were given OvuGel $96 \mathrm{~h}$ post-weaning and were inseminated $22 \pm 2 \mathrm{~h}$ later. Sows in TRT1 and TRT2 groups were inseminated whether behavioral estrus was exhibited or not. Weaned sows allocated to TRT3 received P.G. 600 at weaning, and once-daily estrus detection using a mature boar and females were inseminated when estrus was first detected and then again $24 \mathrm{~h}$ later. Sows allocated to TRT4 were given once-daily estrus detection, and 
inseminated at onset of estrus and again $24 \mathrm{~h}$ later. Treatment groups TRT1 and TRT2 represented the single, FTAI protocol whilst TRT3 and TRT4 groups were representative of current AI practices in today's swine industry. Sows that had received OvuGel had a greater proportion of females displaying estrus by $\mathrm{d} 7$ post-weaning compared to sows that did not receive OvuGel. There were no effects of P.G. 600 alone or P.G. 600 and OvuGel in combination on the proportion of females displaying estrus by $\mathrm{d} 7$ or $\mathrm{d} 10$ post-weaning. Weanto-estrus intervals were decreased in sows receiving P.G. 600 but not for sows receiving OvuGel or P.G. 600 and OvuGel. Reproductive performance measures such as pregnancy rates, total litter size, number of pigs born dead, or number of mummies were not affected by P.G. 600, OvuGel or the combination of P.G. 600 and OvuGel; however, there was an effect of the P.G. 600 by OvuGel interaction on total pigs born alive. Furthermore, sows treated with OvuGel had a greater number of live pigs born per semen dose compared to sows that did not receive OvuGel. These findings suggest that FTAI protocols may be used as a reproductive tool on small-scale pig farms without compromising reproductive performance. 


\section{Acknowledgements}

There are many individuals who have given immense support and have offered guidance throughout this entire process, allowing me to complete this Masters of Science degree program. For that, I am extremely grateful. I would like to acknowledge the following individuals for their positive impact on my graduate career:

Dr. Mark Estienne: major professor, for his willingness to assist me through this entire process and sharing his expertise in swine reproduction and physiology. His overall knowledge and advisement made me not only a better student, but a better individual. I was fortunate to witness his love for the swine industry and his eagerness to assist the small-scale swine producers with their operations. Thank you for your support and encouragement.

Dr. Cindy Wood: graduate committee member, for her continuous support and guidance. Her love for the pork industry is surely evident in her teachings and extension work to the youth in the region.

Dr. Sherrie Clark-Deener: graduate committee member, for her willingness to always be there with answers to my questions and training me in ultrasonography alongside her vet students.

Dr. David Gerrard: departmental head, for pushing me out of my comfort zone and making me into a better-rounded animal scientist. Thank you for allowing me into your lab and offering me new experiences in swine genotyping as well as developing life-long friendships with your students. You directed me into an area of extensive lab work that tested my abilities. 
Kim Williams and Terry Lee: TAREC Swine Farm Managers, for being the best managers I have ever had. You both are amazing individuals who truly cared about all of us students. Being away from home was difficult for me because of the closeness I have with my parents. You two served as parental figures for me and made living in Suffolk, VA such a joy. I cannot thank you two enough for all you have done for me. You both provided me with hands on education that no one can ever take away. I can truly say, you both are two of the best hog farmers I have ever met. H.N.'s for life!

Kim, you are a truly wonderful person inside and out. I hope that I am at least half the mother and pig farmer you are some day. You have helped me more than you will ever know.

Terry Lee, there is truly too much to say. Words cannot express the impact you have had on my life. I wish you only the best in life because you deserve it. Keep those ladies at the shag clubs under control.

Jordan "Stan" Wicks, Bly Patterson, Rosalie Petrone, and Andrew Vinson: for being such great friends and giving support throughout my years at Virginia Tech. Words cannot express how grateful I was for the midnight pep talks and the nights out on the town.

Kevin Young: Campus Swine Farm Manager, for all of your continuous help with my project and consistently providing me weaned sows to use in trials.

KaLynn Harlow, Jeff Wiegert, Richard Preisser: thank you all so much for being another pair of eyes for me throughout this project. Without hesitation you were there to provide support and guidance when I needed it most. Thank you! 
Kendall Fuller, Jeffery Estienne, Mike Estienne, and Deborah Estienne: TAREC employees: Thank you so much for your support and friendship. You guys are awesome and I wish you only the best.

My Show Pig Family: for helping my family keep my show pig dream alive while I was away and pushing me to complete this degree. I could always rely on your help with any issues I had on my farm back at home. I love you all.

Megan Fabi: Thank you for all of your support during my graduate school adventure. You are a great sister and one of my best friends.

Ryan Horsley and Paul Lilley: for volunteering your sows for this project and your willingness to assist throughout trials.

Pig farmers across the nation: for your continuous contribution and passion towards the pork industry. Without you, the future of agriculture would not be as bright.

Most importantly, the Lord blessed me with two of the best parents I could have ever asked for, Jean and John Fabi. Their love and support throughout this whole process has been unconditional. Without them I would not be the individual I am today or have made it as far in my education. You both made sacrifices to keep my dream alive while I was away at school. Thank you for pushing me through difficult times and encouraging me to always do my best. 


\section{Table of Contents}

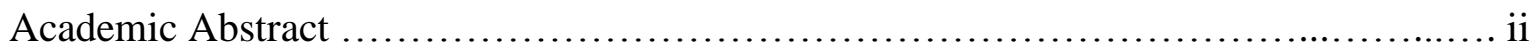

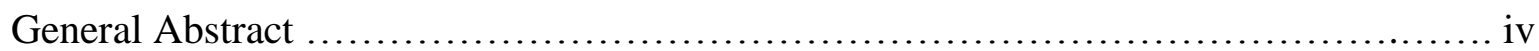

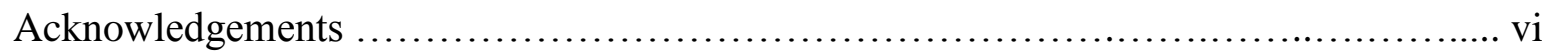

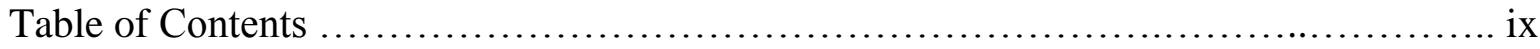

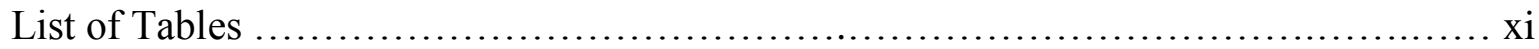

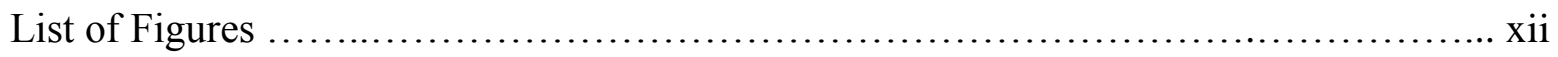

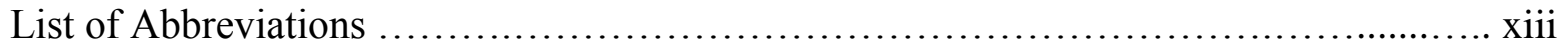

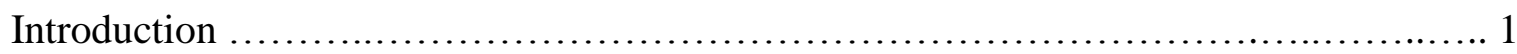

Chapter I: Review of Literature ...................................... 3

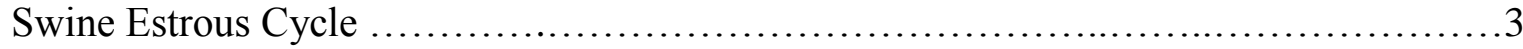

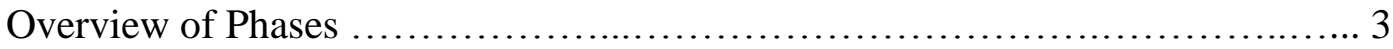

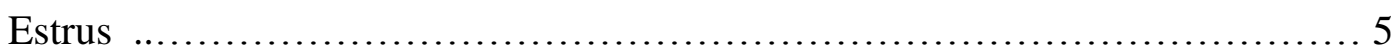

Ovulation ................................................................. 5

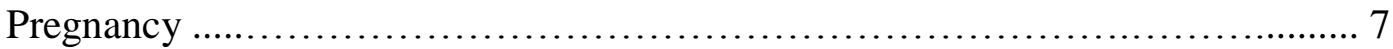

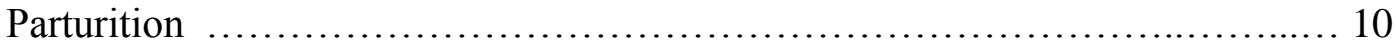

Artificial Insemination ............................................................. 11

Utilization of a Boar in Mating Systems ........................................... 14

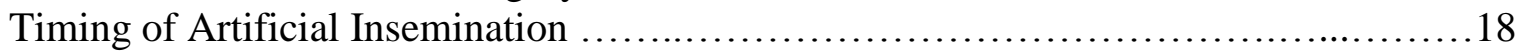

Fixed Time Artificial Insemination ................................................. 22

Exogenous Gonadotropins ................................................. 23

P.G. 600®, Merck Animal Health .............................................. 32

GnRH Agonists ........................................................... 35

OvuGel®, JBS United Animal Health ....................................... 35 
Chapter II: Use of Triptorelin Acetate for Inducing Ovulation and Facilitating a Fixed Time Artificial Insemination of Sows Weaned on SmallScale and Niche Market Pig Farms

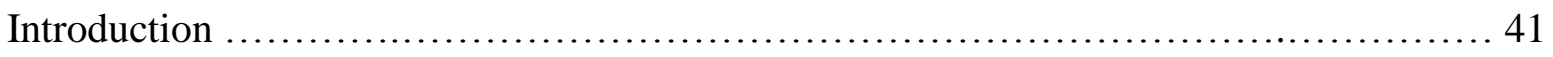

Materials and Methods ........................................................ 43

Statistical Analysis ........................................................ 47

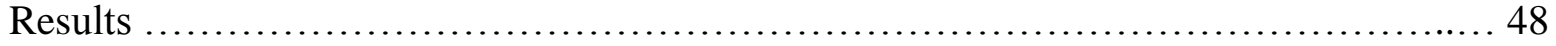

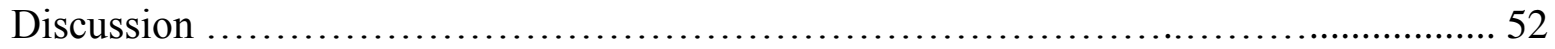

Conclusion. ................................................................ 61

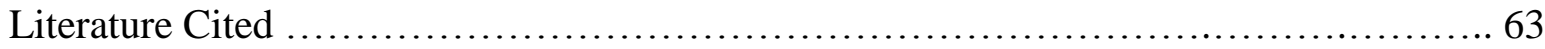

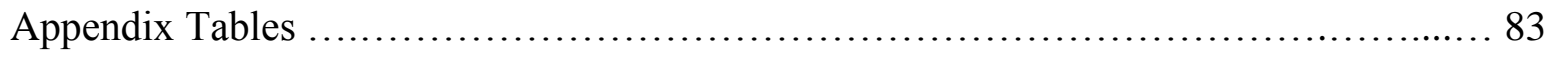

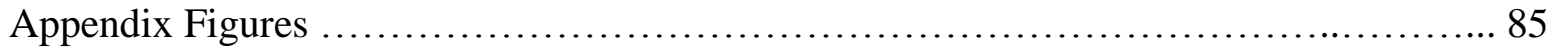




\section{List of Tables}

Table 1. Characteristics of participating small-scale and niche market pig farms

Table 2. Effects of OvuGel® and P.G. $600 ®$ alone or in combination on reproduction

in sows.

Table 3. Effects of OvuGel® and P.G. 600® alone or in combination on litter

characteristics of sows ${ }^{1,2}$

Table A1. Table describing effects of OvuGel® and P.G. 600® alone or in combination on reproduction in sows among TRT1, TRT2, TRT3, and TRT4 sows.

Table A2. Table describing effects of OvuGel® and P.G. $600 ®$ alone or in combination on litter characteristics in sows among TRT1, TRT2, TRT3, and TRT4 sows. 


\section{List of Figures}

Figure 1. Distribution of WEI among treatment groups.................................50

Figure A1. Wean to estrus interval among treatment groups............................ 85

Figure A2. Proportion of sows displaying estrus by d 7 post-weaning.........................86

Figure A3. Proportion of sows displaying estrus by d 10 post-weaning $\ldots \ldots \ldots \ldots \ldots \ldots \ldots \ldots . \ldots 7$

Figure A4. Total litter size for TRT1, TRT2, TRT3, and TRT4 sows.................... 88

Figure A5. Total born alive for TRT1, TRT2, TRT3, and TRT4 sows......................89

Figure A6. Total born dead for TRT1, TRT2, TRT3, and TRT4 sows....................90

Figure A7. Total mummified pigs born in TRT1, TRT2, TRT3, and TRT4

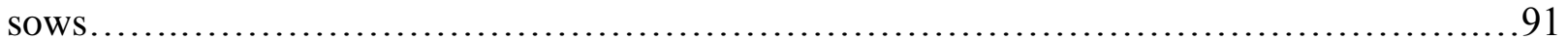

Figure A8. Live pigs born per semen dose for TRT1, TRT2, TRT3, and TRT4 sows. 


\section{Abbreviations}

\begin{tabular}{ll} 
AI & Artificial insemination \\
BCS & Body Condition Score \\
BPT & Back Pressure Test \\
CL & Corpora lutea \\
E2 & Estradiol \\
eCG & Equine chorionic gonadotropin \\
EOI & Estrus to ovulation interval \\
FSH & Follicle-stimulating hormone \\
FTAI & Fixed Time Artificial Insemination \\
GnRH & Gonadotropin-releasing hormone \\
hCG & Human chorionic gonadotropin \\
i.m. & Intramuscular \\
LH & Luteinizing hormone \\
NPD & Non-productive day(s) \\
OT & Oxytocin \\
RTU & Real-time ultrasonography \\
RLX & Relaxin \\
P4 & Progesterone \\
TG & Triptorelin gel \\
TRT1 & OvuGel treatment group \\
TRT2 & P.G. 600 + OvuGel treatment group \\
TRT3 & Control + P.G. 600 treatment group \\
TRT4 & Control treatment group \\
PGF2 $\alpha$ & Prostaglandin F2-alpha \\
pLH & Porcine luteinizing hormone \\
WBI & Wean-to-breed interval \\
WEI & Wean-to-estrus interval \\
WOI & Wean to ovulation interval \\
\hline &
\end{tabular}




\section{Introduction}

In a United States Department of Agriculture census (NASS, 2012), family and individually owned farms accounted for $83 \%$ of total number of hog and pig operations and $41 \%$ of sales. In contrast, large corporate operations represented $8 \%$ of the total number of hog and pig farms and $34 \%$ of total sales. As in many other states, the Virginia swine industry is composed of two basic entities: 1) vertically integrated production in which a large pork processing company (e.g. Smithfield Foods, Inc.) controls its own pork supply through companyowned farms and contract growers, and 2) a growing number of small-scale and niche market farms. The niche market farms tend to be family-owned and operated, generally raise fewer than 2,000 pigs annually, and produce pork in efforts to increase their overall farm revenue. Quite often, these small scale farms specialize in premium pork breeds such as the Berkshire, (i.e., "Berkshire Gold") or seek to promote animal welfare practices in efforts to increase the value and marketability of their pork products. Reproductive efficiency is critical in sustaining these small-scale and niche market pig farms. Artificial insemination (AI) is a method of breeding that can enhance reproductive efficiency, but its use requires excellent estrus detection skills. Failure to properly detect estrus and inseminations at suboptimal times relative to ovulation, contribute to poor reproductive performance in sows bred artificially (Kemp and Soede, 1996; Nissen et al., 1997).

Because the timing of ovulation relative to the onset of standing estrus is variable and cannot be accurately predicted, farmers typically breed sows multiple times during estrus to increase the likelihood that at least one mating occurs during the time of peak fertility ( 0 to $24 \mathrm{~h}$ before ovulation). Two commercially available products have been developed to assist producers with facilitating effective breeding programs. P.G. 600® (Merck Animal Health, Inc., De Sota, 
KS) is a combination of $400 \mathrm{IU}$ of equine chorionic gonadotropin (eCG) and $200 \mathrm{IU}$ of human chorionic gonadotropin (hCG) administered to sows at weaning and to prepubertal gilts. Its use has resulted in accelerated onset of estrus and ovulation in weaned sows (Estienne and Hartsock, 1998) even in months when high ambient temperatures can delay the onset of estrus and ovulation (Bates et al., 1991; Bates et al., 2000). OvuGel® (JBS Animal Health, LLC; Sheridan, IN) is a synthetic gonadotropin releasing hormone (GnRH) agonist in the form of triptorelin acetate used to facilitate a single fixed time artificial insemination (FTAI) protocol by inducing ovulation. Developing a single FTAI protocol during which ovulation is induced could prove extremely beneficial to small-scale swine producers because labor involved in estrus detection would be eliminated and semen costs would be decreased.

This thesis research project was conducted to test the efficacy of an AI breeding system for small-scale and niche market pig farms that is designed to decrease labor associated with estrus detection and minimize the number of semen doses used for AI. It is hypothesized that reproductive performance achieved with FTAI using OvuGel or a combination of OvuGel and P.G. 600 will be similar to that in control sows bred using conventional AI methods. 


\section{Chapter I: Review of Literature}

\section{$\underline{\text { Swine Estrous Cycle }}$}

Overview of Phases: Gilts reach puberty around 6 to 8 months of age when increased secretion of follicle-stimulating hormone (FSH) and luteinizing hormone (LH) cause growth in ovarian follicles, followed by first estrus, ovulation, and then subsequent estrous cycles. The estrous cycle of swine is the $21 \pm 2 \mathrm{~d}$ period between successive estruses, also known as "standing heats." Gonadotropin releasing hormone (GnRH) is a decapeptide produced by the hypothalamus. Hypothalamic GnRH is released from the median eminence into the hypothalamic-hypophyseal portal system and travels to the anterior pituitary gland where it stimulates secretion of the gonadotropins LH and FSH. The LH and FSH circulate in the bloodstream and both the gonadotropins act in concert to stimulate the development and growth of follicles, causing increased production of estradiol (E2). Circulating E2 causes the behavioral changes displayed by sows and gilts approaching estrus (Flowers, 2001), and eventually reaches a high enough concentration to stimulate a massive release of LH from the anterior pituitary gland called the "LH surge" which occurs around the onset of estrus and induces ovulation (Flowers, 2001; Hansel et al., 1973). The events described thus far are characteristics of the follicular phase, which last approximately 4 to $6 \mathrm{~d}$ (Soede et al., 2011).

After ovulation, areas on the ovaries formerly occupied by follicles become corpora lutea (CL).The luteal phase of the estrous cycle lasts approximately $16 \mathrm{~d}$, during which CL produce progesterone (P4). Masuda et al. (1967) found that P4 will reach maximum levels at $\mathrm{d} 7$ to 12 in non-pregnant or pregnant sows whilst, Soede et al. (2011) reported the peak concentrations to occur 8 to $9 \mathrm{~d}$ post-ovulation. The $\mathrm{P} 4$ acts on the hypothalamus to inhibit $\mathrm{GnRH}$ secretion and in 
turn decreases LH production from the anterior pituitary gland. A hypothalamic site for the negative feedback action of the P4 on LH secretion was supported by work from Estienne et al. (1989) who demonstrated that P4 did not suppress the secretion of LH in response to pulsatile injections of GnRH in hypophyseal stalk-transected pigs. The inhibition of LH and FSH prevents ovarian follicles from growing to the pre-ovulatory stage and being further selected for ovulation. Thus, the onset of estrus will not occur.

The uterine endothelium will secrete prostaglandin-F2 $\alpha$ (PGF2 $\alpha)$ by the end of the luteal phase (d 12 to 16). The CL begin to regress due to the luteolytic effects of PGF2 $\alpha$, causing a decrease in circulating P4 that allows follicular development (Dial and Britt, 1986; Guthrie, 2005). Kotwica et al. (1990) reported that the increased concentration of PGF2 $\alpha$ parallels an increased circulating concentration of oxytocin $(\mathbf{O T})$. This indicates that OT could contribute to the occurrence of luteolysis.

During the follicular phase, growth and development of follicles will take place and occur for approximately 4 to $6 \mathrm{~d}$ post CL regression (Soede et al., 2011). Follicles grow from 3 to 5 $\mathrm{mm}$ in diameter on $\mathrm{d} 15$ to $>6 \mathrm{~mm}$ at the time of ovulation. During this phase, follicles secrete inhibin that ultimately causes negative feedback on the anterior pituitary, suppressing FSH secretion (Guthrie, 2005). Luteinizing hormone and FSH are also initially suppressed by circulating E2 concentrations secreted from the proliferated granulosa cells of follicles before the pre-ovulatory LH surge. Increased hypothalamic GnRH secretion resumes because the inhibition by $\mathrm{P} 4$ is removed with luteolysis. Once the LH surge occurs, a process that requires the rapid changeover from E2 to P4 production, follicular E2 secretion decreases rapidly concomitant with follicle rupture (Guthrie, 2005; Soede et al. 2011). Follicular growth, estrus, and ovulation can now continue to progress. 
Estrus. About $48 \mathrm{~h}$ prior to the onset of estrus, concentrations of E2 will continue to rise until it reaches a peak at 8 to $15 \mathrm{~h}$ before the pre-ovulatory surge of LH that occurs around the onset of standing estrus (Van de Wiet et al., 1981; Henricks et al., 1971). Estrogen stimulates the surge of LH by stimulating hypothalamic GnRH secretion to act upon the anterior pituitary gland to release gonadotropins (Sawyer, 1964; Henricks et al., 1971). Henricks et al. (1971) also found that the E2 concentration did not start to rise in a rapid manner until the plasma concentration of P4 began to fall around d 14. Circulating levels of P4 will remain low during estrus (Masuda et al., 1967). In a study performed by Stevenson et al. (1981), the role of E2 and its effect on FSH, $\mathrm{LH}$, and prolactin were analyzed in intact multiparous sows and ovariectomized sows. The authors concluded that the injection of exogenous E2 in ovariectomized sows resulted in estrus behavior and increased FSH and LH to levels seen in intact sows. This result indicates that surges of LH, FSH, and prolactin are all stimulated by circulating E2.

The length of standing heat or estrus beginning on $\mathrm{d} 0$ of the estrous cycle, varies from 24 to $96 \mathrm{~h}$ (Soede and Kemp, 1997). It is often associated with visual changes to the vulva, including redness, swelling, and a clear to milky white discharge (Flowers, 2001). Behavioral changes also accompany estrus, including mounting of other females, vocalization, chomping, and standing or lordosis response when the back pressure test (BPT) is applied (Signoret, 1970). The levels of circulating E2 produced by pre-ovulatory follicles will be a determinant of these behaviors and physical changes (Soede et al., 2011).

Ovulation. Ovulation is the period that begins with the rupturing of the first follicle and ends with the last follicle rupturing, occurring approximately $70 \%$ of the way through estrus (Soede and Kemp, 1997). Niswender et al. (1970), reported that ovulation occurs about $40 \mathrm{~h}$ after the LH surge when estrus lasts approximately $2 \mathrm{~d}$. If estrus lasts longer than $2 \mathrm{~d}$, ovulation will occur 
about $75 \%$ through the duration of estrus. Therefore, timing of ovulation is variable and not accurately predicted without the use of transrectal ultrasonography. Because one cannot visually identify when a female is ovulating, a good predictor is the duration of observed estrus. For example, a sow displaying estrus for a longer period of time tends to ovulate later after onset compared to a sow displaying estrus for a shorter duration, in which case ovulation will occur sooner (Belstra et al., 2001).

Follicle stimulating hormone has been demonstrated to play a role in the initial recruitment of follicles, but follicles that ultimately ovulate are selected for the final maturation process under the influence of LH (Soede et al., 2011; Knox, 2005). This recruitment process begins with a population of small and medium size follicles $(<3 \mathrm{~mm}$ and 3 to $6.9 \mathrm{~mm}$, respectively) on the surface of the ovary. Approximately 10 to 20 follicles will mature to ovulation (Knox, 2005) while the others will be destined for atresia (Hunter et al., 2004). Surviving follicles mature to 6 to $8 \mathrm{~mm}$ in diameter. During the selection process, follicles destined for ovulation produce a maximum concentration of E2 (5.8 to $11.8 \mathrm{pg} / \mathrm{ml}$; Van de Wiel et al., 1981) that will decrease substantially 2 to $3 \mathrm{~d}$ pre-ovulation (Prunier et al., 1987). Scientists have found significant correlations between peak concentrations of peripheral FSH and ovulation rates in sows (Shaw and Foxcroft, 1985) and gilts (Knox et al., 2003). Guthrie (2005) noticed that as the follicle matures and FSH concentrations decline, there is a shift from FSH to LH dependency as evidenced by a change of LH and FSH receptor expression. Expression of the LH receptor is increased whilst expression of the FSH receptor is decreased, causing a loss of FSH response and increase in LH response in porcine granulosa cells during preovulatory maturation. Developing follicles $>2 \mathrm{~mm}$ in diameter become more dependent on pulsatile secretion of LH (Driancourt et al., 1995) rather than FSH. 
The ovulation process has been demonstrated to last 1 to $3 \mathrm{~h}$ in spontaneously ovulating sows (Soede et al., 1998) and up to $6 \mathrm{~h}$ in females induced to ovulate (Brüssow et al., 1990). Signoret et al. (1972) reported that after two natural copulations by a boar, the duration of ovulation was reduced by $2.8 \mathrm{~h}$. This is believed to be attributed to external stimuli (olfactory and physical) from the boar having an effect on the secretion of pituitary gonadotropins in the sow. Once oocytes are expelled from follicles during ovulation, they travel down the tubular infundibulum and pass into the ampullary portion of the oviduct. Oocytes will then reach the ampullary isthmic junction in as little as 45 min, awaiting fertilization (Hunter, 1974; Soede and Kemp, 1997).

Once ovulation has occurred, the theca cells and granulosa cells lining the ruptured follicle wall will undergo proliferation. This luteinization of cells resulting from the LH surge continues to proceed until the CL is formed into a solid mass comprised of luteal cells. The luteal mass and diameter of the CL grow to approximately 8 to $11 \mathrm{~mm}$ at around one week following ovulation (Soede et al., 2011). On d 14 to 15 of the estrous cycle, the ultimate lifespan of the CL is determined based on the presence or absence of viable embryos. The CL lifespan will be extended in a pregnant female; however, if not pregnant, the CL will undergo luteolysis thereby signaling the development of new preovulatory follicles, thus reinitiating the estrous cycle (Ziecik, 2002).

Pregnancy: Gestation length in female swine lasts approximately $114 \pm 2 \mathrm{~d}$. The establishment and maintenance of pregnancy is the result of paracrine and endocrine signaling mechanisms from the ovary, conceptus, and uterus (Spencer and Bazer, 2002). The conceptus of the pig will produce an abundance of E2 on d 11 to 12 after ovulation, which serves as the signal for maternal recognition of pregnancy (Geisert et al., 1990; Bazer et al., 1994). It has been reported 
that at least four viable embryos are necessary to produce the E2 needed for the maternal recognition of pregnancy in swine (Polge et al., 1966, First et al., 1982). The CL are maintained as part of this maternal recognition and in turn secrete P4 needed for further pregnancy maintenance. Progesterone will act on the uterus to stimulate and maintain uterine functions necessary for early embryonic development and future fetal development (Spencer and Bazer, 2004). At least four to six CL need to be present to produce enough P4 to maintain pregnancy (First et al., 1982). Earlier reports by Dhindsa and Dziuk (1968) found that pregnancy in the sow can be maintained with live embryos in only one uterine horn after d 12 whereas Senger (1997) reported that at least two conceptuses must be present in each uterine horn. If not, PGF2 $\alpha$ will be secreted by uterine capillaries, causing luteolysis (Senger, 1997). At the time of maternal recognition of pregnancy blastocytes will undergo a morphological transformation from a spherical to filamentous shape $10 \mathrm{~mm}$ in diameter around d 11.5 (Geisert et al, 1982; Ziecik, 2011). The elongation of filamentous forms will exceed 60 to $100 \mathrm{~cm}$ and complete this process by d 13 (Anderson, 2009).

Estradiol synthesized and released by a conceptus will cause PGF2 $\alpha$, produced in large quantities by the endometrium, to be secreted into the uterine lumen and away from submucosal capillaries. In the endometrium, PGF2 $\alpha$ is metabolized to a non-luteolytic form and therefore cannot exert a luteolytic effect on the CL. Bazer and Thatcher (1977) reported that in nonpregnant females, P4 will enhance or induce the synthesis and secretion of PGF2 $\alpha$ in an endocrine manner. Prostaglandin F2 $\alpha$ will move into the uterine venous circulation where it will reach the CL and exert its luteolytic effects. In pregnant females, $\mathrm{P} 4$ will induce or enhance the synthesis and secretion of PGF2 $\alpha$; however, there will be a shift towards an exocrine direction (Bazer et al., 1994). The E2 synthesized and released by the conceptus will alter the direction of 
movement of PGF2 $\alpha$ (Geisert et al., 1982) so that the secretion will remain exocrine toward the uterine lumen and thus will not have access to the circulation it needs to cause luteolysis. Prolactin has also been demonstrated to play an important role in the movement of PGF2 $\alpha$. Prolactin receptors on the endometrium, increase on d 12 and are maintained through d 30 of pregnancy. The maintenance of exocrine secretion of PGF2 $\alpha$ will contribute to the accumulation of histotrophs in the uterine lumen, thereby serving as nourishment to the developing conceptus (Bazer and Thatcher, 1997). A second peak of E2 will be secreted by the conceptus on d 15 to 20 that is necessary to prolong CL maintenance in the sow (Geisert et al, 1990). Following maternal recognition of pregnancy, embryos will free-float until they attach to the uterine luminal epithelium on d 13 to 14 and assist in tissue remodeling in the endometrium (Reynolds et al., 2005).

Producers often confirm pregnancy in females using visual methods such as checking for estrus 18 to $24 \mathrm{~d}$ post breeding with or without the use of a boar. If physiological and behavioral signs of estrus are not being exhibited by the sow, she is assumed to be pregnant. Additionally, ultrasonography equipment has recently become more affordable for producers. Real-time (BMode) ultrasonography (RTU) with a transducer inserted in the rectum or placed on the abdomen has provided a method of highly effective pregnancy detection (Inaba et al., 1983; Flowers et al., 1999), as early as 18 to 35 d post breeding (Knox and Althouse, 1999). Upon tissue contact, waves are reflected to a hand-held transducer and are converted to a twodimensional image that is displayed on a monitor (Inaba et al., 1983). Black areas correspond to fluid filled structures while gray or white images correspond to tissues. A sow that is pregnant will produce an image displaying irregular black shapes. 
A-Mode ultrasound units are also commonly used by swine producers and are considerably less expensive than B-Mode units while still providing effective pregnancy detection (Flowers et al. 1999). These tools use high frequency sound wave echo signals to detect a liquid-filled structure (e.g. amniotic sac). Once the structure is detected, the echo is converted to an audible tone. The disadvantage to this method is that false-positives can be obtained if other fluid-filled structures such as the bladder are detected (Almond and Dial, 1987). Flowers et al. (2000) were able to demonstrate that both A-Mode and B-Mode (RTU) machines had sensitivity greater than $96 \%$ but A-Mode was less sensitive and unable to detect nonpregnant sows as effectively as B-Mode. Furthermore, results using RTU were obtained 1 to 2 wks sooner compared to the A-Mode unit. A-Mode units should not be used until > $30 \mathrm{~d}$ of gestation due to fundamental sensitivity constraints (Knox and Althouse, 1999). Even though both methods are beneficial tools used for pregnancy detection, RTU should be used for early pregnancy diagnosis in sows when available and cost effective.

Parturition. Successful parturition depends on the contractile ability of the uterus and the ability of the cervix to sufficiently dilate, enabling the passage of the fetus. Parturition is a series of mechanisms initiated by the fetus. Just 1 to $2 \mathrm{~d}$ prior to parturition, $\mathrm{P} 4$ concentrations that were once at 6 to $12 \mathrm{ng} / \mathrm{mL}$ decrease due to what is believed to be a rise in fetal cortisol within maternal circulation and/or increasing levels of E2 produced by the placenta (Ash and Heap, 1975). The increase of E2 stimulates an endocrine cascade preparing the sow for parturition including causing the uterine myometrium to begin contracting. The uterus will release PGF2 $\alpha$ that will cause regression of the CL and in turn decrease P4 levels. Consequently, this leads to removal of the "progesterone block" that prevented the uterus from contracting in order to maintain pregnancy (Baldwin and Stabenfeldt, 1975). Prostaglandin-F2 $\alpha$ stimulates the 
production and secretion of relaxin (RLX) from the ovary prior to parturition. Relaxin performs a dynamic function by suppressing uterine contraction as a way to maintain pregnancy until the time of fetal expulsion. Relaxin is also capable of softening the cervix and expanding the birth canal for easier piglet delivery. Levels of RLX will decrease before the expulsion phase of parturition. During the time at which RLX concentrations increase, PRL concentrations also increase under the influence of PGF2 $\alpha$; however, their peaks are independent of one another (Taverne et al., 1982). Prolactin is responsible for maternal behavior in sows along with the initiation and maintenance of milk production. Additionally, PGF2 $\alpha$ travels through the maternal circulation to the anterior pituitary gland and will stimulate the production of OT (Dial and Britt, 1986). Oxytocin levels remain low during pregnancy but increase in concentration during the expulsion phase of parturition, with a secretory pulse occurring with every fetal expulsion until delivery is completed (Gilbert et al. 1994). Oxytocin has a role in maintaining contractions of smooth muscle myometrium during fetal delivery as well as stimulating milk let down. Although controversial, OT is believed to play a role in initiating parturition; however, little research has been conducted for further support of this theory. Once the last piglet is delivered the sow will expel the placental membranes, concluding the parturition process.

\section{$\underline{\text { Artificial Insemination }}$}

The use of AI on swine farms has increased in the United States with more than $90 \%$ of sows bred by AI in 2012 compared to less than $4 \%$ in 1990 (NAHMS, 1997; NAHMS, 2012). The growing popularity of AI throughout the past decade can be attributed to advancements in breeding methodologies and the potential incorporation of superior genetics into existing herds. 
Flowers and Alhusen (1992) reported that natural mating with a boar required on average 22 min per female including the detection of estrus and mating. Additionally, if four or more sows or gilts were bred at a time, AI required less time than natural mating and actually improved time management practices. Knox et al. (2013) found that by using modern AI technologies in breeding herds, an average of 1 to 2 min were needed for estrus detection and 4 min were needed for the insemination per female. Compared to AI, farrowing rates and litter sizes can be poorer when natural mating is used on small pig farms (Am-in et al., 2010). Contributing factors to the poorer reproduction seen with natural mating could include, but are not limited to: the number of times the sow was serviced by the boar, the reproductive capacity of the boar, and whether or not matings occurred at the peak interval before ovulation. The amount of time and the cost of labor saved by using AI methodologies has proven beneficial to producers on virtually any size operation; however, the lack of experience or skills by AI technicians can be a contributing factor to poor sow reproductive performances (Knox, 2016).

Pig producers have implemented AI techniques that best suit the needs of their operations. Traditionally, a spirette or foam tip catheter that mimics the anatomical structure of the boar penis is inserted through the vulva and locked into the posterior folds of the cervix where semen is deposited. Despite inseminating large numbers of sperm cells into the cervix, only a small number will end up reaching the oviduct, which serves as the sperm reservoir (Hunter, 1981). Movement of sperm cells up the reproductive tract is relatively quick and sperm cells are found in the oviducts minutes after insemination (Baker \& Degen, 1972). Myometrial contractions help transport sperm cells to the ampullary-isthmus junction of the oviduct where fertilization occurs (Einarsson et al., 1980; Viring and Einarsson., 1981; Langendijk et al., 2005a). The ability of sperm cells to fertilize ova is acquired over a $2 \mathrm{~h}$ time frame once sperm 
have reached the ampullary-isthmus junction. Therefore, sperm that arrive within minutes after deposition are unable to fertilize (Knox, 2004).

A majority of sperm cells deposited during AI will be lost in backflow or trapped in the cervical folds (Dimitrov et al. 2007). Backflow is the leakage or loss of diluted semen that is expelled back out through the sow's vulva during or after AI. The occurrence of backflow can be the result of depositing semen too rapidly or incorrect placement of the catheter during insemination (Roca et al., 2006). During natural mating, the boar will produce a gel plug that blocks fluids from coming back out. Because AI does not provide the natural gel block during mating, precaution should be taken when locking the catheter properly into the cervical folds to reduce excessive backflow. Excessive backflow has been shown to negatively affect fertility rates (Steverink et al., 1998). Willenburg et al. (2003) reported that $53 \%$ of sperm cells are lost within an $8 \mathrm{~h}$ period after insemination because of backflow. Oftentimes, less than $1 \%$ of sperm that are inseminated will make it to the sperm reservoir (Mburu et al., 1995).

Soede et al. (1995) demonstrated that optimum fertility with AI results when semen is deposited into the cervix 0 to $24 \mathrm{~h}$ before ovulation. Thus, to increase the likelihood that semen is deposited at the optimum time during estrus, the standard practice is to inseminate 2.5 to 3.0 billion sperm cells at the onset of standing estrus and then again $24 \mathrm{~h}$ later when once daily estrus detection is employed. Producers will even inseminate a third time if sows continue to exhibit standing estrus. On average, most sows will receive 2 doses of semen (Knox, 2016). Each 80 to $100 \mathrm{~mL}$ liquid dose of semen used in conventional intracervical AI contains 2.5 to 3.0 billion sperm cells suspended in extender. Using fewer sperm cells results in poorer reproductive performance no matter how close to ovulation insemination takes place (Bracken et al., 2003). Extender enhances the viability of sperm cells over a period of time. Research has indicated that 
as semen in long term extenders ages past $\mathrm{d} 7$ post-collection, farrowing failure, smaller litter sizes, and failure to conceive increase (Anil et al., 2004). On most commercial boar studs, semen is collected from the boar on Monday and/or Thursday. Collected semen is then diluted using extender, creating multiple doses that are shipped the same day so that producers can benefit from viable, fresh semen the day after collection. Therefore, it is beneficial to schedule the delivery of semen closest to when females are to undergo AI, thus, decreasing the use of aged semen which has been demonstrated to negatively affect reproductive performance.

\section{Utilization of a Boar in Mating Systems}

Exposure to a boar has been shown to be extremely beneficial in facilitating AI in sows. The level of male sexual behavior in mating systems may affect the level of reproductive performance in breeding herds (Hemsworth and Tilbrook, 2007). Behavioral patterns from the boar can include, but are not limited to: nose-to-nose contact, nosing the flank and back end of the sow, and mounting (Pedersen, 2007). According to Soede (1993), boar stimulation (olfactory, auditory, visual, and tactile), is believed to have a positive effect on insemination and estrus detection. The frothy saliva from the submaxillary salivary glands (Signoret, 1970) produced by the mature boar (9 to 10 months of age; Hughes et al., 1990), contain large quantities of the pheromones $3 \alpha$-androstenol and $5 \alpha$-androstenone (Pearce and Hughes, 1987). The $5 \alpha$ androstenone released by the boar can cause the same amount of OT release from the female as that occurring during natural mating (Maffeo et al., 1993) and a strong standing reflex (Perry et al., 1980). It has also been demonstrated that visual cues are important in eliciting sow behavior. Even without direct sight of the boar, sows were still stimulated by olfactory and auditory cues (Pearce and Hughes, 1987), indicating the importance of various types of boar stimuli. 
Proper estrus detection skills are crucial to reproductive performance. According to Knox et al. (2002), the most important outcome of detection frequency is for AI to occur at the optimal time before ovulation through accurate detection of the onset of estrus. Improper detection can lead to AI occurring at suboptimal times which can negatively impact the productivity of gilts and sows. Boar contact has been demonstrated to assist in estrus expression and detection practices, giving producers distinct evidence of estrus and enables more accurate prediction of ovulation. This is supported by Signoret (1970), who found that using mature boar exposure whilst performing BPT to facilitate estrus detection resulted in $97 \%$ accuracy of total sows in estrus being detected. Langendijk et al. (2000b) demonstrated the benefits of using head-to-head contact using a teaser boar for estrus detection after weaning. They reported an earlier detection of the onset of estrus (128 h vs $137 \mathrm{~h}$ ) and a longer duration of estrus ( $56 \mathrm{~h}$ vs $38 \mathrm{~h}$ ) of sows exposed to the boar compared to BPT alone in the absence of a boar. The BPT alone without the boar also resulted in a lower detection rate indicating that boar exposure allowed for a more accurate determination of behavioral estrus. Both studies suggest that boar vocalizations, visualization, and odor are beneficial for accurate estrus detection and all should be optimized during detection protocols.

To further substantiate their findings, Langendijk et al. (2003) studied the response of sows in estrus exposed to different levels of stimuli: tactile BPT performed by a technician, BPT in combination with fence-line boar contact, or BPT in combination with olfactory stimulation. Results indicated that all sows showed behavioral estrus in the presence of the boar whilst BPT alone or in combination with olfactory stimuli resulted in only $30 \%$ of sows exhibiting a standing response. The common practice on most farms is to perform once or twice daily estrus detection with a mature boar either within a designated pen that allows the boar to have full 
contact with sows or by fence-line contact. Some producers may find twice daily-estrus detection advantageous because the chances of accurately determining the onset of estrus are increased. The amount of labor and time associated with estrus detection, however, has to be increased in an already labor intensive task. Therefore, utilizing a boar in routine estrus detection protocols could assist producers with achieving breeding targets; however, they must determine if the time and labor associated with multiple detection times each day proves cost effective.

Boar exposure has also been implicated with decreasing the wean to estrus interval (WEI) and onset of ovulation in sows, particularly in sows that are more likely to be delayed due to various factors (Walton, 1986; Hughes et al., 1990; Langendijk et al., 2000a; Knox et al., 2004). Low concentrations of LH released after weaning is thought to be involved in delayed return to estrus and ovulation. Boar contact is believed to stimulate LH release and enhance the onset of estrus and ovulation in sows that otherwise would not have had sufficient levels of LH to stimulate follicle growth (Kemp et al., 2005; Hemsworth and Tilbrook, 2007). Hughes (1998) did not report any effect of boar contact 1 to 3 times daily on the WEI but rebreeding intervals were shorter in that study ( $4.9 \mathrm{~d}$ to $5 \mathrm{~d}$ ). Other researchers have also reported that different levels of boar exposure (i.e., number of daily exposures) did not affect the WEI (Hemsworth and Hensen, 1990; Langendijk et al., 2000c, Knox et al., 2002). Authors suggested that habituation could have possibly occurred in sows that were given excessive boar exposure. In other words, sows grew accustomed to the boar check protocols and were not as affected by the excessive boar stimuli. Interestingly, Langendijk et al. (2000b) reported that follicular dynamics in sows were not affected by boar contact; however, contact did increase from $30 \%$ to $51 \%$ the number of sows ovulating and exhibiting estrus within $9 \mathrm{~d}$ after weaning compared to sows receiving no contact. These data suggest that controlled, non-excessive exposure to a boar could be useful in 
enhancing WEI and ovulation, especially in sows more susceptible to prolonged return to estrus after weaning.

During natural mating and AI in sows, the process by which sperm cells get transported to the sperm reservoir in the oviduct is relatively passive, so it is essential that sufficient uterine contractility takes place for this transport to occur (Langendijk et al., 2005a). Myometrial contractions help transport spermatozoa to the ampullary-isthmus junction of the oviduct where fertilization will take place (Einarsson et al., 1980; Viring and Einarsson, 1981). The amount of contractility is thought to be controlled by the amount of OT released from the posterior pituitary gland of the female in response to boar exposure (Signoret et al., 1972; Claus, 1989; Kotwicka et al., 1995). Boar presence at the time of AI induces OT release and increases uterine activity for 1 h only for sows with low uterine activity prior to boar exposure (Langendijk et al. 2003). Furthermore, tactile stimulation of the sow genital tract, back, and flanks during AI does not cause a release of OT but does to an extent stimulate uterine contractility in sows with below average frequency of uterine contractions (Langendijk et al. 2003). Supplementing semen with exogenous OT or injection sows with OT in the vulvar lips right before AI during low fertility season (i.e., summer months) have also been considered effective methods for increasing reproductive efficiency (Peña et al., 1998). The change of uterine contractions under the influence of OT or tactile stimulation could assist in quicker transportation of sperm cells and thus increase fertilization, especially in females with suboptimal contractility during estrus.

Willenburg et al. (2003) evaluated in gilts the effects of 15 min boar exposure during AI compared to AI in the absence of a boar. Neither the duration of AI or fertilization of embryos were affected by boar exposure $(P>0.10)$. During initial AI, there was a significant reduction on the volume of semen and the total sperm lost from backflow when gilts were exposed to a 
boar compared to those that were not. Although not evaluated, these findings suggest that boar exposure may have stimulated the frequency of uterine contractions that resulted in less backflow during initial AI even though there was no effect on fertility between treatments. Hemsworth et al. (1978) reported a significant positive effect on litter size when sows were exposed to a boar for a 2 min period prior to $\mathrm{AI}$ in comparison to $\mathrm{AI}$ in the absence of a boar. Boar exposure at the time of AI could, improve low fertility occurrences by stimulating uterine contractions (Soede et al., 2009) and increase the speed at which sperm cells are transported to the oviduct (Knox, 2004). Furthermore, mature boar exposure could in fact help producers overcome sub-optimal breeding times when seasonal infertility is known to affect conception rates in sows (Peña et al., 1998). Boar exposure has been well established as being an effective tool with facilitating AI because of the ability to induce and enhance estrus and ovulation as well as contributing to higher fertilization rates (Langendijk et al., 2005b). Even so, boar use is considered labor intensive for most farms and can be an added cost to the producer.

\section{Timing of Artificial Insemination}

In postpartum sows, gonadotropin secretion is inhibited not by elevated P4 concentrations, but rather by the suckling stimulus from the piglets. This will therefore inhibit follicular development and lactating sows will experience anestrus. When the suckling stimulus is removed at weaning, WEI ensues and sows are considered to be in the follicular phase of the estrous cycle. The post weaning period affects measures of reproductive efficiency, such as WEI and nonreturn to estrus rate. Nonproductive days (NPDs) are defined as the time during which the sow is not lactating or pregnant and are affected by the length of the WEI. It is during this time that more cost is being put into feeding and maintaining the sow than what she is returning. Producers on average will wean pigs at 3 to 4 weeks of age with sows returning to estrus within 
4 to $7 \mathrm{~d}$. The suckling stimulation that inhibited the production of $\mathrm{GnRH}$ is removed, allowing positive feedback to the anterior pituitary gland to stimulate secretion of LH and FSH function. Circulating LH and FSH will stimulate follicular growth and development resulting in the onset of estrus and ovulation (DeRensis et al., 1993).

The inverse relationship of duration of estrus and estrus to ovulation interval (EOI) with WEI can contribute to the occurrence of suboptimal timing of AI relative to ovulation. Long WEI has negative effects on litter size as well as fertilization rate (Steverink et al., 1999). The fertility of sows that are inseminated after a WEI of 6 or more days is significantly lower than that of sows who exhibit a shorter WEI (Vesseur et al., 1994; Kemp and Soede, 1996). Authors concluded that an increase in WEI results in a higher percentage of sows being inseminated too late and a decrease in sows inseminated too early in regards to ovulation. Multiple matings per sow in both cases could prove a wasted expense of semen and labor if they occurred outside the optimal AI interval. Indeed, a more reliable predictor of ovulation could offer a more specified time to AI, ultimately giving producers a better chance of achieving high reproductive efficiency.

According to Knox et al. (2013) the greatest herd infertility issues are due to poor estrus induction and detection practices. The failure to AI sows within $24 \mathrm{~h}$ before ovulation limits farrowing rate and litter size (Jackson et al., 2003). Failure to properly detect estrus and inseminations at suboptimal times relative to ovulation also contribute to poor reproductive performance in sows (Kemp and Soede, 1996; Nissen et al., 1997). To achieve a high conception rate, sperm cells need to be present in the reproductive tract 0 to $24 \mathrm{~h}$ before ovulation. Rodriquez-Martinez (2001) suggested that sperm cells will remain fertile for approximately $24 \mathrm{~h}$. The ovum has a shorter lifespan and should be fertilized within $8 \mathrm{~h}$ or, for maximum litter size, less than $4 \mathrm{~h}$ after ovulation (Hunter, 1990). According to Soede et al. 
(1995), sperm cells can fertilize normally for more than $40 \mathrm{~h}$ after AI when the interval between insemination and ovulation is less than $24 \mathrm{~h}$. Ovulation will take place in sows approximately $2 / 3$ of the way into estrus (Mburu et al., 1995; Nissen et al., 1997), in theory making the duration of estrus rather than the onset of estrus a more reliable predictor for the timing of AI. Because producers do not have the ability to predict the duration of estrus or ovulation time of their sows beforehand, the normal practice of producers is to AI based on the onset of estrus and again at 24 $\mathrm{h}$ intervals for however long the sow will express estrus behavior. The goal is to ensure that at least one of those matings will occur 0 to $24 \mathrm{~h}$ before ovulation.

The timing at which the sow is inseminated has been shown to affect litter size and farrowing rate. In a study performed by Soede et al. (1995), the effects of the timing of insemination relative to fertilization rate was evaluated in sows. Transrectal ultrasonography was performed at $4 \mathrm{~h}$ intervals to determine the occurrence of ovulation. Embryos and oocytes were collected and assessed for quality and morphology. Oocytes were considered unfertilized if the nuclei count was 1 or 0 . Additionally, embryos with a lower number of nuclei and that had degenerate morphology were considered degenerate and associated with partial fertilization. The remaining embryos were considered normal and this percentage was associated with fertilization rate. The authors concluded that when insemination took place between 0 and $24 \mathrm{~h}$ before ovulation, the fertilization rate (i.e., normal embryos) was significantly higher than when insemination took place $>24 \mathrm{~h}$ before ovulation (100 vs. $59 \%$ ). In this study partial fertilization also occurred during the peak interval which is interesting in itself, considering previous assumptions that fertilization was an all or nothing concept (Hunter, 1994). Furthermore, Soede et al. (1995), reported that too few fertile sperm (as indicated by low numbers of accessory sperm cells in the embryos) were present at the site of fertilization when the interval between 
insemination and ovulation was generally greater than $24 \mathrm{~h}$. This further supports AI occurring at an optimal interval of 0 to $24 \mathrm{~h}$ before ovulation, which is in agreement with findings from Kemp and Soede (1996). Matings outside this interval will result in decreased fertilization and a lower number of normal embryos.

In a study performed by Nissen et al. (1997) farrowing rate and litter size of multiparous crossbred sows $(n=143)$ were evaluated for optimal time of AI relative to the time of ovulation. Estrus detection was performed every $8 \mathrm{~h}$ beginning $3 \mathrm{~d}$ after weaning. Ultrasound evaluations of follicles were performed every $6 \mathrm{~h}$ from $12 \mathrm{~h}$ after the onset of estrus until ovulation was determined. Sows were inseminated once at variable time intervals ranging from $36 \mathrm{~h}$ before ovulation to $12 \mathrm{~h}$ after ovulation. Results showed an increased number of piglets born per sow (13.7 vs 9.0) and fewer non pregnant sows (16.3 vs. $62.5 \%$ ) when sows were inseminated $28 \mathrm{~h}$ before to $4 \mathrm{~h}$ after ovulation compared to those bred outside of that range. This interval is larger compared to findings from Waberski et al. (1994) who reported an optimum interval to be 12 to $0 \mathrm{~h}$ before ovulation and Soede et al. (1995) who reported an optimal interval to be 0 to $24 \mathrm{~h}$ before ovulation. Kemp and Soede (1996) also found that an optimum time for AI was $10 \pm 6 \mathrm{~h}$ before ovulation. These data suggest that reproductive efficiency can be increased when AI occurs within an optimal interval relative to ovulation.

The WEI has been found to be correlated with timing of ovulation and fertilization rates in sows (Kemp and Soede, 1996). The authors suggested that the negative effects of a long WEI on subsequent litter size and farrowing rate may not be the result of what is perceived to be poor fertility in sows. The negative effects may instead, be due to suboptimal timing of insemination relative to the time of ovulation. A sow's WEI has been found to be a prospective indicator of time of ovulation because it tends to be inversely related to duration of estrus. Belstra et al. 
(2001) used real-time ultrasound imaging to study the relationship between WEI, estrus, and ovulation. Regardless of differences in the duration of estrus in sows, ovulation will occur at about $70 \%$ of a sow's duration of estrus (Soede and Kemp, 1997); however, an inverse relationship occurs in that EOI decreases as WEI increase. Kemp and Soede (1996) found that an increase in WEI resulted in a decrease in the duration of estrus and a decrease in the time between the onset of estrus and time of ovulation. In their study, a negative correlation was reported between the duration of estrus and WEI. An average duration of estrus for their experiments was $61 \pm 2 \mathrm{~h}, 53 \pm 1 \mathrm{~h}, 49 \pm 2 \mathrm{~h}$ and $38 \pm 6 \mathrm{~h}$ for d 3, 4, 5, and 6 after weaning, respectively. This agrees with findings from Weitze et al. (1994), who reported that the duration of estrus decreased from $72 \mathrm{~h}$ with sows having a WEI less than $4 \mathrm{~d}$ to approximately $50 \mathrm{~h}$ when the WEI increased to 4.5 to $5 \mathrm{~d}$. Additionally, the EOI also was reduced from $53 \mathrm{~h}$ to $39 \mathrm{~h}$ at a WEI of 4 to 4.5 to 5 d, respectively. Kirkwood and Kauffold (2015) reviewed the relationships between WEI, onset of estrus, and ovulation.. Sows that have a short WEI $(<4 \mathrm{~d})$ tend to have a longer duration of estrus and ovulate later (late ovulators). Sows that had a longer WEI (> $5 \mathrm{~d}$ ) tended to have a shorter duration of estrus and ovulate earlier (early ovulators). Estrus duration is considered to be a predictor of ovulation but unfortunately is still highly variable as demonstrated by these studies. As a result, it is not utilized as a standard practice for swine producers.

\section{Fixed Time Artificial Insemination}

Knowing precisely when to AI sows relative to ovulation can increase reproductive performance and achieve breeding targets. With approximately $95 \%$ of sows expressing estrus between 4 and $7 \mathrm{~d}$ post-weaning, there is still variability in the WEI and consequently EOI (Knox and Rodriguez, 2001; De Rensis et al., 2005). As discussed above, it is well established 
that fertilization rate (Soede et al., 1995), farrowing rate (Nissen et al., 1997), and litter size (Rozeboom et al., 1997) all depend on AI taking place within $24 \mathrm{~h}$ before ovulation. Therefore, producers could benefit from a fixed time in which sows can be inseminated relative to time of ovulation in addition to shortening the WEI.

Various FTAI protocols for swine farms have been studied. By understanding the hormonal mechanisms that influence weaning and post-weaning events, attempts can be made to enhance the reproductive processes in sows. Normally sows can be synchronized by weaning in a batch type farrowing system. Batch farrowing is convenient in that multiple sows farrow together in batches and are weaned at the same time with the idea of synchronizing estrus and ovulation once piglets are removed. Producers also benefit from having relative uniformity in size and age of pigs moving through production systems and ultimately being sold to slaughter (Roese et al., 2007). Because the WEI and wean to ovulation interval (WOI) are influenced by the development of follicles at weaning (Lucy et al., 2001), some sows may fall outside the planned breeding window due to insufficient follicle growth that delays or even prevents return to estrus. These sows fall out of schedule and are often culled.

Exogenous Gonadotropins. Exogenous gonadotropins have been used to stimulate ovarian activity in sows that experience suppressed gonadotropin secretion at weaning with the goal of increasing overall reproductive performance. Esbenshade et al. (1990) reviewed the effects on gonadotropins and how they play a role in stimulating the growth and development of follicles in the female pig. Gonadotropic receptors are found on the plasma membranes of thecal, granulosal, luteal, endometrial, and myometrial cells in the female. The use of exogenous gonadotropins to induce the growth and development of follicles involved in ovulation are actually similar to 
processes occurring naturally. Having the ability to synchronize estrus and ovulation could minimize sow NPDs and the amount of doses needed for AI.

Equine chorionic gonadotropin (eCG) is a glycoprotein that is similar to that of equine pituitary LH. The effects on eCG in advancing estrus in weaned sows has been extensively studied. Its use has had positive effects on the follicle development of weaned sows (reviewed by Brüssow et al., 2009), as it exhibits both LH and FSH activity.

Lucia et al. (1999) tested the effects of post-weaning eCG administration on WEI and estrus duration for early weaned females. Primiparous sows $(n=96)$ received $750 \mathrm{IU}$ of eCG i.m. $1 \mathrm{~d}$ after weaning. Estrus detection was performed three times daily using boar stimuli. Authors reported a decrease in the WEI for females that received eCG compared to non-treated control sows ( $98.7 \pm 2.7$ vs $121.5 \pm 3.3 \mathrm{~h}$ ). Authors correlated such a significant reduction to an increase in estrus duration of approximately $16.5 \mathrm{~h}$ in sows treated with eCG based on a linear regression model to explain variation of estrus duration as a function of WEI across treatment groups $\left(\mathrm{R}^{2}=.51\right)$. Results of that study disagree with findings from Weitze et al. (1994) who demonstrated that primiparous sows treated with eCG actually had a reduction in estrus duration compared to untreated sows having two or more parities. It is important to note, that the study did not use primiparous sows as untreated controls.

Sechin et al. (1999) evaluated the i.m. administration of four doses of eCG $(0,500,750$, and 1,000 IU) and the effect on wean-to-first service interval, total litter size, and total born alive across two time periods (July to October and January to September), three farms, and amongst three parity groups $(1,2$, and $3+)$. Sows were administered eCG on $\mathrm{d} 1$ after weaning and given twice daily estrus detection after completion of treatment. The effects of farm and time period 
did not influence the weaning-to-first service interval. Total litter size was found to be larger on Farm 2 compared to Farm 3 but Farm 1 total litter size did not differ from any other farm. This could be attributed to the difference in breeding herd inventories and management practices across farms. A significant interaction was found between eCG treatment and parity on the weaning to first service interval. Results indicated that parity 1 sows treated with $750 \mathrm{IU}$ of eCG had a decrease in the weaning to first service interval compared to non-treated controls (4.98 and 6.05 d, respectively). These findings are in agreement with Lucia et al. (1999), who reported similar results in Parity 1 sows given 750 IU of eCG. This significant reduction was not seen in parity 2 sows. Litter size increased in Parity 1 and 2 sows as the dose of eCG increased from 0 to 1,000 IU of eCG (10.03 and 11.03, respectively) but not for Parity 3 sows (11.88). The number of pigs born alive also followed the same trend, with Parity 1 and Parity 2 sows having an increase (9.61 and 10.56, respectively) but not Parity 3 sows (10.79). Administration of $1000 \mathrm{IU}$ of eCG produced an additional 2 piglets per litter for parity 1 sows and at least 1 additional piglet born for parity 2 sows.

Even though doses higher than $750 \mathrm{IU}$ of eCG would not be necessary to improve wean to service interval in primiparous sows, higher doses could improve subsequent litter size. This disagrees with Cassar et al. (2010), who more recently reported that litter size was unaffected by increasing the dose of eCG to $600 \mathrm{IU}$ or even $900 \mathrm{IU}$ in primiparous sows even though farrowing rate increased when $900 \mathrm{IU}$ of eCG was administered. Furthermore, Cassar et al. (2005) found that $600 \mathrm{IU}$ of eCG was adequate to induce estrus and ovulation for multiparous sows while ovulation rates were greater for gilts given $900 \mathrm{IU}$, contrary to standard administration of $600 \mathrm{IU}$ (Cassar et al., 2010). The response to the higher dose of eCG in primiparous sows indicates the possibility that ovaries of weaned primiparous sows are less sensitive to hormonal stimulation 
compared to multiparous sows. Therefore, a higher dose of eCG may be needed to stimulate the onset of estrus and ovulation. Practical use of eCG would require different doses to cater to different sow parities to balance the cost with potential benefits. Even though eCG alone has demonstrated the ability to synchronize estrus and to some extent ovulation (Guthrie et al., 1974), the time in which ovulation occurs is still highly variable (reviewed by Brüssow et al., 2009). To facilitate successful FTAI, ovulation needs to be induced by gonadotropins with primarily LH activity or GnRH analogues.

Human chorionic gonadotropin (hCG) mimics the endocrine effects of LH and has long been studied with respect to inducing ovulation in weaned sows (Hunter and Polge., 1966; De Rensis et al., 2003; Wongkaweewit et al., 2012). To induce ovulation, hCG acts directly on LH receptors located on ovarian follicle cells (Wongaweewit et al., 2012). GnRH analogues also are effective in inducing ovulation, but unlike hCG, GnRH acts at the pituitary level and stimulates release of endogenous LH. Brüssow et al. (2009) described this as more biologically normal than ovulation induction using hCG. Exogenous hCG has been demonstrated to be effective in inducing ovulation in females 40 to $42 \mathrm{~h}$ after treatment (Hunter, 1967) whereas GnRH induced ovulation $38 \mathrm{~h}$ after treatment (Brüssow et al., 2009). The mentioned intervals from treatment to ovulation gives a better prediction of when AI needs to occur relative to ovulation thereby contributing to successful FTAI.

Wongaweewit et al. (2012) evaluated the use of hCG and GnRH and their effects on controlling ovulation in weaned multiparous sows experiencing moderate heat stress. Sows were examined for behavioral estrus using the BPT method with direct boar contact every $6 \mathrm{~h}(0200$, 0800, 1400, and 2000) from the day after weaning. At the onset of estrus, sows were treated with $750 \mathrm{IU}$ of hCG $(\mathrm{n}=10), 50 \mu \mathrm{g}$ of GnRH analog Buserelin (Receptal®, Intervet) $(\mathrm{n}=13)$, or 
remained as controls $(n=10)$. Ovulation occurrence based on follicle growth was monitored every $6 \mathrm{~h}$ after the onset of estrus using transrectal ultrasonography. Authors reported that all sows in the control and hCG groups had ovulated whereas only 10 out of 13 sows treated with GnRH ovulated. The sows that did not ovulate were discovered to have developed ovarian cysts and authors therefore data from the non-ovulating sows were excluded from further analysis. The EOI of the GnRH $(37.5 \pm 3.3 \mathrm{~h})$ group and hCG group $(40.2 \pm 1.7 \mathrm{~h})$ were shorter than that of control group $(63.6 \pm 9.6 \mathrm{~h})$. They also reported that WOI in GnRH $(5.0 \pm 0.4 \mathrm{~d})$ and $\mathrm{hCG}(5.8 \pm$ $0.3 \mathrm{~d})$ groups were shorter compared to non-treated controls $(6.5 \pm 0.4 \mathrm{~d})$. The duration of estrus was found to be shorter and less variable for hCG $(49.5 \pm 1.1 \mathrm{~h})$ and $\mathrm{GnRH}(47.5 \pm 2.8 \mathrm{~h})$ treated sows compared to controls $(71.1 \pm 8.7 \mathrm{~h})$. It is important to consider that only a small number of sows were involved in this study in addition to treatment effect being evaluated on short WEI ( $4 \mathrm{~d}$ ). Reliability of data could be improved by increasing sampling size of sows. Even so, these results indicate the potential of using hCG or $\mathrm{GnRH}$ to induce ovulation in naturally cycling sows exhibiting a short WEI, without the need for prior eCG treatment, particularly in heat stress environments. In contrast, Kirkwood et al. (1999) found that exogenous hCG was not effective in inducing ovulation and actually prolonged the WEI; however, hCG in the Thailand study was administered to sows at $24 \mathrm{~h}$ intervals post farrowing, generating responses that were considered too limited to be of commercial application.

Variation of pre-ovulatory LH surge relative to the onset of estrus is assumed to play a role in causing differences in timing surrounding ovulation during estrus (Tilton et al., 1982). Homologous porcine luteinizing hormone ( $\mathbf{L L H})$ has been demonstrated to cause an ovulation response $38 \mathrm{~h}$ after administration in gilts (Degenstein et al., 2008) and sows (Cassar et al., 2005; Bennett-Steward et al., 2007) which is similar to previous reports by Willis et al. (2003) who 
indicated that the endogenous peak of the LH-surge-to-ovulation interval in conventionally weaned sows as $37.1 \pm 2.4 \mathrm{~h}$. Based on these findings, using $\mathrm{pLH}$ injection at the onset of estrus to induce ovulation could in fact contribute to a FTAI protocol with AI occurring at optimal mating intervals relative to ovulation.

Zak et al. (2010) tested the effects of pLH administration on the synchronization of ovulation to facilitate a double FTAI protocol on weaned sows under standard herd practices. Multiparous sows were randomly assigned to either a control $(n=150)$ or $\mathrm{pLH}(\mathrm{n}=168)$ treatment. Both treatment groups were given twice-daily estrus detection using fence-line contact with a high-libido boar. Control sows were inseminated based on an AM-PM barn schedule with AI occurring at 6,18 , and $24 \mathrm{~h}$ intervals based on behavioral estrus. Sows that were assigned to pLH treatment received $5 \mathrm{mg}$ of pLH intramuscularly at the onset of first detected behavioral estrus $(0 \mathrm{~h})$. For sows having the first detection of estrus in the morning, AI occurred at 24 and $30 \mathrm{~h}$ after the injection of $\mathrm{pLH}$. If onset of estrus was detected in the afternoon, AI occurred at 24 and $42 \mathrm{~h}$ the day after the injection. Authors found that fewer inseminations were performed for pLH treated sows $(2.00 \pm 0.02)$ compared to control sows $(2.13 \pm 0.02)$. Total born and born alive were greater for $\mathrm{pLH}$ treated sows compared to control sows $(12.88$ vs 11.80 , and 11.80 vs 10.80, respectively). These findings are in agreement with similar reports by Cassar et al. (2005). There was no effect of treatment on farrowing rate or pregnancy rate. Data indicated that sow productivity was enhanced by administration of $\mathrm{pLH}$ at the time of first detected behavioral estrus to synchronize ovulation in multiparous weaned sows under standard farm settings. The total number of semen doses needed for AI was reduced using a double FTAI without any negative effect on pregnancy or farrowing rates. Authors did not attribute the larger litter size in response to FTAI a result of an increase in ovulation rate because of previous reports of similar 
ovulation responses irrespective of pLH or control treatment in gilts (Degenstein et al., 2008). Instead, they attributed the difference in litter size to suboptimal timing of AI relative to ovulation in the control sows.

Ideally, successful FTAI would be achievable with estrus synchronization followed by the induction of ovulation. Cassar et al. (2005) evaluated the combination of eCG followed by pLH on subsequent fertility in multiparous sows. In the first experiment, 17 multiparous sows received an intramuscular injection of $600 \mathrm{IU}$ eCG at weaning (d 0) to induce estrus by stimulating follicular development. Sows then received an intramuscular injection of $5 \mathrm{mg} \mathrm{pLH}$ $80 \mathrm{~h}$ after eCG treatment. The timing of ovulation was evaluated using RTU every $8 \mathrm{~h}$ from 16 to $32 \mathrm{~h}$ after $\mathrm{pLH}$ injection, and then at 2 to $4 \mathrm{~h}$ intervals until ovulation was complete. The time from pLH treatment to ovulation ranged from 34.3 to $42.5 \mathrm{~h}$. In the second experiment, the effects of gonadotropin-induced estrus and ovulation on fertility were evaluated using the same dosage of pLH and eCG as Experiment 1. Mixed parity sows $(n=567)$ were assigned to one of five treatment groups: no hormone treatments, $\mathrm{AI}$ in the AM and PM on $5 \mathrm{~d}$ post wean $(\mathrm{n}=131)$; eCG at weaning, AI in the AM and PM d 5 post wean $(n=111)$; pH 80 h post wean, AI 36 and $44 \mathrm{~h}$ later $(\mathrm{n}=113)$; eCG at weaning, pLH $80 \mathrm{~h}$ later, AI 36 and $44 \mathrm{~h}$ after $\mathrm{pLH}(\mathrm{n}=110)$; eCG at weaning, pLH $80 \mathrm{~h}$ later, AI $36 \mathrm{~h}$ after $\mathrm{pLH}(\mathrm{n}=102)$. The timing of ovulation was evaluated using RTU performed on 20 sows per treatment at $8 \mathrm{~h}$ intervals from 16 to $48 \mathrm{~h}$ after the time of pLH injection. Any sow not in estrus by d 5 was excluded from the study. Since only six sows exhibited estrus on $\mathrm{d} 4$, authors removed them from the experiment. Sows in the fifth treatment, only receiving one AI at h 36 after pLH, were inseminated regardless of estrus expression. Authors reported that of the 567 weaned sows, $93.5 \%$ were bred and $76.0 \%$ farrowed. There was no effect of eCG on subsequent fertility; however, farrowing rate was found to be higher for 
sows receiving eCG followed by $\mathrm{pLH}$ in single or double AI compared to eCG alone which also is in agreement with Cassar et al. (2010). This is interesting because sows receiving a single AI were inseminated whether they exhibited behavioral estrus or not; therefore, all sows (100\%) allotted to that treatment were bred compared to control sows $(90.8 \%)$ who were bred based on estrus behavior. There was no effect of treatment on litter size. Authors describe the enhanced efficacy of eCG in combination with $\mathrm{pLH}$, rather than $\mathrm{pLH}$ alone, likely a result of eCG inducing more late-ovulating sows making them available for a controlled ovulation. This would have then increased the number of sows receiving AI at the optimal time relative to ovulation. This was then further supported when the eCG and pLH combination maintained fertility at maximum levels even after a single AI. Based on these findings, authors concluded that eCG-induced estrus and pLH-induced ovulation allowed for predictable timing of ovulation and optimal AI occurring relative to ovulation, thereby facilitating a single FTAI protocol whilst maintaining fertility.

Bennett-Steward et al. (2008) tested the efficacy of using eCG and pLH as an estrus and ovulation synchronization protocol on the wean-to-breed interval (WBI), farrowing rate, and litter size of parity one and parity two sows. Parity one and parity two sows were assigned to two treatment groups $(\mathrm{n}=596$ and $\mathrm{n}=599$, respectively) and two control groups $(\mathrm{n}=571$ and $\mathrm{n}=$ 597, respectively). Treated sows were given an intramuscular injection of $600 \mathrm{IU}$ of eCG at weaning, followed by an intramuscular injection of $5 \mathrm{mg} \mathrm{pLH}$ at the first sign of estrus. Estrus detection was facilitated by twice-daily boar exposure beginning $24 \mathrm{~h}$ after weaning. Treated sows were inseminated twice at fixed times after pLH administration. The first AI occurred $12 \mathrm{~h}$ after $\mathrm{pLH}$, with the second occurring $32 \mathrm{~h}$ after $\mathrm{pLH}$. Control sows received AI at $12 \mathrm{~h}$ after the onset of estrus and again at $32 \mathrm{~h}$. The WBI of treated sows was reported to be lower in parity one sows ( $4.59 \mathrm{~d})$ by $1 \mathrm{~d}$ and by $0.3 \mathrm{~d}$ in parity two sows ( $4.32 \mathrm{~d}$ ) compared to non-treated controls 
(5.43 and $4.68 \mathrm{~d}$, respectively). Treated sows also had a shorter breeding period especially in parity one sows. Parity one sows treated with eCG followed by pLH experienced $82.7 \%$ bred by $\mathrm{d} 5,90.1 \%$ bred by d 7 , and $91.2 \%$ bred by d 10 , which contributed to a shorter breeding period compared to controls sows $(62.5,80.0$, and $84.6 \%$, respectively). Treated parity two sows also experienced the same trend but there was no significant difference from controls for $\mathrm{d} 7$ (95.4 vs $93.4 \%)$ and d 10 (96.2 vs $95.6 \%)$. Indeed, more parity two sows were bred within $5 \mathrm{~d}$ compared to parity one sows $(89.2$ vs $84.6 \% ; P<0.05)$. Treatment had no effect on farrowing rates or litter sizes. The unaffected litter sizes found in this study agree with findings from a more recent study conducted by Cassar et al. (2010); however, unlike Bennet-Steward et al. (2008), they demonstrated that farrowing rates were higher for eCG-pLH treated primiparous sows even when the eCG to $\mathrm{pLH}$ treatment interval was reduced to $72 \mathrm{~h}$.

Based on the results of their study, Bennet-Steward et al. (2008) concluded that the combination of exogenous eCG and pLH to facilitate double FTAI by inducing estrus and ovulation shortened the WBI in parity one and two sows without negatively affecting farrowing rates and litter sizes. Variability in results could have been due to variation in management practices across the 11 farms used in this study. Moreover, the farm staff was responsible for administering all doses of gonadotropins. Whether or not the same individual performed this across treatments was not described. Consequently, it is assumed that different staff members had administered the injections which could also produce less reliable data.

Research has supported the use of exogenous gonadotropins to aid in the removal of uncertainty in regards to the timing of ovulation therefore making FTAI feasible (Brüssow et al., 2009). Unfortunately, some of the drugs may not be commercially available to producers in the 
U.S. due to FDA regulations. For those that are, the producer must determine if usage will be cost effective for their breeding operations.

\section{PG 600®, Merck Animal Health}

P.G. 600 is a combination of $400 \mathrm{IU}$ eCG and $200 \mathrm{IU}$ of hCG that is administered intramuscularly to induce estrus in prepubertal gilts (Britt et al., 1989) and accelerate the onset of estrus in weaned sows, which shortens the WEI and decreases sow NPDs (Estienne and Hartsock 1998; Vargas et al., 2006). The combination of eCG and hCG mimics the endocrine effects of FSH and LH, respectively, stimulating follicle development. As previously mentioned, when the sow is lactating, there is a suppression of LH and FSH due to the suckling stimulus of the piglets, causing a period of anestrus (Barb et al., 1986). Once the suckling stimulus is removed, the endocrine cascade can once again occur to further develop the follicles and lead to estrus. Because suppressed gonadotropin secretion and ovarian inactivity is thought to be involved in a delay of the onset of estrus, P.G. 600 has been used to stimulate ovarian activity in weaned sows.

Reproductive performance in sows has been shown to be associated with environmental factors including season (Love et al., 1992; Xue et al., 1994). Even in healthy sows, these factors can influence NPDs and production costs. The time of year impacts WEI. In a study performed by Estienne and Hartsock (1998), P.G. 600 was used to accelerate the onset of estrus in sows weaned during the summer when seasonal anestrus can occur due to high ambient temperatures. Treatment with P.G. 600 increased the percentage of sows in estrus within $7 \mathrm{~d}$ after weaning (97 vs $82.9 \%)$. Relative to controls, sows given P.G. 600 expressed estrus sooner $(3.8 \pm 0.1 \mathrm{~d}$ vs 4.5 $\pm 0.1 \mathrm{~d})$. Treated sows had a lower farrowing rate and farrowed lighter pigs when compared to the control sows that were inseminated during a natural estrus occurring up to $7 \mathrm{~d}$ after weaning. 
These findings are similar to those found in a study by Bates et al. (1991) in which the use of P.G. 600 for first and second litter sows during periods of seasonal anestrus decreased days to estrus after weaning.

Manjarin et al. (2010) also showed that gonadotropins such as P.G.600 can be used to increase estrus response in weaned sows, however, giving supplemental hCG along with initial gonadotropin treatment can cause a decrease in sow fertility and farrowing rate based on parity. They suggested that a reduction in farrowing rates for sows receiving $200 \mathrm{IU}$ of supplemental hCG after P.G. 600 treatment may have been caused by the development of cysts. Breen et al. (2006) reported that greater than recommended doses of P.G. 600 induced the development of cysts acting as a primary source of P4 causing a restriction on embryo development. These findings address the importance of using the recommended dose of P.G. 600 to reduce the risk of potential reproductive complications among sows or gilts.

Bates et al. (2000) demonstrated that sows conventionally weaned Parity 2 sows (> $14 \mathrm{~d}$ lactation) receiving P.G. 600 to sows in and weaned during fall and winter were more likely to return to estrus than control sows (99.0 vs $93.6 \%$, respectively). Farrowing rates of conventionally weaned sows (Parities 3 to 6) treated with P.G. 600 were greater than controls (84.4 vs $71.3 \%$, respectively). The authors also showed that in early weaned Parities 3 to 6 sows ( $\leq 14$ d lactation), P.G. 600 increased subsequent litter size. These findings conflict with previous reports from Bates et al. (1991) who found that treatment with P.G. 600 did not change farrowing percentage in six out of eight herds that were studied. Bates et al. (1991) conducted their study during summer months when farrowing rates are lower than for sows weaned in the fall and winter (Koketsu et al., 1997). This could explain the differences of farrowing rates as 
sows weaned in the fall and winter may be able to respond more effectively to P.G. 600 treatment without being impacted by environment stressors.

In a study conducted by Knox et al. (2001), the effects of P.G. 600 administered to mixed parity sows $(n=72)$ at weaning was evaluated to determine if it altered the interval from estrus to ovulation in comparison to non-treated sows $(n=65)$. Once sows were weaned, estrus detection occurred with fence line contact with a mature boar twice a day. At the onset of estrus and beyond, transrectal ultrasound was performed twice daily to determine the average size of the three largest follicles and the occurrence of ovulation after the onset of estrus. There were more P.G. 600 treated sows displaying estrus within 8 d compared to controls (94.4 vs $78.4 \%$, respectively). Furthermore, WEI was reduced in treated sows compared to the controls (3.8 \pm 0.01 vs $4.9 \pm 0.1 \mathrm{~d})$. Multivariate analysis showed an effect of treatment on WEI, WOI, and EOI. Results indicated that $81 \%$ of the P.G. 600-treated sows expressed estrus within $4 \mathrm{~d}$ after weaning compared to $33 \%$ of the controls; however, the treatment group had $35 \%$ ovulating by $36 \mathrm{~h}$ after estrus compared to $40 \%$ for controls. Farrowing rates and litter size were not affected by treatment. Ovarian follicle development was stimulated by using P.G. 600 administered to sows on the first day of weaning. More sows expressed estrus earlier and ovulated later compared to untreated sows. The use of P.G. 600 has been shown to have great benefits to producers seeking to lower NPDs by shortening the WEI in weaned sows. Regardless, improvement of methodology could lead to a better timing of AI relative to ovulation and a decrease in suboptimally timed matings. 


\section{GnRH Agonists}

Hypothalamic GnRH is a key hormone that controls the reproductive processes in the sow. A pulsatile pattern of GnRH release stimulates maturing ovarian follicles and ultimately a preovulatory LH surge from the anterior pituitary gland that induces ovulation. The GnRH binds with high affinity to receptors on pituitary gonadotropes to stimulate the release of LH and FSH. Understanding the endocrine processes surrounding GnRH has led to the development of analogs to elicit certain responses such as the synchronization of ovulation in gilts and sows (Brüssow et al., 1996). These analogs have served as replacements for formerly used hCG for follicle growth stimulation because $\mathrm{GnRH}$ stimulates a more natural ovulation induction process (reviewed by Brüssow et al., 2009). These GnRH agonists are modified peptides that are similar to GnRH; however, their receptor binding affinity has been enhanced and resistance to peptidase degradation has led to a longer half-life in circulation (Herbert and Trigg, 2005). Synthetic GnRH agonists that are commercially available to producers can effectively improve breeding regimens by facilitating FTAI in weaned sows (Hühn et al., 1996) by causing ovulation induction. Small scale swine farms seek methods of cost effective production. Producers will want to evaluate the cost effectiveness of using commercially available GnRH analogues within their breeding operations.

\section{OvuGel® JBS United Animal Health}

OvuGel $®($ JBS United Animal Health, Sheridan, IN) is the first commercially available product approved by the Food and Drug Administration to synchronize ovulation and allow for a single FTAI in weaned sows (Kraeling and Webel, 2015). Unlike other GnRH agonists, OvuGel is administered in the form of triptorelin acetate, intravaginally, with a commercially available 
applicator at $2 \mathrm{ml}$ per dose, $96 \mathrm{~h}$ after sows are weaned. This will elicit a surge of $\mathrm{LH}$ from the anterior pituitary gland causing ovulation induction. An injection is not needed which contributes to better animal welfare practice and less stress on the sow. About $22 \pm 2 \mathrm{~h}$ after OvuGel treatment, sows are inseminated with a single dose of semen whether signs of estrus are exhibited or not (Kraeling and Webel, 2015; Webel and Swanson., 2014). Because of AI occurring regardless of estrus, the need for a boar for estrus detection is eliminated and labor can be reallocated elsewhere, such as d 1 piglet care.

As a synthetic GnRH agonist, OvuGel has a longer half-life than naturally produced GnRH. It stimulates the release of $\mathrm{LH}$ and therefore causes the sow to ovulate. According to Knox (2014), the absorption of OvuGel into the bloodstream causes an endocrine effect on the anterior pituitary gland, resulting in an LH surge. Follicles on the ovary begin to enlarge, releasing more E2 into the bloodstream. The LH surge will then trigger the ovulation of the follicles.

Application of OvuGel is relatively simple and on average takes $20 \mathrm{sec}$ per sow to complete. Anyone who is proficient in AI can be easily trained to administer OvuGel. Each bottle contains $52.5 \mathrm{~mL}$ of product and will cost on average $\$ 6.75$ per treated sow. Facilitating a single FTAI protocol using one dose of semen per sow compared to the average of two to three doses used in traditional AI could potentially be a strategy for small-scale swine farms seeking cost effective production.

In a patent by Webel and Swanson, (2014), the reproductive performance of sows housed at six farms were examined using a control group $(\mathrm{n}=1,479)$, and a Triptorelin Gel (TG) or OvuGel, treatment group $(\mathrm{n}=1,475)$. Control sows were inseminated following a normal AI 
protocol on the day of detected estrus, and again at $22 \pm 2 \mathrm{~h}$. The treatment group was treated at $96 \mathrm{~h}$ post-weaning with the TG and then inseminated $22 \pm 2 \mathrm{~h}$ later with a single dose of semen. Although there were no significant differences in farrowing rate/weaned sow utilization, total born, or born alive, the total born per semen dose was greater for the treatment group compared to the control sows, 11.9 vs. 7.5 , respectively. This is attributed to a single AI in the treatment group compared to 1.9 average doses of semen used in the control group. This study suggests that by using TG, weaned sows can be bred on a single day with no increase in the amount of stillborn pigs. Pregnancy rate (number pregnant/number weaned) also showed no significant differences between control sows and treatment sows. Furthermore, TG will effectively synchronize the time of ovulation, therefore allowing a FTAI protocol using a single dose of semen. The cost of semen will ultimately be reduced, as well as labor costs. These results also concur with a study performed by Knox et al. (2011) during which the reproductive performance of TG treated sows induced to ovulate and inseminated at fixed times were similar and sometimes improved compared to control sows bred at least once each day during two days of observed estrus.

Jackson et al. (2003) reported a study evaluating OvuGel and its use in a FTAI protocol in weaned sows. The control group $(n=126)$ were inseminated twice during estus $(\mathrm{AI}$ at 2 and $26 \mathrm{~h}$ after onset of estrus), the OvuGel-96 group $(\mathrm{n}=126)$ received OvuGel $96 \mathrm{~h}$ after weaning and two inseminations (AI at 8 and $32 \mathrm{~h}$ post treatment), and OvuGel-E group $(\mathrm{n}=126)$ received two inseminations based on observed estrus (AI at 2 and $26 \mathrm{~h}$ after onset of estrus). Results of this study indicated that when OvuGel was given to fertile sows (OvuGel-96) $96 \mathrm{~h}$ after weaning, the EOI and the duration of estrus was reduced compared to controls. The OvuGel-96 treatment had no effect on farrowing rates or litter sizes compared to controls. These findings suggest that 
using OvuGel as a treatment $96 \mathrm{~h}$ post-weaning can reduce the EOI and contribute to the success of FTAI. This also will contribute to less NPDs and thusly increase sow reproductive performance.

Interestingly enough, Knox et al. (2014) conducted experiments testing the efficacy of timing the administration of intravaginal TG on advancing and synchronizing ovulation in weaned sows. In one experiment, weaned sows were randomly assigned to one of four treatments, receiving $200 \mu \mathrm{g}$ of TG at $72(\mathrm{n}=32), 84(\mathrm{n}=31)$, or $96 \mathrm{~h}(\mathrm{n}=31)$ post weaning or serving as untreated controls $(n=32)$. Sows treated with TG were inseminated once at 24 to $28 \mathrm{~h}$ after treatment and control sows were inseminated on each day of standing estrus. Estrus was detected two to three times daily using a mature boar and ultrasound examinations were digitally recorded to assess ovulation and follicle count. Results of this experiment showed no treatment effect on the WEI among treatment groups. Wean to ovulation intervals were, however, reduced in the TG-72 and TG-84 groups compared to TG-96 and control sows. Additionally, more sows ovulated $40 \mathrm{~h}$ after treatment in TG-72 (56.5\%) and TG-84 (32.3\%) compared to TG-96 and non-treated controls $(13 \%)$. All sows that were treated with the TG after weaning ovulated $48 \mathrm{~h}$ after treatment compared to non-treated controls. In this experiment, farrowing rates for sows treated with TG 72 and 84 h post weaning were lower compared with sows treated with TG $96 \mathrm{~h}$ and non-treated controls. The number of total live born pigs did not differ among treatments. Authors suggested that the timing of GnRH administration may be a critical factor in the success of inducing ovulation. If treatment in weaned sows were to occur before optimal follicle maturation, GnRH may induce an LH surge when immature follicles are present, causing an inability to ovulate. Treatment after estrus may also result in the inability to effectively synchronize ovulation. 
In another experiment conducted by Knox et al. (2014), weaned sows $(n=113)$ were assigned to three treatment groups: untreated control $(n=35)$, a placebo group $(n=37)$ involving a dose of $2 \mathrm{~mL}$ of intravaginal gel without triptorelin $96 \mathrm{~h}$ post-weaning, or OvuGel treatment group $(n=38)$ in which OvuGel was administered 96 h post weaning. Estrus detection was again performed daily using a mature boar and ultrasound imaging was used to determine ovulation. The WEI did not differ among treatments but the duration of estrus tended to be reduced in OvuGel treated sows compared to the other two treatment groups. More OvuGel treated sows ovulated by $48 \mathrm{~h}$ after treatment compared to the non-treated controls and placebo groups (79.1, 46.4, and 37.9\%, respectively). Farrowing rate and total born alive did not differ among treatments. The results of the two experiments indicated that OvuGel given $96 \mathrm{~h}$ post weaning synchronized ovulation and resulted in fertility rates similar to non-treated controls. The authors do address the potential for the inability to induce ovulation in sows treated too early with OvuGel due to immature follicle growth.

Sow NPDs are the most significant factor affecting litters per mated female per year and can be costly to a producer. There much variability in the time the sow will return to standing estrus and as Kemp and Soede (1996) demonstrated, improper timing of AI relative to ovulation can result in negative effects on subsequent litter size and farrowing rate. Additionally, because the only real predictor of ovulation is the duration of estrus, farmers will typically AI sows with two to three doses of semen to ensure that at least one of those matings will occur at the optimum timing of 0 to $24 \mathrm{~h}$ before ovulation. The standard practice on most swine farms involves oncedaily estrus detection of weaned sows using a mature boar. Using FTAI, sows are inseminated regardless of behavioral estrus. Thus, producers can re-allocate labor and put more focus on other intensive sectors of the operation. Furthermore, OvuGel treated sows have been 
demonstrated to have similar reproductive performance compared to non-treated control sows (Webel et al., 2014; Jackson et al., 2003).

The use of OvuGel provides a way to facilitate FTAI, in which AI with one dose of semen is able to achieve similar farrowing rates and litter sizes compared to non-treated control sows receiving multiple doses of semen. One concern is the time of OvuGel treatment relative to the maturity of ovarian follicles. If follicle maturation is not optimal at $96 \mathrm{~h}$ post weaning, treatment may lead to anestrus or delayed estrus in sows, leading to reduced response to ovulation induction and negatively impact reproductive performance (Knox et al., 2011; Knox et al., 2014). Exogenous gonadotropins at weaning can stimulate follicle development, shorten the WEI, and improve return to estrus in weaned sows; therefore the use of P.G. 600 in combination with OvuGel could decrease variability, leading to a better FTAI protocol and sow reproductive performance similar to that of non-treated controls. The potential to remove the variability associated with predicting ovulation based on estrus duration and inseminate at a fixed-time could offer producers an effective breeding protocol. Producers would benefit from the reduction in semen doses per sow as well as re-allocating labor to other intensive sectors of the farm. By utilizing OvuGel and P.G. 600 in a small-scale swine breeding herd, producers may have access to a protocol that will allow a single FTAI among weaned sows and increase the ability to achieve high reproductive performance. 


\section{Chapter II: Use of Triptorelin Acetate for Inducing Ovulation and Facilitating a Fixed Time Artificial Insemination of Sows Weaned on Small- Scale and Niche Market Pig Farms}

\section{Introduction}

Reproductive tools that will help the increasing number of small-scale and niche market swine farmers achieve optimum reproductive efficiency will assist in keeping them a viable sector in the U.S. pork industry. Artificial insemination has been demonstrated to enhance reproductive efficiency but it requires excellent estrus detection skills. According to Knox et al. (2013), one of the greatest contributions to herd infertility is inadequate estrus detection practices. Moreover, Soede et al. (1995) demonstrated that optimum fertility with AI results when semen is deposited 0 to $24 \mathrm{~h}$ before ovulation which results in fertilization rates of greater than $90 \%$. Inseminations occurring outside of this interval can result in suboptimal pregnancy rates and litter sizes (Soede et al., 1995; Rozeboom et al., 1997). Thus, to increase the likelihood that semen is deposited at the optimum time during estrus, the standard practice is to inseminate 2.5 to 3.0 billion sperm cells at the onset of standing estrus and then again $24 \mathrm{~h}$ later (based on once-daily estrus detection). Producers will even inseminate a third time if sows continue to exhibit standing estrus.

Developing a single FTAI protocol would benefit small-scale and niche market pork producers by decreasing semen costs and labor associated with detection of estrus. OvuGel® (JBS United Animal Health, LLC; Sheridan, IN) is an FDA-approved GnRH agonist (triptorelin acetate) that stimulates ovulation in weaned sows offering potential for use in FTAI. A dose of 2 $\mathrm{ml}(200 \mu \mathrm{g}$ triptorelin acetate) is given intravaginally $96 \mathrm{~h}$ post-weaning, with the goal to inseminate a single dose of semen $22 \pm 2 \mathrm{~h}$ later. Therefore, labor involved with estrus detection 
is no longer needed and a single, rather than multiple, AI dose is required. OvuGel has been demonstrated to advance the onset of ovulation in weaned sows (Knox et al., 2011; Webel and Swanson, 2014) and has resulted in pregnancy rates and litter sizes in treated sows similar to control sows (Knox et al., 2011). However, concern lies over the time of treatment relative to the maturity of ovarian follicles. If follicle maturation is not optimal at $96 \mathrm{~h}$ post weaning, treatment with OvuGel may lead to delayed estrus or anestrus, negatively impacting reproductive performance (Knox et al., 2011). Previous work from our laboratory showed that an i.m. injection of P.G. 600® (Merck Animal Health, Inc., De Sota, KS) which contains eCG (400 IU) and hCG (200 IU), accelerated the onset of estrus and ovulation in weaned sows (Estienne and Hartsock, 1998; Estienne et al., 2001). Use of P.G. 600 for this purpose has proven effective even in months when ambient temperatures can delay the onset of estrus and ovulation (Bates et al., 1991; Bates et al., 2000). Additionally, Knox et al. (2001) found that administering P.G. 600 at weaning stimulated follicular development and led to more sows expressing estrus within $8 \mathrm{~d}$ post-weaning, with a majority of treated sows exhibiting estrus by $\mathrm{d} 4$.

The objective of this thesis project was to test the efficacy of an AI breeding system for small pig farms that is designed to decrease labor associated with heat detection and minimize the number of semen doses used for AI. It is hypothesized that similar reproductive performance will occur in sows treated with OvuGel or the combination of OvuGel and P.G. 600 and receiving FTAI as compared to control sows that receive two AI services. 


\section{Materials and Methods}

General. The experimental protocol was approved by the Institutional Animal Care and Use Committee of Virginia Tech (Blacksburg, VA).

Experimental design. The experiment took place from July, 2015 until January, 2017. A total of 96 sows (parity, $3.5 \pm 0.2$ ) were weaned (h 0) after a $24.8 \pm 0.6 \mathrm{~d}$ lactation on five participating small-scale or niche market pig farms. Characteristics of the farms (identified as Farm A, B, C, $\mathrm{D}$, and E) are contained in Table 1 . Sows were visually evaluated at different angles for body condition score (BCS) based on a 5-point scale (Elanco Animal Health, 2007) assessing the amount of fat reserves at the time of weaning $(2.5 \pm 0.07)$ and allocated to one of four treatment groups as per a 2 x 2 factorial arrangement: 1) OvuGel (2 mL containing $200 \mu \mathrm{g}$ triptorelin acetate) applied intravaginally at h 96 and AI at h 120 (TRT1; n = 24); 2) P.G. 600 applied i.m. at weaning, OvuGel at h 96 and AI at h 120 (TRT2; n = 24); 3) P.G. 600 at weaning, and AI at 0 and $24 \mathrm{~h}$ after first detection of standing estrus (TRT3; $\mathrm{n}=24)$; and 4) AI at 0 and $24 \mathrm{~h}$ after first detection of standing estrus (TRT4; $\mathrm{n}=24)$. 


\begin{tabular}{|c|c|c|c|c|c|}
\hline Farm & $\begin{array}{c}\text { Sow Herd } \\
\text { Size }\end{array}$ & $\begin{array}{c}\text { Sows } \\
\text { on } \\
\text { Project }\end{array}$ & Genetics $^{1}$ & Type of Market & Boar Stud Used \\
\hline A & 200 & 16 & $\mathrm{H} \times \mathrm{Y}$ & Show Pig/ Commercial & $\begin{array}{l}\text { Stolquist Show } \\
\text { Pigs }\end{array}$ \\
\hline B & 40 & 8 & $\mathrm{~B}, \mathrm{D}, \mathrm{Y}$ & Show Pig/Niche Market & $\begin{array}{c}\text { Swine Genetics } \\
\text { International }\end{array}$ \\
\hline $\mathrm{C}$ & 90 & 12 & Yx L & Commercial & $\begin{array}{c}\text { Makin' Bacon Boar } \\
\text { Stud }\end{array}$ \\
\hline $\mathrm{D}$ & 55 & 24 & $\mathrm{~N} \times \mathrm{L}, \mathrm{N} \times \mathrm{Y}$ & Research/Commercial & $\begin{array}{l}\text { Swine Genetics } \\
\text { International }\end{array}$ \\
\hline $\mathrm{E}$ & 65 & 36 & $\mathrm{D} \times \mathrm{Y}, \mathrm{Y} \times \mathrm{L}$ & Research/Commercial & $\begin{array}{l}\text { Swine Genetics } \\
\text { International }\end{array}$ \\
\hline
\end{tabular}

${ }^{1}$ Genetic abbreviations: $\mathrm{B}=$ Berkshire, $\mathrm{D}=$ Duroc, $\mathrm{H}=$ Hampshire, $\mathrm{L}=$ Landrace, $\mathrm{N}=$ Newsham, $\mathrm{Y}=$ Yorkshire

P.G. $600 \AA$ Administration. P.G. 600 was stored at approximately $6^{\circ} \mathrm{C}$ prior to use. Before administration, a sterile syringe with a needle were used to transfer approximately $5 \mathrm{~mL}$ of the diluent into the vial containing the freeze-dried powder. The vial was then shaken to dissolve the powder into the diluent. The contents of that vial were then transferred back into the vial of the diluent and then gently shaken to mix the combination. At weaning (h 0$)$, sows belonging to TRT2 and TRT3 were given an i.m. injection of $5 \mathrm{~mL}$ of P.G. 600 using an 18 gauge, $25.4 \mathrm{~mm}$ sterile needle into the muscle of the neck, behind the ear at weaning (h 0$)$.

Estrus Detection. Sows in TRT3 and TRT4 were observed for signs of behavioral estrus beginning d 3 post-weaning using once-daily mature boar exposure. On one farm, sows were placed in a pen with the boar for approximately 20 min allowing full body contact. For the remaining four farms, the boar was allowed to walk the alleyways or around gestation stalls 
providing fence-line exposure to sows for approximately 20 min daily. Nose-to-nose contact was permitted but not full body contact. For each sow, BPT was performed in the presence of a boar by an experienced technician and behavioral estrus response was evaluated using a scale of 0 to 2: 0 , representing no response/interest or immobilization, 1 , representing some response/interest or partial immobilization, and 2, showing signs of lordosis as indication of estrus. For TRT1 and TRT2 groups, sows were observed for signs of estrus daily beginning $3 \mathrm{~d}$ post-weaning using the same scale previously described in response to the BPT in the absence of a boar. Sows that exhibited lordosis were considered in estrus. Wean-to-estrus interval was determined as the interval from weaning (h 0 ) until the time that estrus was first detected (i.e., score of 2).

OvuGel® preparation and administration. Sows were treated with $2 \mathrm{~mL}$ of OvuGel $(200 \mu \mathrm{g}$ triptorelin acetate) given intravaginally $96 \mathrm{~h}$ post-wean. OvuGel was stored at approximately $6^{\circ}$ $\mathrm{C}$ and warmed to room temperature at least $10 \mathrm{~min}$ prior to administration to allow adequate viscosity of the gel. The OvuGel bottle was then placed onto the commercially available multidose applicator (JBS United Animal Health, LLC) allowing the bottle mount to puncture and enable withdrawal of the gel. A delivery catheter (infusion tube) was attached to the applicator and covered with a disposable protective sheath. Prior to use, $2 \mathrm{~mL}$ of OvuGel was pre-loaded into the catheter by slowly compressing and releasing the applicator handle. This allowed displacement of any air from the infusion tube. The anterior end of the catheter and sheath were then inserted into the vagina at an upward angle of approximately $45^{\circ}$. Once resistance was felt indicating that the cervix had been reached, the catheter was retracted approximately 17 or 18 $\mathrm{mm}$ and $2 \mathrm{~mL}$ of OvuGel was deposited by squeezing the applicator. If urine excretion occurred, the catheter and sheath were removed and discarded to avoid potential contamination. After 
administration, the disposable protective sheath was then discarded and replaced before the treatment of the next sow. Each OvuGel administration required approximately 30 sec per sow.

Artificial Insemination. Inseminations were performed intra-cervically by experienced technicians using either spirallette or foam tip catheters. Each 80 to $100 \mathrm{~mL}$ dose of extended semen contained $2.5 \times 10^{9}$ to $4.8 \times 10^{9}$ sperm cells and was stored at approximately $17^{\circ} \mathrm{C}$ and gently rotated once-daily. Semen was purchased from three commercial boar studs as per the cooperating producers' preference. Vulvas were wiped using a paper towel prior to insertion of the catheter to avoid potential contamination. Non-spermicidal lubricant gel was placed onto the tip of each catheter with careful consideration of not covering the opening. The vulva lips were parted and the catheter was then inserted using a counter-clockwise rotation at a $45^{\circ}$ angle. Catheters were discarded immediately if urine contamination occurred. Proper location of the tip was determined when resistance was felt by pulling slightly backwards, indicating that the cervix had been reached. The dose of semen was attached to the end of the catheter and inverted allowing sow myometrial contractions of the sow to withdraw the sperm/extender from the container. The number and the timing of AI was dependent on treatment as follows:

For sows in TRT3 and TRT4 AI occurred at onset (h 0) with a second mating occurring $24 \mathrm{~h}$ later in the presence of a boar. For sows in TRT1 and TRT2, a single FTAI took place $22 \pm$ $2 \mathrm{~h}$ after OvuGel was administered in the absence of a boar and without regards to estrus behavior.

Pregnancy Detection. Pregnancy was confirmed by checking for signs of estrus in sows in the presence of a boar once daily beginning approximately $21 \pm 4 \mathrm{~d}$ after AI and/or using a portable 
B-Mode ultrasound unit (KeeboMed; Mount Pleasant, IL) to perform trans-abdominal scanning at 27 to $37 \mathrm{~d}$ post AI. Sows that were confirmed pregnant did not exhibit behaviors indicating a return to estrus and/or produced an ultrasoung image depicting black, irregular circles representing embryonic sacs. Sows that were recorded as negative either showed signs of heat around d 21 post-AI and/or produced an image showing white myometrium and no black irregular circles. Pregnancy rate was calculated using two methods as follows:

$$
\begin{gathered}
\mathbf{P R}_{\text {Inseminated }}=(\text { Number of sows pregnant } \div \text { Number of sows inseminated }) \times 100 \\
\mathbf{P R}_{\text {Allotted }}=(\text { Number of sows pregnant } \div \text { Number of sows allotted per treatment }) \times 100
\end{gathered}
$$

Farrowing and Reproductive Performance. At approximately d 108 to 110 of gestation, sows were moved into farrowing crates that contained one heat lamp raised above a designated area for the piglets to access away from the sow. Sows were given ad libitum access to water for the duration at which they were first placed into the crate until weaning. Feed was provided on an $a d$ libitum basis from farrowing through weaning. Total litter size, total born alive, number stillborn, and number born mummified for each sow were recorded. Farrowing rate amongst treatment groups was calculated using two methods as follows:

$\mathbf{F R}_{\text {Inseminated }}=($ Number of sows farrowing $\div$ Number of sows inseminated $) \times 100$

FR $_{\text {Allotted }}=($ Number of sows farrowing $\div$ Number of sows allotted per treatment $) \times 100$

Statistical Analysis. Production data was evaluated using SAS (SAS Institute Inc., Cary, NC). Least squares means were computed for all response variables. Binary response variables included estrus expression within $7 \mathrm{~d}$ and $10 \mathrm{~d}$ of weaning, pregnancy rates of sows allotted to treatments and sows inseminated, and farrowing rates of sows allotted to treatments and sows 
inseminated. Continuous variables in this study included, WEI, number of semen doses used per sow, total pigs born, total pigs born alive, stillborns, and mummied pigs. All models included the main effects of treatment, farm location, P.G. 600 (Yes or No), OvuGel (Yes or No) and the P.G. 600 by OvuGel interaction as possible sources of variation. A $P$-level of $\leq 0.05$ was considered significant and a $P$-level of 0.05 to $<0.10$ was considered a trend.

\section{Results}

Estrus Response. Estrus response among treatments are shown in Fig. 1 and Table 2. It is important to mention that some sows did not show a return to estrus (TRT1, $\mathrm{n}=1$, TRT3, $\mathrm{n}=4$, TRT $4, \mathrm{n}=1$ ) and were excluded from WEI analysis but included when analyzing overall estrus expression. The proportion of females expressing estrus by d 7 post-weaning was greater $(P<$ 0.05) for sows that received OvuGel $(94.5 \%)$ compared to sows that did not $(82.2 \%)$. There were no effects $(P>0.05)$ of P.G. 600 or P.G. 600 x OvuGel on females displaying estrus by d 7. The proportion of females displaying estrus by d 10 post weaning was not affected $(P>0.05)$ by treatment but a tendency was detected $(P<0.10)$ for sows treated with OvuGel $(99.4$ and 95.2 $\%$, for TRT1 and TRT2 groups, respectively) to have a greater response rate compared to sows that were not (82.7 and $95.2 \%$ for TRT3 and TRT4 groups, respectively). Weaning to estrus interval was decreased $(P<0.05)$ for sows that received P.G. $600(4.9 \pm 0.4 \mathrm{~d})$ compared to sows that did not $(5.4 \pm 0.4 \mathrm{~d})$. Sows treated with OvuGel tended to have a shorter WEI $(P<0.10)$, however, there were no effects of P.G. 600 x OvuGel $(P>0.10)$. Of the sows receiving OvuGel treatment, $19 \%(9 / 48)$ did not express estrus at the time of AI (data not shown). 
Table 2. Effects of OvuGel® (JBS United LLC, Sheridan, IN) and P.G. 600® (Merck Animal Health, Inc., De Sota, KS) alone or in combination on reproduction in sows. Values are LS means \pm SE.

\begin{tabular}{|c|c|c|c|c|c|c|c|c|}
\hline & \multicolumn{2}{|c|}{ OvuGel } & \multicolumn{2}{|c|}{ No OvuGel } & \multirow[b]{2}{*}{ SEM } & \multicolumn{3}{|c|}{$P$-values } \\
\hline Item: & $\begin{array}{l}\text { P.G. } \\
600\end{array}$ & $\begin{array}{l}\text { No P.G. } \\
600\end{array}$ & $\begin{array}{l}\text { P.G. } \\
600\end{array}$ & $\begin{array}{l}\text { No P.G. } \\
600\end{array}$ & & $\begin{array}{l}\text { OvuGel vs. } \\
\text { No OvuGel }\end{array}$ & $\begin{array}{l}\text { P.G. } 600 \\
\text { vs. No } \\
\text { P.G.600 }\end{array}$ & $\begin{array}{l}\text { P.G. } 600 \\
\text { x OvuGel }\end{array}$ \\
\hline Number of sows & 24 & 24 & 24 & 24 & & --- & --- & --- \\
\hline $\begin{array}{l}\text { Estrus by day } 7 \\
\text { post-weaning, } \\
\%\end{array}$ & 96.8 & 92.1 & 79.5 & 84.9 & 0.1 & 0.03 & 0.95 & 0.35 \\
\hline $\begin{array}{l}\text { Estrus by day } \\
10 \text { post- } \\
\text { weaning, \% }\end{array}$ & $99.4^{\mathrm{a}}$ & $95.2^{\mathrm{a}, \mathrm{b}}$ & $82.7^{\mathrm{b}}$ & $95.2^{\mathrm{a}, \mathrm{b}}$ & 0.1 & 0.09 & 0.39 & 0.09 \\
\hline $\begin{array}{l}\text { Wean-to-estrus, } \\
\text { days }\end{array}$ & 4.7 & 5.2 & 5.0 & 5.5 & 0.4 & 0.09 & 0.03 & 0.92 \\
\hline Pregnant $^{1}, \%$ & 53.7 & 61.0 & 68.5 & 61.4 & 0.1 & 0.46 & 0.99 & 0.48 \\
\hline Pregnant $^{2}, \%$ & 54.0 & 61.8 & 61.8 & 58.4 & 0.1 & 0.99 & 0.68 & 0.73 \\
\hline Farrowing 1 , \% & 45.6 & 62.1 & 65.3 & 53.7 & 0.1 & 0.59 & 0.81 & 0.18 \\
\hline Farrowing $^{2}, \%$ & 45.4 & 61.8 & 54.1 & 49.5 & 0.1 & 0.86 & 0.56 & 0.31 \\
\hline
\end{tabular}

\footnotetext{
${ }^{1}$ Sows pregnant or farrowing/sows inseminated

${ }^{2}$ Sows pregnant or farrowing/sows allotted to treatments

a,b Values with different superscripts tend to differ $(P=0.09)$.
} 


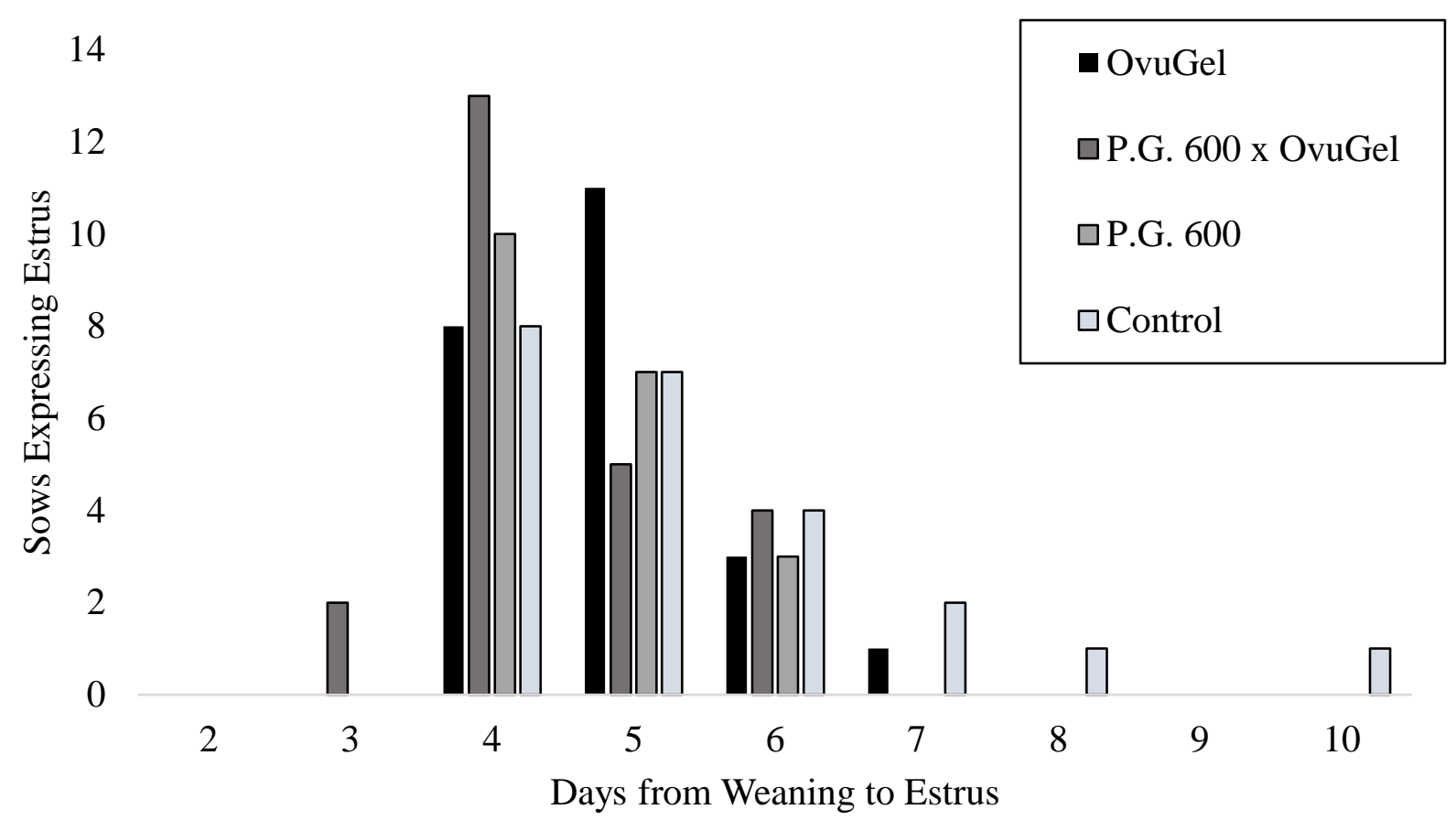

Figure 1. Distribution of WEI among treatment groups. Sows in TRT1 received $5 \mathrm{~mL}$ of OvuGel (JBS United Animal Health; Sheridan, IN) approximately $96 \mathrm{~h}$ post-weaning. Sows in TRT2 received $5 \mathrm{~mL}$ of P.G. 600 (Merck Animal Health; De Sota, KS) at weaning (h 0) and $2 \mathrm{~mL}$ of OvuGel $96 \mathrm{~h}$ post-weaning. Sows in TRT3 received $5 \mathrm{~mL}$ of P.G. 600 at weaning. Sows in TRT4 received no hormonal treatments. Data are represented as number of sows per treatment per $\mathrm{d}$. There was a treatment effect of P.G. $600(P<0.05)$ on WEI but not for OvuGel $(P<0.10)$ or P.G. $600 \times$ OvuGel $(P>0.10)$.

Pregnancy Rate and Farrowing Rate. The effects of treatment on pregnancy rates and farrowing rates are included in Table 2. All sows that were treated with OvuGel (TRT1 and TRT2) received a single AI regardless of behavioral estrus. This was not the case in TRT3 and TRT4 fow which sows received AI at the onset of behavioral estrus followed by a second AI $24 \mathrm{~h}$ later. Therefore, pregnancy rate and farrowing rate were calculated based on the number of total sows allocated to each treatment group and on the number of sows inseminated within that group. There were no effects of P.G. 600, OvuGel or P.G. $600 \times$ OvuGel $(P>0.1)$ on pregnancy rate of 
total sows inseminated $(61.2 \%)$ or allocated to treatment $(59.0 \%)$. Furthermore, it was found that there were no effects of P.G. 600, OvuGel or P.G. 600 x OvuGel $(P>0.1)$ on farrowing rate of total sows inseminated $(56.7 \%)$ or for total sows allotted to treatment $(52.7 \%)$. Of the $19 \%$ of sows receiving OvuGel in TRT1 and TRT2 not expressing estrus at the time of AI, $67 \%(6 / 9)$ were found to be not pregnant (data not shown). One sow in TRT2 was confirmed pregnant but did not farrow due to reasons unknown. In TRT4, one sow suffered from a respiratory illness and died while gestating.

Table 3. Effects of OvuGel® (JBS United LLC, Sheridan, IN) and P.G. 600® (Merck Animal Health, Inc., De Sota, KS) alone or in combination on litter characteristics of sows ${ }^{1,2}$. Values are LS means \pm SE.

\begin{tabular}{|c|c|c|c|c|c|c|c|c|}
\hline \multirow[b]{2}{*}{ Item: } & \multicolumn{2}{|c|}{ OvuGel } & \multicolumn{2}{|c|}{ No OvuGel } & \multirow[b]{2}{*}{ SEM } & \multicolumn{3}{|c|}{$P$-values } \\
\hline & $\begin{array}{l}\text { P.G. } \\
600\end{array}$ & $\begin{array}{c}\text { No } \\
\text { P.G. } \\
600\end{array}$ & $\begin{array}{l}\text { P.G. } \\
600\end{array}$ & $\begin{array}{c}\text { No } \\
\text { P.G. } \\
600\end{array}$ & & $\begin{array}{c}\text { OvuGel } \\
\text { vs. No } \\
\text { OvuGel }\end{array}$ & $\begin{array}{l}\text { P.G. } 600 \\
\text { vs. No } \\
\text { P.G.600 }\end{array}$ & $\begin{array}{c}\text { P.G. } 600 x \\
\text { OvuGel }\end{array}$ \\
\hline $\begin{array}{l}\text { Total Litter } \\
\text { Size }\end{array}$ & 11.5 & 9.9 & 11.9 & 12.4 & 0.9 & 0.11 & 0.53 & 0.26 \\
\hline Born Live & $11.0^{\mathrm{a}}$ & $8.8^{\mathrm{a}, \mathrm{b}}$ & $9.8^{\mathrm{b}}$ & $11.4^{\mathrm{a}, \mathrm{b}}$ & 0.9 & 0.43 & 0.72 & 0.04 \\
\hline Born Dead & 0.4 & 0.8 & 1.5 & 0.8 & 0.4 & 0.11 & 0.54 & 0.10 \\
\hline Mummies & 0.0 & 0.21 & 0.46 & 0.18 & 0.2 & 0.22 & 0.85 & 0.16 \\
\hline $\begin{array}{l}\text { Live pigs/dose } \\
\text { of semen }\end{array}$ & 5.22 & 5.61 & 3.31 & 3.09 & 1.0 & 0.03 & 0.93 & 0.76 \\
\hline
\end{tabular}

${ }^{1}$ Results based off of 49 sows that had farrowed. TRT $1, \mathrm{n}=14$; TRT2, $\mathrm{n}=11$; TRT3, 13; and TRT4, $\mathrm{n}=11$.

${ }^{2}$ TRT2 had 1 sow not farrow for unknown reasons; TRT 4 had 1 sow die before farrowing. a,b Values with different superscripts differ $(P<0.10)$

Litter Characteristics. Litter characteristics among treatments are shown in Table 3. There were no effects of P.G. 600, OvuGel or P.G. $600+$ OvuGel $(P>0.10)$ on total litter size (11.3), born dead (1.0) or mummies (0.2). There was an effect $(P<0.05)$ of P.G. 600 x OvuGel on total born 
live (10.2) demonstrating that P.G. 600 had a different effect on the number of total born live among sows treated with OvuGel compared to sows that did not receive OvuGel. There was an effect $(P<0.05)$ on the number of live pigs born per semen dose for OvuGel vs. No OvuGel $(5.4$ vs. 3.2, respectively). There was no main effect of P.G. $600(P>0.10)$ or P.G. 600 x OvuGel $(P$ $>0.10)$ on the number of live pigs born per semen dose.

\section{Discussion}

Reproductive efficiency is critical for sustainability of small-scale and niche market pig farms, and indices of performance such as pigs weaned per litter and litters weaned per sow per year are key determinants of profitability (Sanders et al., 2012). It has been well established that the optimum time for AI to occur is 0 to $24 \mathrm{~h}$ before ovulation which results in high reproductive performance (Soede et al. 1995; Kemp and Soede, 1996). Ovulation has been found to occur approximately $70 \%$ of estrus duration (Soede and Kemp, 1997), but it is still variable and difficult to predict because of the absence of any external indication. Any matings occurring too late or too early in relation to ovulation can negatively impact litter size and farrowing rate (Rozeboom et al., 1997). Real-time ultrasonography has been used to determine ovulation onset and duration by identifying ovarian follicle size and changes (Soede et al., 1995; Kemp and Soede, 1996; Soede and Kemp, 1997; Stewart et al., 2010; Knox et al., 2011); however, this method is expensive and impractical for small-scale and niche market swine farms. Therefore, the onset of estrus has been used as a predictor of ovulation with multiple matings occurring to increase the likelihood that at least one mating occurs during the optimum time. Excellent estrus detection skills are necessary for effective use of AI and poor estrus detection negatively impacts 
herd fertility (Knox et al., 2013). Inaccurate detection of estrus and improperly timed AI can result in poor reproductive performance. This study evaluated the use of commercially available GnRH agonist alone or in combination with P.G. 600 to facilitate a single FTAI protocol on small scale and niche market swine farms. The examined protocol was designed to decrease labor associated with heat detection, minimize the number of semen doses used for AI, and improve reproductive efficiency.

Reproductive failure in weaned sows has been associated with poor ovarian activity once the piglet suckling stimulus has been terminated. Poor ovarian activity can be caused by numerous factors, including season, when high ambient temperatures can reduce and delay gonadotropin secretion (Britt, 1986; Almond and Dial, 1990; Van de Weil and Booman., 1993) and the onset of estrus and ovulation (Bates et al., 1991; Bates et al., 2000). To overcome these obstacles and improve reproductive performance of weaned sows, exogenous gonadotropins have been used to stimulate ovarian activity after weaning. Previous work in our laboratory has shown that treatment with P.G. 600 hastened onset of estrus in gilts (Estienne et al., 2001) and weaned sows (Estienne and Hartsock, 1998). Therefore, P.G. 600 was used in this study as a current industry practice that could potentially stimulate follicular growth in weaned sows prior to ovulation induction. The success of FTAI is dependent upon sows having ovarian follicles mature enough to respond to OvuGel treatment (Knox et al., 2011).

Our current findings showed that there was an overall reduction in WEI in sows receiving P.G. 600 (TRT2, TRT3), indicating that P.G. 600 injected at weaning (h 0) successfully stimulated follicular growth and enhanced return to estrus. These findings are in accordance with previous work in primiparous (Bates et al., 1991; Kirkwood et al., 1999) and multiparous (Estienne and Hartsock 1998; Knox et al., 2001) sows. In these studies, the average onset of 
estrus after treatment with P.G. 600 at weaning was reported to be as early as $3.8 \pm 0.1 \mathrm{~d}$, vs 4.9 $\pm 0.1 \mathrm{~d}$ for control sows. In our study, even though P.G. 600 treatment had an effect on reducing WEI, P.G. 600 did not affect the percentage of sows expressing estrus by d 7 and d 10, which agrees with previous work conducted by Vargas et al. (2006). Our results do conflict with findings from previous studies in which treatment with P.G. 600 increased the percentage of sows expressing estrus within $7 \mathrm{~d}$ after weaning compared to non-treated controls (97.1 vs 82.9 \%; Estienne and Hartsock, 1998) and within d 9 post-weaning (94.4 vs $78.4 \%$; Knox et al. 2001).

Although the effect of season on reproductive performance was not evaluated in the current study, equivocal results among studies could be explained by seasonal effects, as P.G. 600 has been demonstrated to be most effective in enhancing estrus in sows weaned in summer (Estienne and Hartsock, 1998) or early fall months (Bates et al., 1991) when high ambient temperatures can prolong WEI or cause anestrus in weaned sows (Estill, 2000). The current study took place throughout the year and sows weaned during spring and winter months may not have experienced environmental stressors that impact ovarian function post-weaning (Estienne and Hartsock, 1998). Our findings showed that sows not receiving P.G. 600 had a longer average WEI yet still demonstrated estrus in the typical range of 4 to $7 \mathrm{~d}$ post-weaning (Britt et al., 1985). We speculate that for many of the sows used in this study, gonadotropin secretion and ovarian activity were functional after piglet removal and not in need of exogenous stimulation, further allowing estrus to be expressed in a majority of the sows by $\mathrm{d} 7$ or 10 post-weaning.

Ovarian follicles grow and regress in waves after weaning, resulting in sows potentially having different sized follicles at insemination (Lucy et al., 2001). Multiparous sows tend to have larger follicles at weaning $(\sim 3.3 \mathrm{~mm})$ than primiparous sows $(2.5 \mathrm{~mm}$; Langendijk et al., 
2000b) and are less susceptible to compromised follicle development at weaning compared to primiparous sows (Gerritsen et al., 2008). Our results indicate that four out of 24 sows that were treated with P.G. 600 alone at weaning did not show a return to estrus. Three of those sows were multiparous and one was primiparous. In this regard, the developmental status of follicles or parity could have affected the responsiveness (i.e., estrus expression) of sows treated with or without P.G. 600 in the current study as reviewed by Kirkwood and Kauffold, 2015. Perhaps P.G. 600 proved ineffective in stimulating follicular growth in sows experiencing variable follicle maturation that caused anestrus. Other factors that could have impacted current findings are spontaneous lactational ovulation (Kemp et al., 2009), return to estrus occurring before $\mathrm{d} 3$ post-wean when estrus detection began, or various responses to P.G. 600 between sow herds on the participating five farms (Flowers et al., 2001).

Our data indicate that there were no significant effects of OvuGel or P.G. 600 x OvuGel on WEI; however, there was a tendency for OvuGel treated sows to have a shorter return to estrus, particularly in sows allotted to TRT2. Those sows also received P.G. 600 at weaning, which could have contributed to a reduced WEI. The proportion of females displaying estrus by d 7 post-weaning was greater for sows that received OvuGel (94\%) compared to sows that did not $(82 \% ; P<0.05)$. Furthermore, there was a tendency for more OvuGel treated sows to express estrus by d 10 post-weaning compared to other sows. These findings are interesting, because the sows receiving OvuGel did not have mature boar exposure after weaning. Instead, return to estrus was determined by the technician performing the BPT during once-daily estrus detection in the absence of a boar. It has been well established that boar exposure can enhance estrus after weaning, although endocrine mechanisms are not well understood (Langendijk et al., 2000a; Langendijk et al., 2000b; Langendijk et al., 2000c). Thus, it would be expected that the 
sows allotted to the two non-OvuGel groups (TRT3 and TRT4) would have had a higher percentage of sows displaying estrus by 7 or $10 \mathrm{~d}$ post-weaning, but this was not the case. These findings differ from previous reports in which the proportion of TG treated sows expressing estrus by d 7 did not differ $(P>0.05)$ from control sows (Knox et al., 2011; Knox et al., 2014; Webel and Swanson, 2014). In those studies, however, sows across treatment groups received mature boar contact as part of estrus detection protocols, which may have contributed to the similarities in overall estrus expression.

Estrogen acts at the central nervous system to regulate $\mathrm{GnRH}$ and is responsible for behavioral changes associated with estrus. The triptorelin acetate evaluated in this study is a synthetic GnRH agonist in gel form that mimics endogenous GnRH causing a pre-ovulatory LH surge from the anterior pituitary gland. In pigs, the LH surge is distinct from LH pulse release as a surge can only be induced after a period of time following E2 exposure (Britt et al., 1991). Stewart et al. (2010) administered TG 96 h following weaning, and $73 \%$ of treated sows had an LH surge approximately $6.5 \mathrm{~h}$ after treatment. Approximately $67 \%$ of those sows ovulated between 36 to $48 \mathrm{~h}$ later. Similarly, Knox et al. (2011) reported that TG given to sows $96 \mathrm{~h}$ postweaning advanced ovulation to $35 \mathrm{~h}$ but synchrony was still less than optimal during the 36 to 48 $\mathrm{h}$ period after treatment. In the current study, ovarian status was not measured in regards to ovulation timing but it would appear that the average WEI for OvuGel treatment groups (TRT1 [5.2 d] and TRT2 [4.7 d]) created an ideal situation for OvuGel administration on d 4 post-wean. A total of $48 \%$ of those sows were expressing estrus at the time of treatment and approximately $80 \%$ of sows were expressing estrus at the time of the single FTAI occurring $22 \pm 2 \mathrm{~h}$ later. Moreover, a significantly higher proportion of OvuGel treated sows were found to have expressed estrus by $\mathrm{d} 7$ and $\mathrm{d} 10$ post-weaning. The similarities in reproductive performances 
found between treatments implementing FTAI compared to control treatments further support the effectiveness of using OvuGel to initiate an LH surge and induce ovulation.

It was observed that a small group of sows treated with OvuGel (19\%) were not expressing estrus at the time AI occurred $22 \pm 2 \mathrm{~h}$ after treatment. Of those sows, $67 \%$ were confirmed not pregnant which could have been a result of the quality of AI service or unsuccessful ovulation induction due to poorer follicular development at the time of treatment. Different from our observations, Stewart et al. (2010) reported that TG treated sows not expressing behavioral estrus at the time of AI had similar reproductive performance compared to control sows receiving AI only when a strong standing reflex was exhibited. Similar to the current study, Stewart et al. (2010) did indicate that additional data are needed to substantiate their findings because such a small sample size was analyzed. More recently, Webel and Swanson (2014) reported $84 \%$ of sows treated with OvuGel had expressed estrus at the time of AI compared to $100 \%$ of control sows, yet similar pregnancy rates resulted (80 vs $74 \%$, respectively). Previous evidence has suggested that estrus detection and expression is not a requirement for ovulation induction and AI (Brussow et al. 1996; Knox et al., 2011) supporting the use of OvuGel in FTAI protocols. A larger sample size in future studies is needed to substantiate this theory.

Although overall reproductive performance was not significantly affected by treatment, there was a slight decrease in pregnancy rate for total sows inseminated and allocated to study for sows treated with OvuGel compared to controls. Perhaps the slight difference in pregnancy rates could be attributed to whether or not mature boar contact was used during AI. Sows in treatments TRT3 and TRT4 received AI in the presence of a mature boar whereas sows in treatments TRT1 and TRT2 did not. Myometrial contractions help transport spermatozoa to the 
ampullary-isthmus junction of the oviduct where fertilization occurs (Einarsson et al., 1980; Viring and Einarsson., 1981). Using a mature boar to stimulate the frequency of these contractions in the female through auditory and olfactory stimulation (Signoret, 1970; Kotwicka et al., 1995; Langendijk et al., 2003) may have contributed to a slight increase in pregnancy rates for sows in treatments TRT3 and TRT4. Estrus detection using BPT in the absence of boar exposure has previously resulted in a lower accuracy of detection (Signoret, 1970) as the boar has been demonstrated to elicit a stronger standing response in sows (Perry et al., 1980). Because sows in TRT3 and TRT4 received AI based on estrus onset, using a mature boar for detection and performing the BPT in his presence could have resulted in accurate determination of estrus, thus allowing for at least one of the matings to occur 0 to $24 \mathrm{~h}$ before ovulation. Indeed, the determination of estrus onset may have been improved if estrus detection occurred twice-daily; however, more labor would have had to be reallocated in order to meet this need and was not a current practice of participating farms.

Knox et al. (2011) evaluated the influence of follicle size on efficacy of triptorelin gel (TG) to induce ovulation in weaned sows. They reported that when poor follicle maturation occurred $(<6.5 \mathrm{~mm})$ by $96 \mathrm{~h}$, administering TG at $96 \mathrm{~h}$ post-weaning led to a reduced response to ovulation induction treatment and AI during anestrus or delayed estrus. As a likely result, farrowing rates and litter sizes were reduced. Authors suggested that implementing the use of gonadotropins to stimulate follicular development would assist in facilitating successful ovulation induction. In the current study, the results of the OvuGel treatment groups showed slightly lower, non-significant, decreases in pregnancy rates and farrowing rates when P.G.600 was administered prior to OvuGel treatment. This was not expected as it was originally predicted that P.G. 600 use would have stimulated follicle growth before the time of treatment 
and resulted in a better response to ovulation induction. The endogenous LH surge has been reported to occur -5 to $\pm 10 \mathrm{~h}$ after the onset of estrus (Soede et al., 1994); however, sows that express estrus soon after weaning have longer intervals from the onset of estrus to ovulation (Kemp and Soede, 1996). It is not known whether WEI delays the onset of LH surge relative to onset of estrus (Knox et al., 2011). Moreover, the effect of P.G. 600 to enhance the return to estrus may have led to ovulation being induced at a suboptimal time, especially in the sows experiencing a return to estrus prior to treatment.

Our observations are consistent with findings in previous studies in which reproductive performance was similar and sometimes improved in sows receiving intravaginal administration of triptorelin and following a FTAI protocol compared with sows bred with multiple doses depending on how many d estrus is expressed (Knox et al., 2003; Stewart et al., 2010; Webel and Swanson, 2014). Overall, there were no differences in farrowing rates of sows inseminated within treatments $(56 \%)$ or allotted to study (53\%), total litter size (11.4), born dead (0.7) or the number of mummified pigs (0.2) which are in agreement with results from previous studies (Stewart et al., 2010; Knox et al., 2011; Stewart et al., 2010; Webel and Swanson, 2014). There was a significant effect of P.G. 600 x OvuGel on total born alive where P.G. 600 had a different effect among sows treated with OvuGel and sows that were not.

The results of our study show that treatment of OvuGel using a single AI produced a greater number of live pigs born per semen dose (5.4 vs 3.2). These findings are similar to a previous study conducted by Webel and Swanson (2014) who demonstrated that sows treated with OvuGel produced more total pigs born per semen dose compared to controls (9.6 vs 5.6, respectively). Our study involved sows of terminal (i.e., Berkshire and Duroc) and maternal breed lines that differed among farms, whereas previous studies involved sows of primarily 
maternal crosses. Although not evaluated, this could have had an effect on the number of pigs born as maternal breeds tend to have larger litters; however, the proportion of these females was so small that a significant impact would be unlikely. Furthermore, our study based calculated live piglets born per semen dose and not total pigs born which would have included piglets born dead and not of value to the producer. The increase in live piglets born per semen dose in OvuGel treated sows represents a measure of efficiency that is of great value to producers. In other words, the producer benefits from an increase in piglet production while reducing costs associated with multiple semen doses.

A larger sample size and a reduction in the variability among farms (i.e., boar studs used, breeds of sows, parity, and management practices) would have provided an increase in reliability of the data herein. The following study evaluated the effect of commercially available products to facilitate a single FTAI protocol through ovulation induction on small-scale farms that differentiated in production goals. Participating swine producers were seeking cost efficient methodologies to improve timing of AI relative to ovulation as a way to achieve breeding targets. Intravaginal OvuGel administration alone allowed for easy and rapid treatment of sows without added injection stress. Anxiety was only observed when sows received an injection of P.G. 600 at weaning, yet this was not observed to affect overall reproductive performance. Small-scale, niche market swine producers who specifically promote animal welfare practices as a marketing strategy may be especially interested in utilizing OvuGel within breeding regimens. 


\section{Conclusion}

According to results reported herein and previous studies, it was concluded that using OvuGel alone or in combination with P.G. 600 to induce ovulation and facilitate a FTAI protocol for which sows receive a single AI irrespective of display of heat resulted in reproductive performance that is in general, similar to that achieved with traditional breeding systems in which sows are mated at 0 and $24 \mathrm{~h}$ after first displaying standing heat. Furthermore, sows treated with OvuGel produced more live piglets born per semen dose compared to control sows. A FTAI protocol utilizing commercially available OvuGel to induce ovulation in weaned sows offers producers a precise time to AI relative to ovulation regardless of estrus expression; thus the errors associated with improper estrus detection are no longer an impediment. Labor previously involved with estrus detection can then be reallocated to more intensive sectors of the farm such as d 1 pig care.

Furthermore, the use of P.G. 600 resulted in a shortened WEI in this experiment but did not affect overall estrus expression of sows by d 7 or 10 post-wean. Even though follicle maturation was not evaluated, perhaps P.G. 600 was an effective tool to stimulate follicular growth in weaned sows. Thus, the combination of P.G. 600 and OvuGel or OvuGel alone has the potential to decrease variability and contribute to a better single FTAI protocol with sow reproductive performance similar to that of controls. More research evaluating follicular maturation at the time of OvuGel treatment should be conducted as this can cause variable responses to ovulation induction. For small-scale and niche market pig farmers, OvuGel has the potential to be a useful tool to facilitate AI breeding protocols with all treated sows receiving AI by d 5 post-wean. Moreover, the reduced cost associated with using fewer doses of semen per 
sow on small-scale and niche market swine farms could prove extremely beneficial especially to the majority of producers seeking cost-efficient production. 


\section{Literature Cited}

Almond, G. W., and G. D. Dial. 1987. Pregnancy diagnosis in swine: Principles, applications and accuracy of available techniques. J. Am. Vet. Med. 191: 858-870.

Almond G.W., and G. D. Dial. 1990 Steroid hormone and luteinizing hormone concentrations in the anestrous sow. Can. J. Vet. Res. 54: 209-214.

Am-in, N., W. Tantasuparuk, and M. Techakumphu. 2010. Comparison of artificial insemination with natural mating on smallholder farms in Thailand, and the effects of boar stimulation and distance of semen delivery on sow reproductive performance. Trop. Anim. Health Prod. 42: 921-924.

Anderson, L. L. 2009. Reproductive biology of pigs. Animal industry report: AS 655, ASL R2443. Iowa State University, IA. http://lib.dr.iastate.edu/ans_air/vol655/iss 1/66/. (Accessed 21 May 2016).

Anil, S. S., A. Larriestra, J. Deen, R. B. Morrison, and L. Minion. 2004. A retrospective study on the preserving capacity of a commercial boar semen extender. Therio. 62: 425-36.

Ash, R.W. and R. B. Heap. 1975. Oestrogen, progesterone, and corticosteroid concetrations in peripheral plasma of sows during pregnancy, lactation and after weaning. J. Endocrinol. 64: $141-54$

Baker, R. D., and A. A Degen. 1972. Transport of live and dead boar spermatozoa within the reproductive tract of gilts. J. Reprod. Fertil. 28: 369-377. 
Baldwin, D. M., and G. H. Stabenfeldt. 1975. Endocrine changes in the pig during late pregnancy, parturition and lactation. Bio. Repro. 12: 508-515.

Barb, C. R., R. R. Kraeling, G. B. Rampacek, and C. S. Whisnant. 1986. Opioid inhibition of luteinizing hormone secretion in the postpartum lactating sow. Bio. Repro. 35: 368371.

Bates, R. O., B. N. Day, J. H. Britt, L. K. Clark, and M. A. Brauer. 1991. Reproductive performance of sows treated with a combination of pregnant mare's serum gonadotropin and human chorionic gonadotropin at weaning in the summer. J. Anim. Sci. 69: 894898.

Bates, R. O., J.Kelpinski, B. Hines. And D. Ricker. 2000. Hormonal therapy for sows weaned during fall and winter. J. Anim. Sci. 78: 2068-2071.

Bazer, F. W., and W.W. Thatcher. 1977. Theory of maternal recognition of pregnancy in swine based on estrogen controlled endocrine versus exocrine secretion of prostaglandin F $2 \alpha$ by the uterine endometrium. Prostagl. 14: 397-401.

Bazer, F. W., Ott, T. L., \& Spencer, T. E. 1994. Pregnancy recognition in ruminants, pigs and horses: signals from the trophoblast. Therio. 41: 79-94.

Belstra, B.A., Flowers, W.L., Rozeboom K.J., \& See, M.T. 2001. Factors contributing to variation of duration of estrus and time of ovulation in a commercial sow herd. North Carolina State University, A and T State University, Cooperative Extension. 
Bennett-Steward, K., G. Cassar. C. Plante, R. M. Friendship, and L. Zak. 2007. Ovulation induction protocol using equine chorionic gonadotropin and porcine luteinizing hormone in the weaned sow. J. Swine Health Prod. 15: 194.

Bracken, C. J., T. J. Safranski, T. C. Cantley, M. C. Lucy, and W. R. Lamberson. 2003. Effect of time of ovulation and sperm concentration on fertilization rate in gilts. Therio. 60: 669676.

Breen, S. M., S. L. Rodriguez-Zas, and R. V. Knox. 2006. Effect of altering dose of PG600 on reproductive performance responses in prepubertal gilts and weaned sows. Anim. Reprod. Sci. 95: 316-323.

Britt J. H., J. D. Armstrong, N. M. Cox, and K. L. Esbenshade. 1985. Control of follicular development during and after lactation in sows. J. Reprod. Fert. (Suppl 33): 37-54

Britt, J. H. 1986. Improving sow productivity through management during gestation, lactation and after weaning. J. Anim. Sci. 63:1288-1296.

Britt, J. H., B. N. Day, S. K. Webel, and M. A. Brauer. 1989. Induction of fertile estrus in prepuberal gilts by treatment with a combination of pregnant mare's serum gonadotropin and human chorionic gonadotropin. J. Anim. Sci. 67: 1148-1153.

Britt J. H., K. L. Esbenshade, and A. J. Ziecik. 1991. Roles of estradiol and gonadotropinreleasing hormone in controlling negative and positive feedback associated with the luteinizing hormone surge in ovariectomized pigs. Biol. Reprod. 45: 478-485.

Brüssow, K.-P., J. Ratky, W. Kanitz, and F. Becker. 1990. Determination of the duration of ovulation in gilts by means of laparoscopy. Reprod. Dom. Anim. 25: 184-190. 
Brüssow, K. P., W. Jöchle, and U. Hühn. 1996. Control of ovulation with a GnRH analog in gilts and sows. Therio. 46: 925-934.

Brüssow, K. P., F. Schneider, W. Kanitz, J. Ratky, J. Kauffold, and M. Wähner. 2009. Studies on fixed-time ovulation induction in the pig. Nottingham University Press. pp. 187-198.

Cassar, G., R. N. Kirkwood, Z. Poljak, K. Bennett-Steward, and R. M. Friendship. 2005. Effect of single or double insemination on fertility of sows bred at an induced estrus and ovulation. J. Swine Health Prod. 13: 254.

Cassar, G., R. M. Friendship, L. J. Zak, D. Rogan, and R. N. Kirkwood. 2010. Effect of dose of equine chorionic gonadotropin on the estrus responses of gilts and weaned sows and effect of the interval between equine chorionic gonadotrophin and luteinizing hormone injections on sow performance. J. Swine Health Prod. 18: 182-186.

Claus, R. 1989. Physiological role of seminal components in the reproductive tract of the female pig. J. Reprod. Fertil. (Suppl. 40): 117-131.

Degenstein, K. L., R. O’Donoghue, J. L. Patterson, E. Beltranena, D. J. Ambrose, G. R. Foxcroft, and M. K. Dyck. 2008. Synchronization of ovulation in cyclic gilts with porcine luteinizing hormone $(\mathrm{pLH})$ and its effects on reproductive function. Therio. 70: 10751085.

De Rensis F., M. G. Hunter, and G. R. Foxcroft. 1993. Suckling-induced inhibition of luteinizing hormone secretion and follicular development in the early postpartum sow. Biol Reprod. 48: 964-969. 
De Rensis, F., S. Benedetti, P. Silva, R. N. Kirkwood, 2003. Fertility of sows following artificial insemination at a gonadotrophin induced estrus coincident with weaning, Anim. Reprod. Sci. 76: 245-25.

De Rensis, F., M. Gherpelli, P. Superchi, and R. N. Kirkwood. 2005. Relationships between backfat depth and plasma leptin during lactation and sow reproductive performance after weaning. Anim. Reprod. Sci. 90: 95-100.

Dhindsa, D. S., and P. J. Dziuk. 1968. Effect on pregnancy in the pig after killing embryos or fetuses in one uterine horn in early gestation. J. Anim. Sci. 27: 122-126.

Dial, G.D. and J. H. Britt. 1986. The clinical endocrinology of reproduction in the pig. In: D.A. Morrow, editor. Current therapy in theriogenology. W.B. Saunders. Philadelphia, PA. pp. 908-9

Dimitrov, S., Jeliazkov, E., \& Levis, D. 2007. Deep intrauterine and transcervical insemination of sows and gilts. Trakia J. Sci. 5: 40-46.

Driancourt, M. A., A. Locatelli, and A. Prunier. 1995. Effects of gonadotrophin deprivation on follicular growth in gilts. Reprod. Nutr. Dev. 35: 663-673.

Elanco Animal Health, 2007. No matter how you look at it: body condition scoring is an important part of successful swine management (poster).

Einarsson, S., B. Jones, K. Larsson, and S. Viring. 1980. Distribution of small-and mediumsized molecules within the genital tract of artificially inseminated gilts. J. Reprod. Fertil. 59: $453-457$. 
Esbenshade, K. L., Ziecik, A. J., \& Britt, J. H. (1990). Regulation and action of gonadotrophins in pigs. J. Reprod. Fertil. (Suppl. 40): 19-32.

Estienne, M. J., J. S. Kesner, R. R. Kraeling, G. B. Rampacek, and C. R. Barb. 1989. Luteinizing hormone secretion in hypophysial stalk-transected pigs given progesterone and pulsatile gonadotropin-releasing hormone. Proc. Soc. Exp. Biol. Med. 190: 14-17.

Estienne, M. J., and T. G. Hartsock. 1998. Effect of exogenous gonadotropins on the weaning-toestrus interval in sows. Therio. 49: 823-828.

Estienne, M. J., A. F. Harper, B. R. Horsley, C. E. Estienne, and Knight, J. W. 2001. Effects of PG 600 on the onset of estrus and ovulation rate in gilts treated with Regu-mate. J. Anim. Sci. 79: 2757-2761.

Estill, C. T. 2000. Current concepts in estrus synchronization in swine. J. Anim. Sci. (Suppl.77): 1-9.

First, N.L., J. K. Lohse, and B. S. Nara. 1982. The endocrine control of parturition. In: D.J.A. Cole and G.R. Foxcroft (Ed.), Control of Pig Reproduction. Butterworths, London. p. 311

Flowers, W. L., and Alhusen, H. D. 1992. Reproductive performance and estimates of labor requirements associated with combinations of artificial insemination and natural service in swine. J. Anim. Sci. 70: 615-621.

Flowers, W. L., J. D. Armstrong, S. L. White, T. O. Woodard, and G. W. Almond. 2000. Realtime ultrasonography and pregnancy diagnosis in swine1,2. J. Anim. Sci. 77(Suppl):1-9. doi:10.2527/jas2000.77E-Suppl11 
Flowers, W. L., J. D. Armstrong, S. L. White, T. O. Woodard, and G. W. Almond. 2000. Realtime ultrasonography and pregnancy diagnosis in swine. J. Anim. Sci. (E-Suppl. 77): 1-9.

Flowers, W. L., S. Webel, and M. Estienne. 2001. Synchronization of estrus in swine. North Carolina State University, Pork Information Gateway, USA, 1-8. http://porkgateway.org/resource/synchronization-of-estrus-in-swine (Accessed 20 December 2016).

Gerritsen, R., N. M. Soede, P. Langendijk, S. J. Dieleman, W. Hazeleger, and B. Kemp. 2008. Peri-oestrus hormone profiles and follicle growth in lactating sows with oestrus induced by intermittent suckling. Reprod. Dom. Anim. 43: 1-8.

Geisert, R. D., M. T. Zavy, R. J. Moffatt, R. M. Blair, and T. Yellin. 1990. Embryonic steroids and the establishment of pregnancy in pigs. J. Reprod. Fertil. (Suppl. 40): 293-305.

Geisert, R. D., R. H., Renegar, W. W. Thatcher, R. M. Roberts, and F. W. Bazer. 1982. Establishment of pregnancy in the pig: I. Interrelationships between preimplantation development of the pig blastocyst and uterine endometrial secretions. Bio. Reprod. 27: 925-939.

Gilbert, C. L., J. A. Goode, and T. J. McGrath. 1994. Pulsatile secretion of oxytocin during parturition in the pig: temporal relationship with fetal expulsion. J. Physiol. 475: 129.

Guthrie, H. D., D. M. Henricks, and D. L. Handlin. 1974. Plasma hormone levels and fertility in pigs induced to superovulate with PMSG. J. Reprod. Fertil. 41: 361-370.

Guthrie, H. D. 2005. The follicular phase in pigs: Follicle populations, circulating hormones, follicle factors and oocytes. J. Anim. Sci. 83: E79-E89. 
Hansel, W., P.W. Concannon, and J. H. Lukaszewska. 1973. Corpora lutea of the large domestic animals. Bio. Reprod. 8: 222-245.

Hemsworth, P. H., R. G. Beilharz, and W. J. Brown. 1978. The importance of the courting behaviour of the boar on the success of natural and artificial matings. Appl. Anim. Ethol. 4: 341-347.

Hemsworth, P. H., and A. J. Tilbrook. 2007. Sexual behavior of male pigs. Horm. Behav. 52: 3944.

Henricks, D. M., H. D. Guthrie, and D. L. Handlin. 1972. Plasma estrogen, progesterone and luteinizing hormone levels during the estrous cycle in pigs. Bio. Reprod. 6: 210-218.

Herbert, C. A., and T. E. Trigg. 2005. Applications of GnRH in the control and management of fertility in female animals. Anim. Reprod. Sci. 88: 141-153.

Hughes, P. E., Pearce, G. P., Paterson, A. M., Cole, D. J. A., Foxcroft, G. R., \& Weir, B. J. 1990. Mechanisms mediating the stimulatory effects of the boar on gilt reproduction. J. Reprod. Fertil. (Suppl. 40): 323-341.

Hughes, P. E. 1998. Effects of parity, season and boar contact on the reproductive performance of weaned sows. Livest. Prod. Sci. 54: 151-157.

Hühn, U., W. Jöchle, and K. P. Brüssow. 1996. Techniques developed for the control of estrus, ovulation and parturition in the East German pig industry: a review. Therio. 46: 911-924.

Hunter, R. H. F., and C. Polge. 1966. Maturation of follicular oocytes in the pig after injection of human chorionic gonadotrophin. J. Reprod. Fertil. 12: 525-531. 
Hunter, R. H. 1967. Porcine ovulation after injection of human chorionic gonadotrophin. Vet.

Rec. 81: 21-23.

Hunter, R. H. F. 1974. Chronological and cytological details of fertilization and early embryonic development in the domestic pig, Sus scrofa. Anat. Rec. 178: 169-186.

Hunter, R. H. F. 1981. Sperm transport and reservoirs in the pig oviduct in relation to the time of ovulation. J. Reprod. Fert. 63: 109-117

Hunter, R. H. F., 1990. Fertilization of pig eggs in vivo and in vitro. J. Reprod. Fertil. (Suppl. 40): 211-226.

Hunter, M. G., R. S. Robinson, G. E. Mann, and R. Webb. 2004. Endocrine and paracrine control of follicular development and ovulation rate in farm species. Anim. Reprod. Sci. 82: 461477.

Inaba, T., K. Nakazima, N. Matsui, and T. Imori. 1983. Early pregnancy diagnosis in sows by ultrasonic linear electronic scanning. Therio. 20: 97-101.

Jackson, A., S. Rodriguez-Zas, R. Knox, K. Willenburg, D. Gregor, and M. Swanson. 2003. Controlling estrus and ovulation. National Hog Farmer. 48: 18-20. http://www.nationalhogfarmer.com/mag/farming_controlling_estrus_ovulation (Accessed 12 June 2016).

Kemp, B., and N. M. Soede. 1996. Relationship of weaning-to-estrus interval to timing of ovulation and fertilization in sows. J. Anim. Sci. 74: 944-949.

Kemp, B., N. M. Soede, and P. Langendijk. 2005. Effects of boar contact and housing conditions on estrus expression in sows. Therio. 63: 643-656. 
Kemp, B., J. G. M. Wientjes, and N. M. Soede. 2009. The post-partum sow: physiology of the sow during lactation. Luentokokoelma. Helsinki, Finland. 28-30 October, 2009. pp. 107113.

Kirkwood, R. N., S. C. Henry, L. M. Tokach, and G. R. Foxcroft. 1999. Human chorionic gonadotropin at parturition fails to consistently induce ovulation in sows. J. Swine Health Prod. 7: 69-72.

Kirkwood, R. N., and Kauffold, J. 2015. Advances in breeding management and use of ovulation induction for fixed- time AI. Reprod. Dom. Anim. 50: 85-89.

Knox, R. V. 2004. The real impact of boars in breeding programs. Adv. in Pork Prod. No. 15. Banff Pork Seminar, Univ. of Alberta, Edmonton, Canada. pp. 307-314

Knox, R. V. 2005. Recruitment and selection of ovarian follicles for determination of ovulation rate in the pig. Dom. Anim. Endo. 9: 385-397.

Knox, R. V. 2016. Artificial insemination in pigs today. Therio. 85: 83-93.

Knox, R. V., and G. C. Althouse. 1999. Visualizing the reproductive tract of the female pig using real-time ultrasonography. Swine Health. Prod. 7: 207-216.

Knox R.V., and S. Rodriguez-Zas. 2001. Factors influencing estrus and ovulation in weaned sows as determined by transrectal ultrasound. J. Anim. Sci. 79: 2957-2963.

Knox, R.V., S. L. Rodriguez-Zas, G. M. Miller, K. L. Willenburg, and J. A. Robb. 2001. Administration of P.G. 600 to sows at weaning and the time of ovulation as determined by transrectal ultrasound. J. Anim. Sci. 79: 796-802. 
Knox, R.V., G. M. Miller, K. L. Willenburg, and S. L. Rodriguez-Zas. 2002. Effect of frequency of boar exposure and adjusted mating times on measures of reproductive performance in weaned sows. J. Anim. Sci. 80: 892-899.

Knox, R. V., G. Vatzias, C. H. Naber, and D. R. Zimmerman. 2003. Plasma gonadotropins and ovarian hormones during the estrous cycle in high compared to low ovulation rate gilts. J. Anim. Sci. 81: 249-60.

Knox, R. V., S. M. Breen, K. L. Willenburg., S. Roth, G. M. Miller, K. M. Ruggiero, S. Rodriguez-Zas. 2004. Effect of housing system and boar exposure on estrus expression in weaned sows. J. Anim. Sci. 82: 3088-93.

Knox, R. V., K. L. Willenburg, S. L. Rodriguez-Zas, D. L. Greger, H. D. Hafs, and M. E. Swanson. 2011. Synchronization of ovulation and fertility in weaned sows treated with intravaginal triptorelin is influenced by timing of administration and follicle size. Therio. 75: 308-319.

Knox, R. V., S. L. Rodriguez Zas, N. L. Sloter, K. A. McNamara, T. J. Gall, D. G. Levis, and W. L. Singleton. 2013. An analysis of survey data by size of the breeding herd for the reproductive management practices of North American sow farms. J. Anim. Sci. 91: 433445.

Knox, R. V., J. N. Taibl, S. M. Breen, M. E. Swanson, and S. K. Webel. 2014. Effects of altering the dose and timing of triptorelin when given as an intravaginal gel for advancing and synchronizing ovulation in weaned sows. Therio. 82: 379-386.

Koketsu, Y., G. D. Dial, and V. L. King. 1997. Influence of various factors on farrowing rate on farms using early weaning. J. Anim. Sci. 75: 2580-2587. 
Kotwica, G., L. Dusza, R. Ciereszko, S. Okrasa, and D. Schams. 1990. Oxytocin plasma levels during spontaneous and cloprostenol-induced luteolysis in sows. Anim. Reprod. Sci. 22: 109-119.

Kotwica, G., J. Sobczak, and M. Koziorowski. 1995. Effects of opioid peptides, indomethacin and age on oxytocin and prolactin release during mating in sows. Reprod. Dom. Anim. 30: $257-263$.

Kraeling, R. R., and S. K. Webel. 2015. Current strategies for reproductive management of gilts and sows in North America. J. Anim. Sci. Biotechnol. 6: 3.

Langendijk, P., N. M. Soede, E. G. Bouwman, and B. Kemp. 2000a. Responsiveness to boar stimuli and change in vulvar reddening in relation to ovulation in weaned sows. J. Anim. Sci. 78: 3019-3026.

Langendijk, P., H. Van den Brand, N. M. Soede, and B. Kemp. 2000b. Effect of boar contact on follicular development and on estrus expression after weaning in primiparous sows. Therio. 54: 1295-1303.

Langendijk, P., N. M. Soede, and B. Kemp. 2000c. Effects of boar contact and housing conditions on estrus expression in weaned sows. J. Anim. Sci. 78: 871-878.

Langendijk, P., E.G. Bouwman, D. Schams, N. M. Soede, and B. Kemp. 2003. Effects of different sexual stimuli on oxytocin release, uterine activity and receptive behavior in estrous sows. Therio. 59: 849-861. 
Langendijk, P., N. M. Soede, and B. Kemp. 2005a. Uterine activity, sperm transport, and the role of boar stimuli around insemination in sows. Therio. 63: 500-513.

Langendijk, P., Soede, N. M., \& Kemp, B. 2005b. Effects of boar stimuli on the follicular phase and on oestrous behaviour in sows. Soc. Reprod. Fertil. (Suppl. 62): 219-230.

Love, R. J., G. Evans, and C. Klupiec. 1992. Seasonal effects on fertility in gilts and sows. J. Reprod. Fertil. (Suppl. 48): 191-206.

Lucia, T., M. N. Corrêa, J. C. Deschamps, I. A. Peruzzo, J. E. Matheus, and J. A. Aleixo. 1999. Influence of equine chorionic gonadotropin on weaning-to-estrus interval and estrus duration in early-weaned, primiparous, female swine. J. Anim. Sci. 77: 3163-3167.

Lucy, M. C., J. Liu, C. K. Boyd, and C. J. Bracken. 2001. Ovarian follicular growth in sows. Reprod. (Cambridge, England) (Suppl. 58): 31.

Manjarin, R., J. C. Garcia, J. C. Dominguez, M. J. Castro, B. Alegre, J. D. Munoz, and R. N. Kirkwood. 2010. Effect of gonadotropin treatment on estrus, ovulation, and litter size in weaned and anestrous sows. J. Anim. Sci. 88: 2356-2360.

Maffeo, G., D. Vigo, R. Salvo, M. Mattioli, and E, Seren. 1993. Myometrial activity following exposure of estrous gilts to boar pheromone (5 alpha androst-16-en-3-one). Archivio. Veterinario. Italiano. 44: 83-91.

Masuda, H., L. L. Anderson, and D. M. Henricks. 1967. Progesterone in ovarian venous plasma and corpora lutea of the pig. Endocrin. 80: 240-246. 
Mburu, J. N., S. Einarsson, A. M. Dalin, and H. Rodriguez- Martinez. 1995. Ovulation as determined by transrectal ultrasonography in multiparous sows: relationships with oestrous symptoms and hormonal profiles. J. Vet. Med. Series A. 42: 285-292.

NAHMS. 2012. Part I: Baseline Reference of Swine Health and Management in the United States. (USDA Census of Agriculture). https://www.aphis.usda.gov/animal_health/nahms/swine/downloads/swine2012/Swine2 12 dr_PartI.pdf (Accessed 24 Nov. 2016)

NAHMS. 1997. Part III: Changes in the U.S. Pork Industry, 1990-1995. (USDA Census of Agriculture). https://www.aphis.usda.gov/animal_health/nahms/swine/downloads/swine95/Swine95_dr PartIII.pdf (Accessed 6 Dec. 2016).

NASS. 2012. Hog and Pig Farming (USDA Census of Agriculture) http://www.agcensus.usda.gov/Publications/2012/Online_Resources/Highlights/Hog_and _Pig_Farming/Highlights_Hog_and_Pig_Farming.pdf (Accessed 29 March 2016).

Nissen, A. K., N. M. Soede, P. Hyttel, M. Schmidt, and L. D'hoore. 1997. The influence of time of insemination relative to time of ovulation on farrowing frequency and litter size in sows, as investigated by ultrasonography. Therio. 47: 1571-1582.

Niswender, G. D., L. E. Reichert Jr, and D. R. Zimmerman. 1970. Radioimmunoassay of serum levels of luteinizing hormone throughout the estrous cycle in pigs. Endocr. 87: 576-580.

Pearce, G. P., and P. E. Hughes. 1987. An investigation of the roles of boar-component stimuli in the expression of proceptivity in the female pig. Appl. Anim. Behav. Sci. 18: 287-299. 
Pedersen, L. J. 2007. Sexual behaviour in female pigs. Horm. Behav. 52: 64-69.

Pena, F. J., J. C. Dominguez, M. Carbajo, L. Anel, and B. Alegre. 1998. Treatment of swine summer infertility syndrome by means of oxytocin under field conditions. Therio. 49: 829-836.

Perry, G. C., R. L. S. Patterson, H. J. H. MacFie, and C. G. Stinson. 1980. Pig courtship behaviour: pheromonal property of androstene steroids in male submaxillary secretion. Anim. Prod. 31: 191-199.

Polge, C., L. E. A. Rowson, and M. C. Chang. 1966. The effect of reducing the number of embryos during early stages of gestation on the maintenance of pregnancy in the pig. J. Reprod. Fertil. 12: 395-397.

Prunier, A., F. Martinat-Botte, J. P. Ravault, and S. Camous. 1987. Perioestrous patterns of circulating LH, FSH, prolactin and oestradiol-17 $\beta$ in the gilt. Anim. Reprod. Sci. 14: 205218.

Reynolds L. P., P. P. Borowicz, K. A. Vonnahme, M. L. Johnson, A. T. Grazul-Bilska, J. M. Wallace, J. S. Caton, and D. A. Redmer. 2005. Animal models of placental angiogenesis. Placenta. 26: 689-708.

Roca, J., J. M. Vázquez, M. A. Gil, C. Cuello, I. Parrilla, and E. A. Martinez. 2006. Challenges in pig artificial insemination. Reprod. Dom. Anim. 41: 43-53.

Rodriguez-Martinez, H. 2001. Oviduct function in cows and pigs: with special reference to sperm capacitation. Asian-Australasian J. Anim. Sci. 14: 28-37. 
Roese, G., G. Taylor, and J. Morgan. 2007. Batch farrowing for the pig industry. NSW Dept. of Primary Industries. PRIMEFACT. 143: 1-6.

Rozeboom, K. F., M. H. T. Troedsson, G. C. Shurson, J. D. Hawton, and B. G. Crabo. 1997. Late estrus or metestrus insemination after estrual inseminations decreases farrowing rate and litter size in swine. J. Anim. Sci. 75: 2323-2327.

Sanders, D.R., I.J. Altman, and G.A. Apgar. 2012. Determinants of profitability in niche swine production. J. Amer. Soc. Farm Manag. Rural Apprais.75: 68-79.

Sawyer, C. H. 1964. Control of secretion of gonadotropins. In: Gonadotropins. Their Chemical and Biological Properties and Secretory Control. H. H. Cole, editor. Freeman, San Franscico, CA. p. 113.

Sechin, A., J. C. Deschamps, T. Lucia, J. A. Aleixo, and V. Bordignon. 1999. Effect of equine chorionic gonadotropin on weaning-to-first service interval and litter size of female swine. Therio. 51: 1175-1182.

Senger, P. L. 1997. Pathways to Pregnancy and Parturition. Current Conceptions, Pullman WA. Current Conceptions, Inc. pp. 6-8.

Shaw, H. J., and G. R. Foxcroft. 1985. Relationships between LH, FSH and prolactin secretion and reproductive activity in the weaned sow. J. Reprod. Fertil. 75: 17-28.

Signoret, J.P., 1970. Reproductive behaviour of pigs. J. Reprod. Fertil. (Suppl. 11): 105-117.

Signoret, J. P., F. D. M. Du Buisson, and P. Mauleon. 1972. Effect of mating on the onset and duration of ovulation in the sow. J. Reprod. Fertil. 31: 327-330. 
Soede, N. M. Boar stimuli around insemination affect reproductive processes in pigs: a review. 1993. Anim. Reprod. Sci. 32:107-25.

Soede, N. M., and B. Kemp. 1997. Expression of oestrus and timing of ovulation in pigs. J. Reprod. Fertil. (Suppl. 52): 91-103.

Soede, N. M., C. C. H. Wetzels, W. Zondag, M. A. I. De Koning, and B. Kemp. 1995. Effects of time of insemination relative to ovulation, as determined by ultrasonography, on fertilization rate and accessory sperm count in sows. J. Reprod. Fertil. 104: 99-106.

Soede, N.M., W. Hazeleger, and B. Kemp. 1998. Follicle size and the process of ovulation in sows as studied with ultrasound. Reprod. Domest. Anim. 33: 239-244.

Soede, N. M., W. Hazeleger, P. Langendijk, and B. Kemp. 2009. Reproductive management in pigs: emphasis on the different roles of the boar and on optimal insemination management. Luentokokoelma. Helsinki, Finland, 28-30 October, 2009. pp. 122-130.

Soede, N. M., P. Langendijk, and B. Kemp. 2011. Reproductive cycles in pigs. Anim. Reprod. Sci. 124: 251-258.

Spencer, T. E. and F. W. Bazer. 2002. Biology of progesterone action during pregnancy recognition and maintenance of pregnancy. Front. Biosci. 7: d1879-d1898.

Stevenson, J. S., N. M. Cox, and J. H. Britt. 1981. Role of the ovary in controlling luteinizing hormone, follicle stimulating hormone, and prolactin secretion during and after lactation in pigs. Biol. Reprod. 24: 341-353. 
Steverink, D. W. B., N. M. Soede, E. G. Bouwman, and B. Kemp. 1998. Semen backflow after insemination and its effect on fertilization results in sows. Anim. Reprod. Sci. 54: 109119.

Steverink, D.W.B., N.M. Soede, G.J.R. Groenland, F.W. van Schie, J.P.T.M. Noordhuizen, and B. Kemp. 1999. Duration of estrus in relation to reproduction results in pigs on commercial farms. J. Anim. Sci. 77: 801-809.

Stewart, K. R., W. L. Flowers, G. B. Rampacek, D. L. Greger, M. E. Swanson, and H. D. Hafs. 2010. Endocrine, ovulatory and reproductive characteristics of sows treated with an intravaginal GnRH agonist. Anim. Reprod. Sci. 120: 112-119.

Taverne, M., M. Bevers, J. M. Bradshaw, S. J. Dieleman, A. H. Willemse, and D. G. Porter. 1982. Plasma concentrations of prolactin, progesterone, relaxin and oestradiol-17 $\beta$ in sows treated with progesterone, bromocriptine or indomethacin during late pregnancy. J. Reprod. Fertil. 65: 85-96.

Tilton, J. E., G. R. Foxcroft, A. J. Ziecik, S. L. Coombs, and G. L. Williams. 1982. Time of the preovulatory LH surge in the gilt and sow relative to the onset of behavioral estrus. Therio. 18: 227-236.

Van de Weil, D. F. M., J. Evans, W. Koops, E.Vos and A.A. J. Van Landeghem. 1981. Perioestrous and midluteal time courses of circulating LH, FSH, prolactin, estradiol-17 $\beta$ and progesterone on the domestic pig. Biol. Reprod. 24: 223.

Van de Wiel, D. F. M., and P. Booman. 1993. Post-weaning anestrus in primiparous sows: LH patterns and effects of gonadotropin injection and boar exposure. Vet. Q. 15: 162-166. 
Vargas, A. J., M. L. Bernardi, I. Wentz, G. B. Neto, and F. P. Bortolozzo. 2006. Time of ovulation and reproductive performance over three parities after treatment of primiparous sows with PG600. Therio. 66: 2017-2023.

Vesseur, P. C., B. Kemp, and L. D. Hartog. 1994. The effect of the weaning to oestrus interval on litter size, live born piglets and farrowing rate in sows. J. Anim. Phys. Anim. Nutr. 71: 30-38.

Viring, S., and S. Einarsson. 1981. Sperm distribution within the genital tract of naturally inseminated gilts. Nord. Vet. Med. 33:145-149.

Waberski, D., K. F. Weitze, T. Gleumes, M. Schwarz, T. Willmen, and R. Petzoldt. 1994. Effect of time of insemination relative to ovulation on fertility with liquid and frozen boar semen. Therio. 42: 831-840.

Walton, J.S., 1986. Effect of boar presence before and after weaning on estrus and ovulation in sows. J. Anim. Sci. 62: 9-15.

Webel, S.K. and M. E. Swanson. JBS United Animal Health LLC., 2014. Method and composition for synchronizing time of insemination. U.S. Patent 8,905,913.

Weitze, K. F., Wagner-Rietschel, H., Waberski, D., Richter, L., \& Krieter, J. 1994. The onset of heat after weaning, heat duration, and ovulation as major factors in AI timing in sows. Reprod. Dom. Anim. 29: 433-443.

Willenburg, K. L., Miller, G. M., Rodriguez-Zas, S. L., \& Knox, R. V. 2003. Effect of boar exposure at time of insemination on factors influencing fertility in gilts. J. Anim. Sci. 81: 9-15. 
Willis, H. J., L. J. Zak, and G. R. Foxcroft. 2003. Duration of lactation, endocrine and metabolic state, and fertility of primiparous sows. J. Anim. Sci. 81: 2088-2102.

Wongkaweewit, K., P. Prommachart, R. Raksasub, K. Buranaamnuay, M. Techakumphu, F. De Rensis, and P. Tummaruk. 2012. Effect of the administration of GnRH or hCG on time of ovulation and the onset of estrus-to-ovulation interval in sows in Thailand. Tropic. Anim. Health. Prod. 44: 467-470.

Xue, J. L., G. D. Dial, W. E. Marsh, and P. R. Davies. 1994. Multiple manifestations of season on reproductive performance of commercial swine. J. Amer. Vet. Med. Assoc. 204: 14861489.

Zak, L. J., Patterson, J., Hancock, J., Rogan, D., \& Foxcroft, G. F. 2010. Benefits of synchronizing ovulation with porcine luteinizing hormone $(\mathrm{pLH})$ in a fixed time insemination protocol in weaned multiparous sows. J. Swine Health Prod. 18: 125-131.

Ziecik, A. J. 2002. Old, new and the newest concepts of inhibition of luteolysis during pregnancy in pig. Dom. Anim. Endocrinol. 23: 265-275.

Ziecik, A. J., A. Waclawik, M. M. Kaczmarek, A. Blitek, B. M. Jalali, and A. Andronowska. 2011. Mechanisms for the establishment of pregnancy in the pig. Reprod. Dom. Anim. 46: 3141. 


\section{Appendix Tables}

Table A1. Effects of OvuGel ${ }^{\circledR}$ and P.G. $600 ®$ alone or in combination on reproduction in sows by treatment.

\begin{tabular}{|c|c|c|c|c|c|c|c|c|}
\hline \multirow[b]{2}{*}{ Item: } & \multirow[b]{2}{*}{ TRT1 $^{1}$} & \multirow[b]{2}{*}{ TRT2 ${ }^{1,2}$} & \multirow[b]{2}{*}{ TRT3 $^{2}$} & \multirow[b]{2}{*}{ TRT4 } & \multirow[b]{2}{*}{ SEM } & \multicolumn{3}{|c|}{$P$-values } \\
\hline & & & & & & $\begin{array}{c}\text { OvuGel } \\
\text { vs. No } \\
\text { OvuGel } \\
\end{array}$ & $\begin{array}{c}\text { P.G. 600 } \\
\text { VS. No } \\
\text { P.G.600 } \\
\end{array}$ & $\begin{array}{c}\text { P.G. 600 x } \\
\text { OvuGel }\end{array}$ \\
\hline Number of sows & 24 & 24 & 24 & 24 & & --- & --- & --- \\
\hline $\begin{array}{l}\text { Estrus by day } 7 \\
\text { post-weaning, } \\
\%\end{array}$ & 92.1 & 96.8 & 79.5 & 84.9 & 0.1 & 0.03 & 0.95 & 0.35 \\
\hline $\begin{array}{l}\text { Estrus by day } \\
10 \text { post- } \\
\text { weaning, } \%\end{array}$ & $95.2^{\mathrm{a}, \mathrm{b}}$ & $99.4^{\mathrm{a}}$ & $82.7^{\mathrm{b}}$ & $95.2^{\mathrm{a}, \mathrm{b}}$ & 0.1 & 0.09 & 0.39 & 0.09 \\
\hline $\begin{array}{l}\text { Wean-to-estrus, } \\
\text { days }\end{array}$ & 5.2 & 4.7 & 5.0 & 5.5 & 0.4 & 0.09 & 0.03 & 0.92 \\
\hline Pregnant $^{3}, \%$ & 61.0 & 53.7 & 68.5 & 61.4 & 0.1 & 0.46 & 0.99 & 0.48 \\
\hline Pregnant ${ }^{4}, \%$ & 61.8 & 54.0 & 61.8 & 58.4 & 0.1 & 0.99 & 0.68 & 0.73 \\
\hline Farrowing $^{3}, \%$ & 62.1 & 45.6 & 65.3 & 53.7 & 0.1 & 0.59 & 0.81 & 0.18 \\
\hline Farrowing ${ }^{4}, \%$ & 61.8 & 45.4 & 54.1 & 49.5 & 0.1 & 0.86 & 0.56 & 0.31 \\
\hline
\end{tabular}

${ }^{1}$ Sows treated with OvuGel $96 \mathrm{~h}$ post-weaning

${ }^{2}$ Sows treated with P.G. 600 at weaning (h 0 )

${ }^{3}$ Sows pregnant or farrowing/sows inseminated

${ }^{4}$ Sows pregnant or farrowing/sows allotted to treatments

${ }^{\mathrm{a}, \mathrm{b}}$ Values with different superscripts tend to differ $(P<0.10)$. 
Table A2. Effects of OvuGel® and P.G. 600® alone or in combination on litter characteristics in sows by treatment.

\begin{tabular}{|c|c|c|c|c|c|c|c|c|}
\hline \multirow[b]{2}{*}{ Item: } & \multirow[b]{2}{*}{ TRT1 $^{1}$} & \multirow[b]{2}{*}{ TRT2 $^{1,2}$} & \multirow[b]{2}{*}{ TRT3 $^{2}$} & \multirow[b]{2}{*}{ TRT4 } & \multirow[b]{2}{*}{ SEM } & \multicolumn{3}{|c|}{$P$-values } \\
\hline & & & & & & $\begin{array}{c}\text { OvuGel } \\
\text { vs. No } \\
\text { OvuGel } \\
\end{array}$ & $\begin{array}{c}\text { P.G. } 600 \\
\text { vs. No } \\
\text { P.G.600 } \\
\end{array}$ & $\begin{array}{l}\text { P.G. 600 } \\
\text { x OvuGel }\end{array}$ \\
\hline Total Litter Size & 9.9 & 11.5 & 11.9 & 12.4 & 0.9 & 0.11 & 0.53 & 0.26 \\
\hline Born Live & 8.8 & 11.0 & 9.8 & 11.4 & 0.9 & 0.43 & 0.72 & 0.04 \\
\hline Born Dead & 0.8 & 0.4 & 1.5 & 0.8 & 0.4 & 0.11 & 0.54 & 0.10 \\
\hline Mummies & 0.21 & 0.0 & 0.46 & 0.18 & 0.2 & 0.22 & 0.85 & 0.16 \\
\hline $\begin{array}{l}\text { Live pigs/dose } \\
\text { of semen }\end{array}$ & 5.61 & 5.22 & 3.31 & 3.09 & 1.0 & 0.03 & 0.93 & 0.76 \\
\hline
\end{tabular}

${ }^{1}$ Sows treated with OvuGel $96 \mathrm{~h}$ post-weaning

${ }^{2}$ Sows treated with P.G. 600 at weaning (h 0) 


\section{Appendix Figures}

Figure A1. Wean to estrus interval among treatments. Sows in TRT2 and TRT3 received $5 \mathrm{~mL}$ of P.G. 600 (Merck Animal Health; De Sota, KS) at weaning (h 0) and sows in TRT1 and TRT2 received $2 \mathrm{~mL}$ of OvuGel (JBS United Animal Health; Sheridan, IN) 96 h post-wean. Data are represented as least-square means \pm SE. There was a main treatment effect of P.G. 600 on WEI (P $<0.05$ ) but no effect of OvuGel or P.G. 600 x OvuGel.

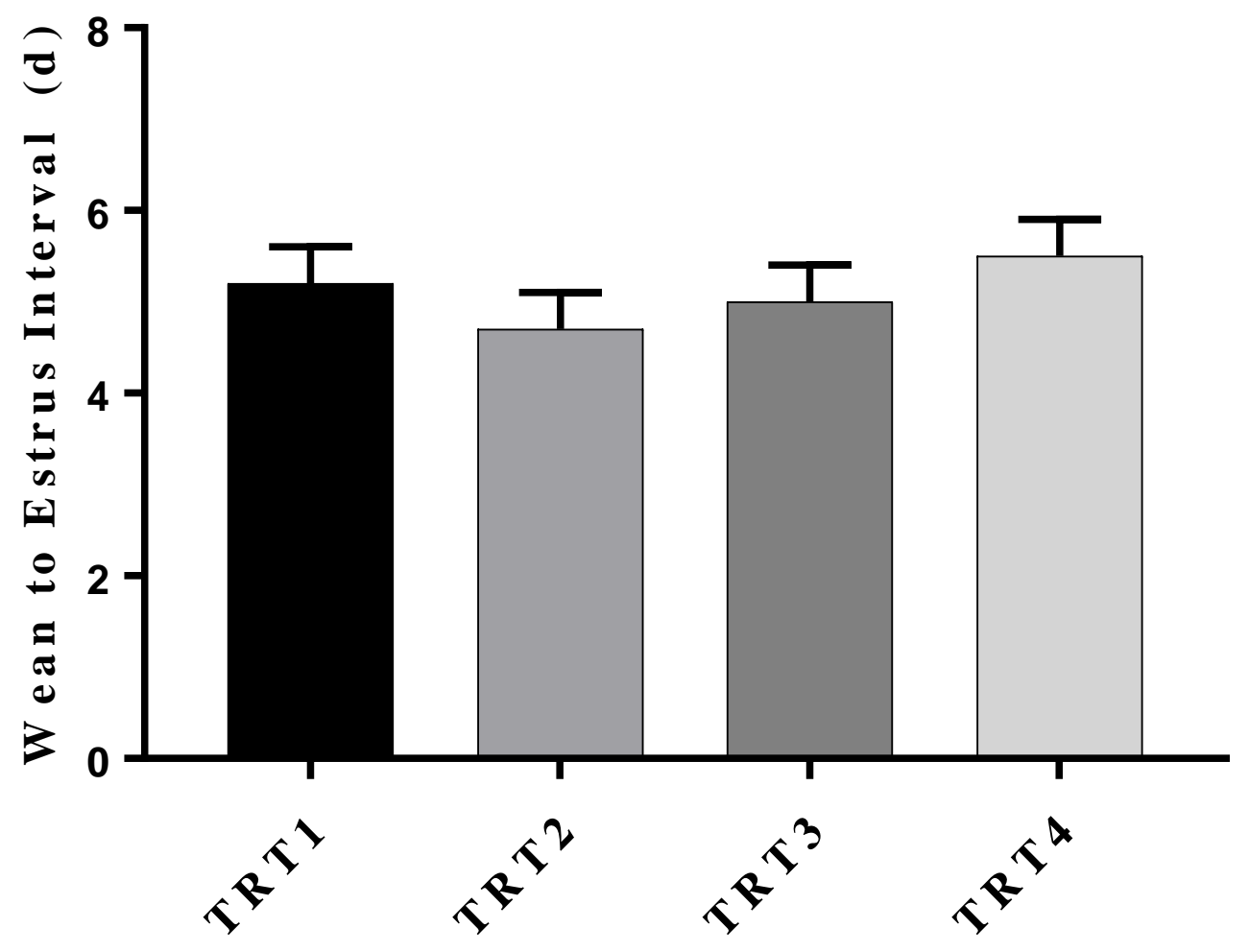


Figure A2. Proportion of sows displaying estrus by d 7 post-weaning. Sows in TRT2 and TRT3 received $5 \mathrm{~mL}$ of P.G. 600 (Merck Animal Health; De Sota, KS) at weaning (h 0) and sows in TRT1 and TRT2 received $2 \mathrm{~mL}$ of OvuGel (JBS United Animal Health; Sheridan, IN) $96 \mathrm{~h}$ postwean. Data are represented as least-square means \pm SE. The proportion of females displaying estrus by $\mathrm{d} 7$ post-weaning was greater for sows that received OvuGel compared to sows that did not $(\mathrm{P}<0.05)$. There were no effects of P.G. 600 or P.G. 600 x OvuGel.

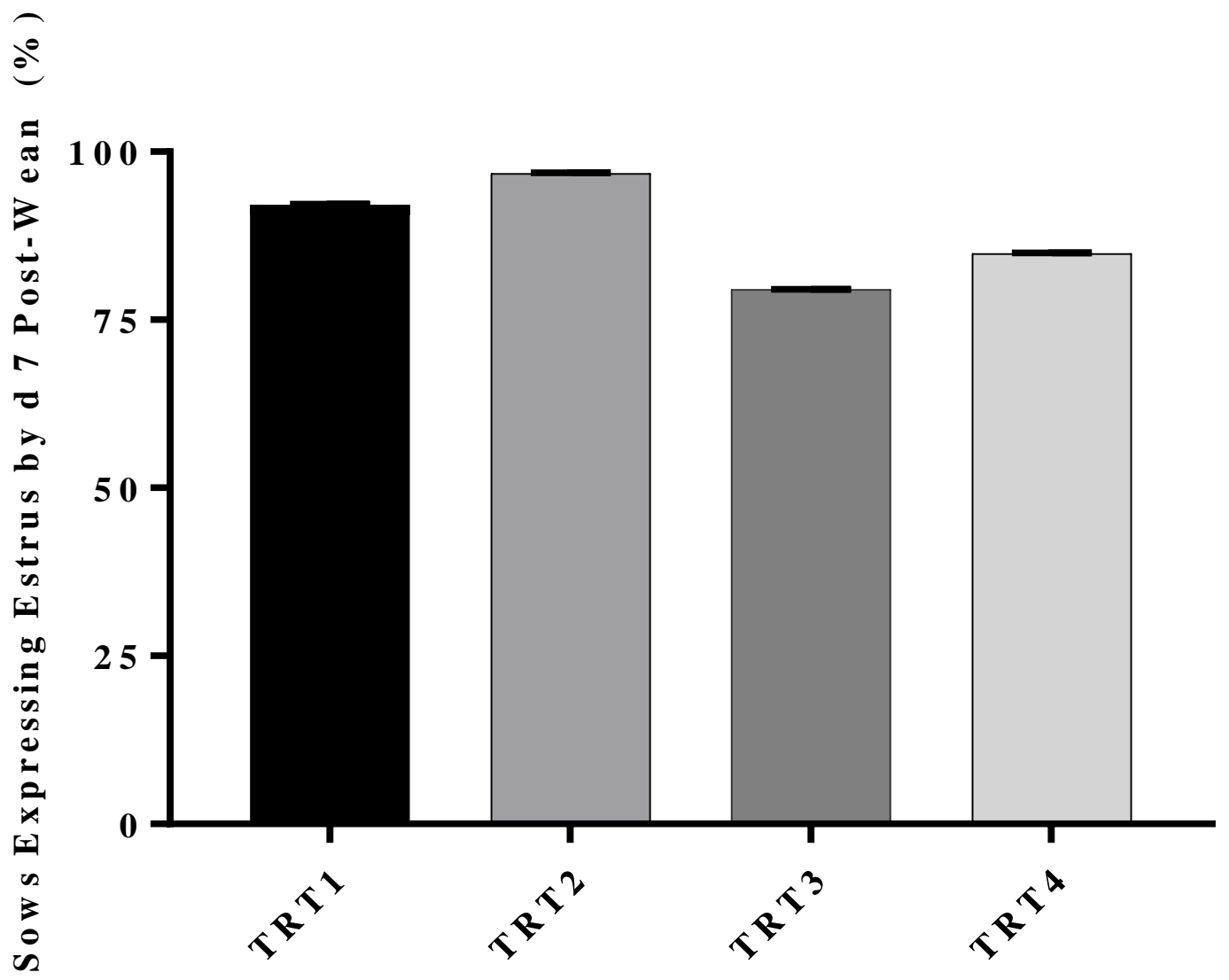


Figure A3. Proportion of sows displaying estrus by d 10 post-weaning. Sows in TRT2 and TRT3 received $5 \mathrm{~mL}$ of P.G. 600 (Merck Animal Health; De Sota, KS) at weaning (h 0) and sows in TRT1 and TRT2 received $2 \mathrm{~mL}$ of OvuGel (JBS United Animal Health; Sheridan, IN) $96 \mathrm{~h}$ postwean. Data are represented as least-square means \pm SE. There were no effects of P.G. 600, OvuGel, or P.G. $600 \mathrm{x}$ OvuGel on females displaying estrus by d 10. The proportion of females displaying estrus by $\mathrm{d} 10$ post weaning was not affected by treatment.

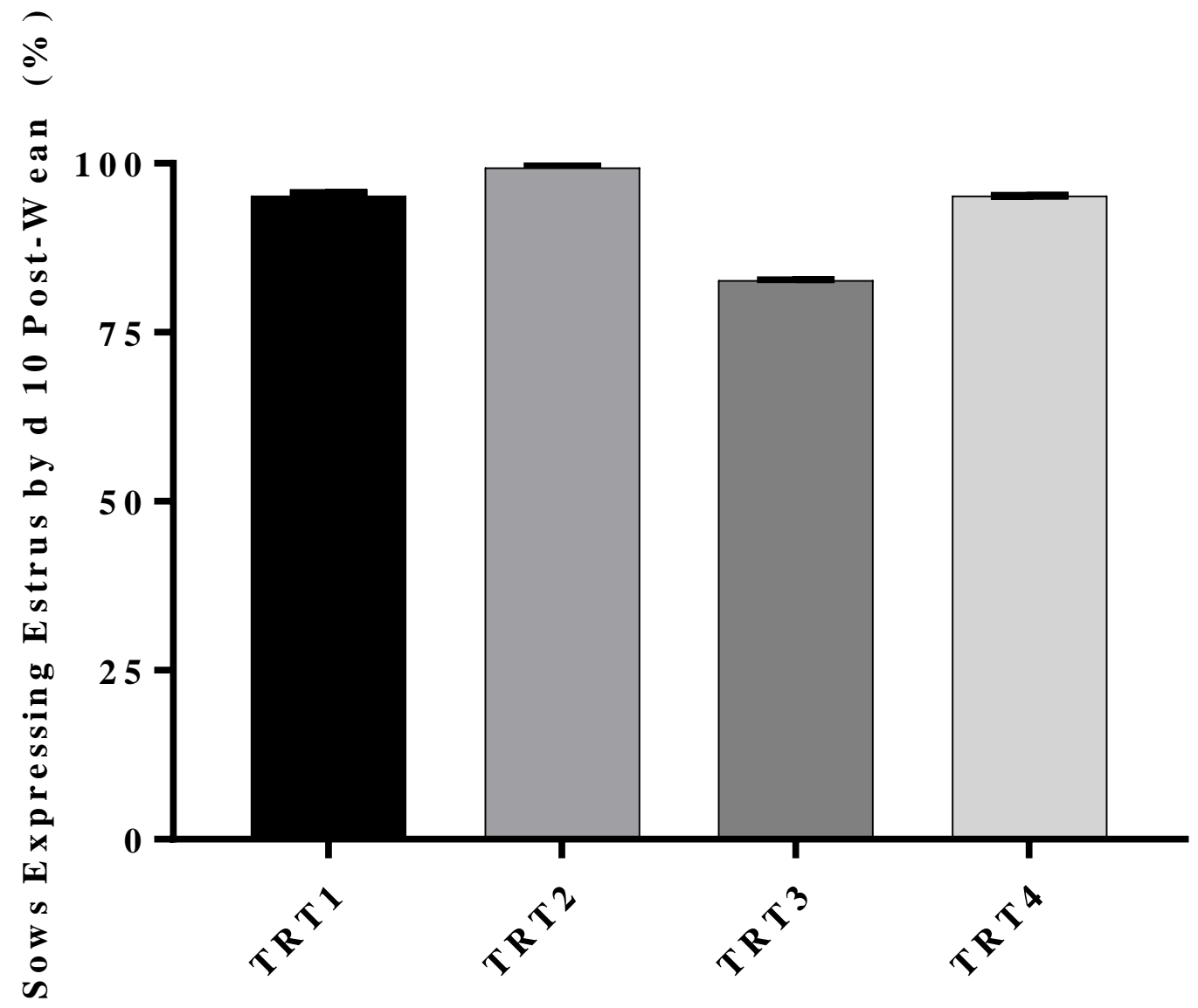


Figure A4. Total litter size for TRT1, TRT2, TRT3, and TRT4 sows. Sows in TRT2 and TRT3 received $5 \mathrm{~mL}$ of P.G. 600 at weaning (h 0 ) and sows in TRT1 and TRT2 received $2 \mathrm{~mL}$ of OvuGel $96 \mathrm{~h}$ post-wean. Data are represented as least-square means \pm SE. There was no effect of P.G. 600, OvuGel, or P.G. 600 x OvuGel on total litter size across groups.

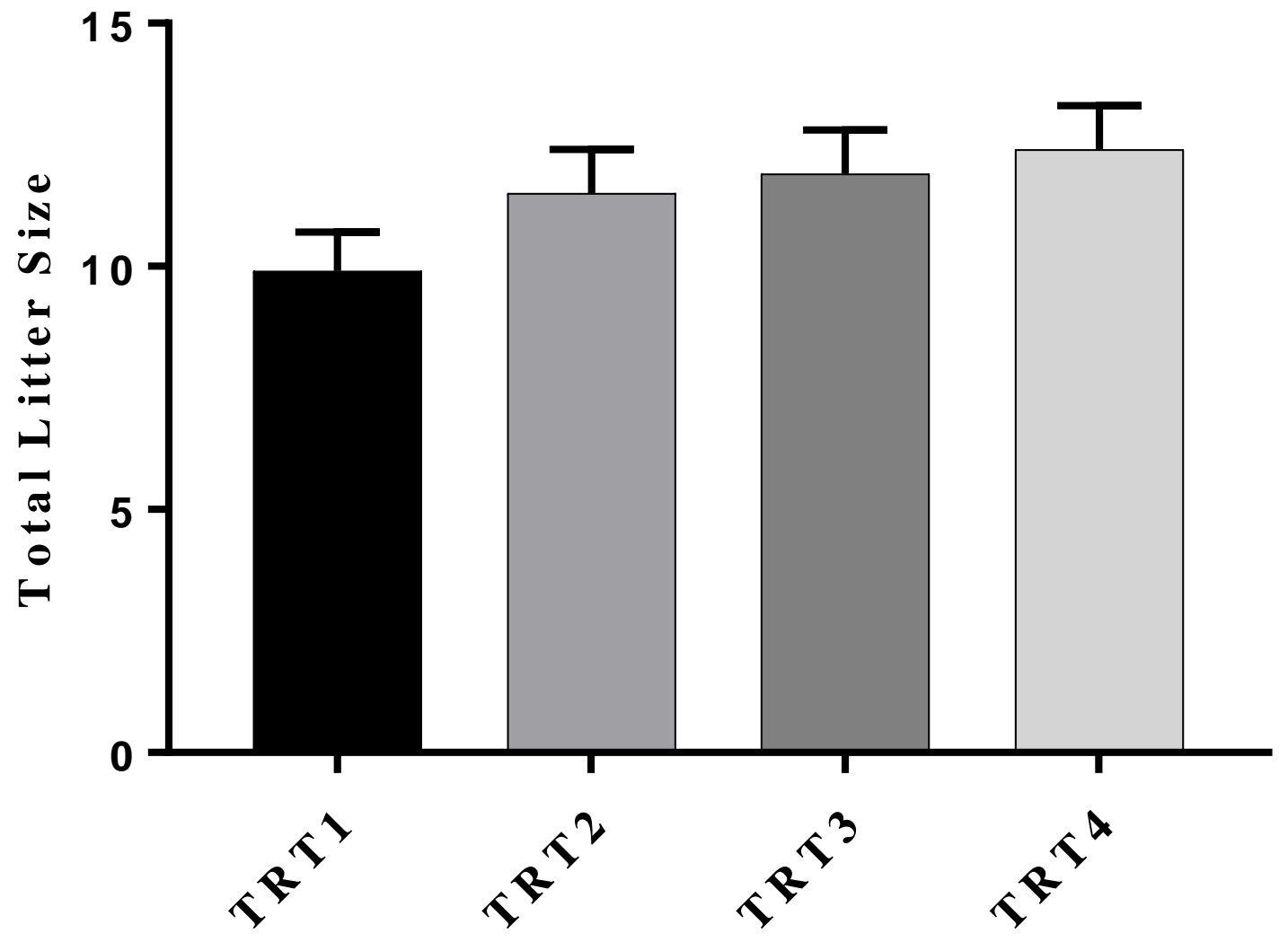


Figure A5. Total born alive for TRT1, TRT2, TRT3, and TRT4 sows. Sows in TRT2 and TRT3 received $5 \mathrm{~mL}$ of P.G. 600 at weaning (h 0$)$ and sows in TRT1 and TRT2 received $2 \mathrm{~mL}$ of OvuGel $96 \mathrm{~h}$ post-wean. Data are represented as least-square means \pm SE. There was no effect of P.G. 600 or OvuGel on total born alive across groups. There was an effect $(\mathrm{P}<0.05)$ of P.G. 600 x OvuGel on total born alive across groups where P.G. 600 had a different effect among sows in treatments receiving OvuGel and sows in treatments not receiving OvuGel.

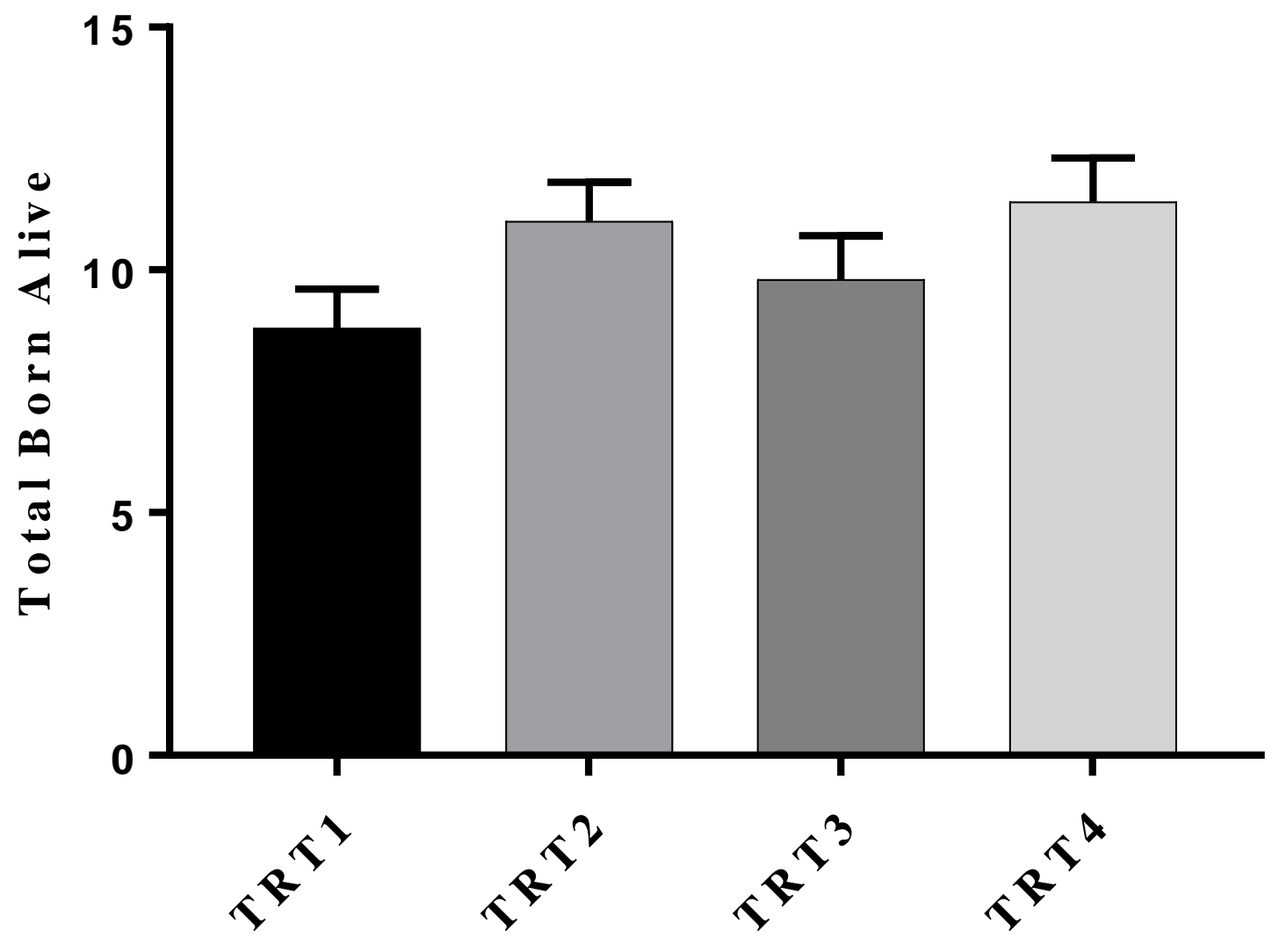


Figure A6. Total born dead for TRT1, TRT2, TRT3, and TRT4 sows. Sows in TRT2 and TRT3 received $5 \mathrm{~mL}$ of P.G. 600 at weaning (h 0$)$ and sows in TRT1 and TRT2 received $2 \mathrm{~mL}$ of OvuGel $96 \mathrm{~h}$ post-wean.. Data are represented as least-squares means \pm SE. There was no effect of P.G. 600, OvuGel, or P.G. 600 x OvuGel on total born dead across groups.

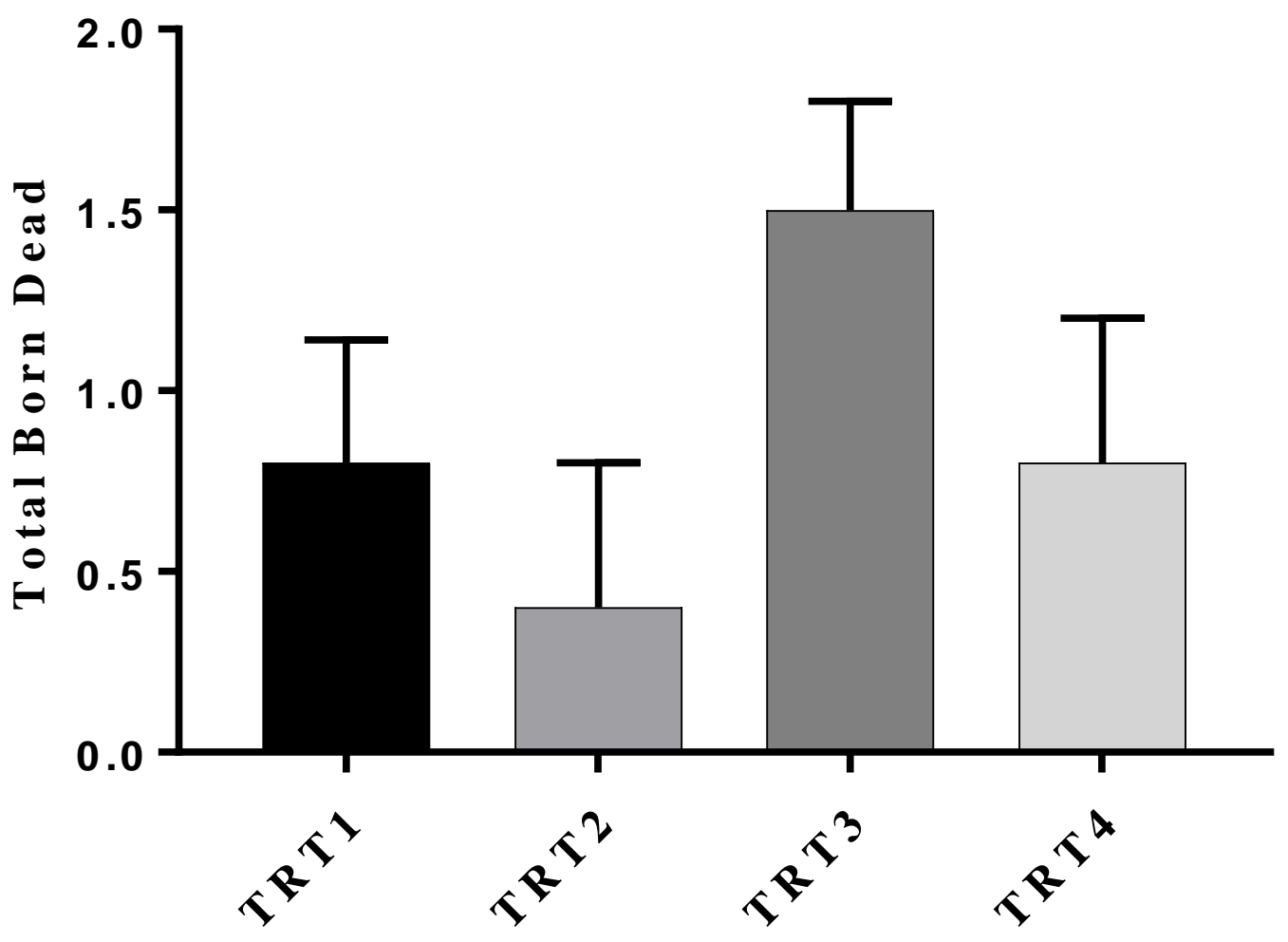


Figure A7. Total mummified pigs born in TRT1, TRT2, TRT3, and TRT4 sows. Sows in TRT2 and TRT3 received $5 \mathrm{~mL}$ of P.G. 600) at weaning (h 0) and sows in TRT1 and TRT2 received 2 $\mathrm{mL}$ of OvuGel $96 \mathrm{~h}$ post-wean. Data are represented as least squares means $\pm \mathrm{SE}$. There was no effect of P.G. 600, OvuGel, or P.G. 600 x OvuGel on total mummified pigs born across groups

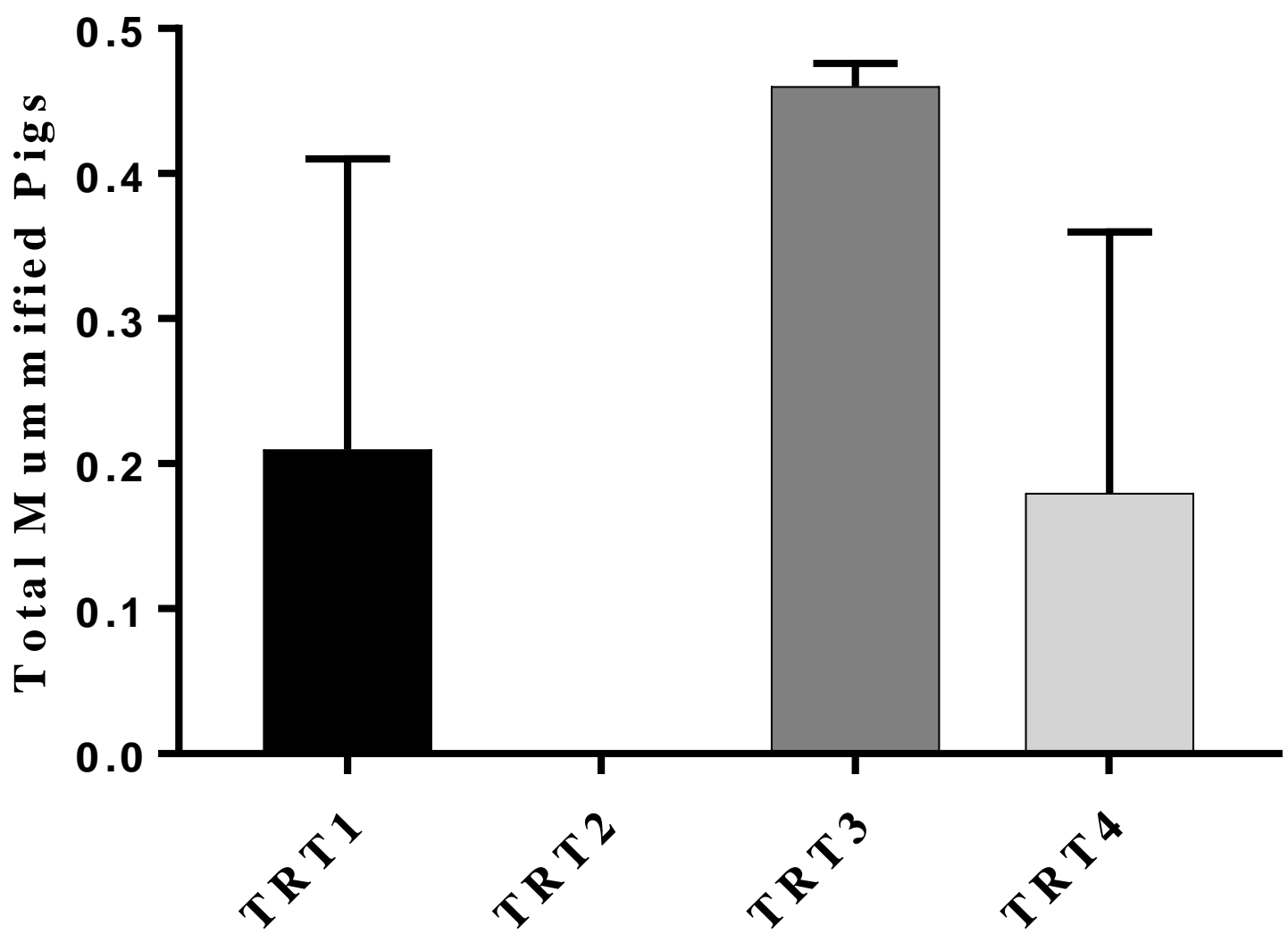


Figure A8. Live pigs born per semen dose for TRT1, TRT2, TRT3, and TRT4 sows. Sows in TRT2 and TRT3 received $5 \mathrm{~mL}$ of P.G. 600 at weaning (h 0) and sows in TRT1 and TRT2 received $2 \mathrm{~mL}$ of OvuGel $96 \mathrm{~h}$ post-wean. Data are represented as least-square means $\pm \mathrm{SE}$. There was an effect $(\mathrm{P}<0.05)$ of OvuGel on the live pigs born per semen dose. There was no effect of P.G. 600 or P.G. 600 x OvuGel on the live pigs born per semen dose.

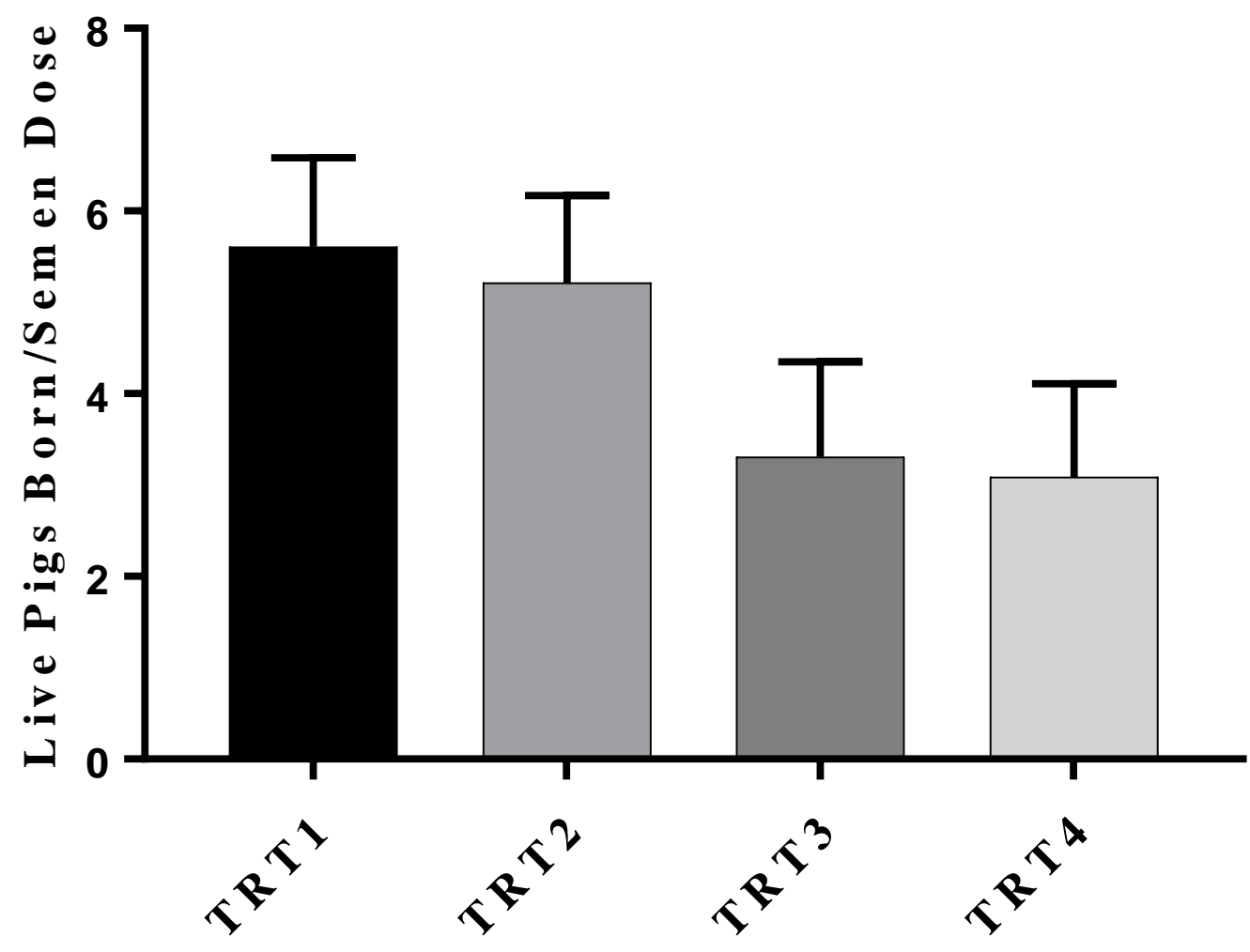

